\title{
Team Software Process (TSP) Coach Mentoring Program Guidebook Version 1.1
}

Timothy A. Chick

Robert Cannon

James McHale

William Nichols

Marsha Pomeroy-Huff

Jefferson Welch

Alan Willett

June 2010

SPECIAL REPORT

CMU/SEI-2010-SR-016

Unlimited distribution subject to the copyright.

http://www.sei.cmu.edu

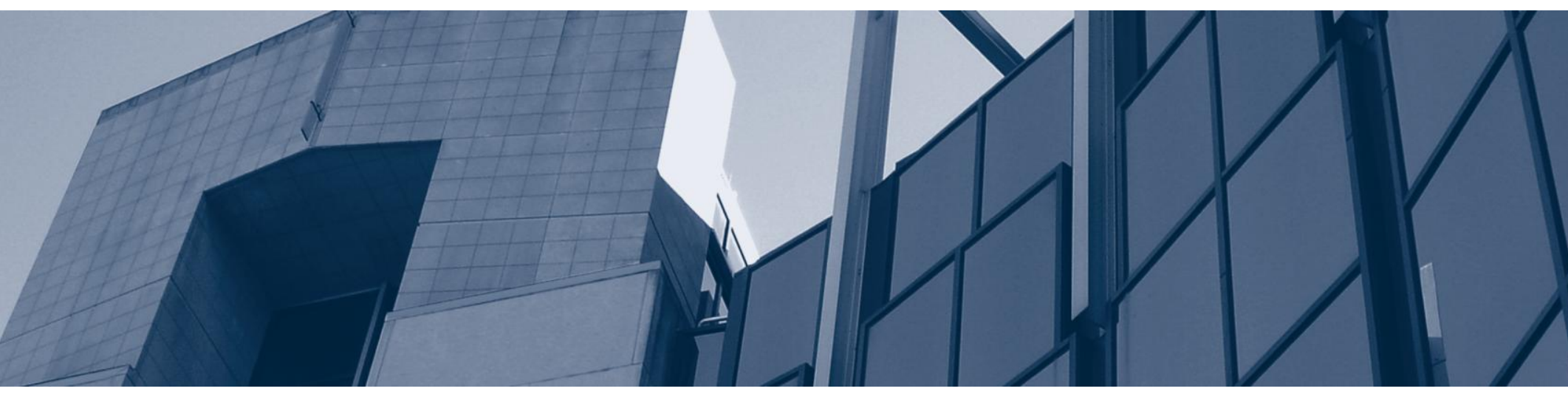


This report was prepared for the

SEI Administrative Agent

$\mathrm{ESC} / \mathrm{XPK}$

5 Eglin Street

Hanscom AFB, MA 01731-2100

The ideas and findings in this report should not be construed as an official DoD position. It is published in the interest of scientific and technical information exchange.

This work is sponsored by the U.S. Department of Defense. The Software Engineering Institute is a federally funded research and development center sponsored by the U.S. Department of Defense.

Copyright 2010 Carnegie Mellon University.

\section{NO WARRANTY}

THIS CARNEGIE MELLON UNIVERSITY AND SOFTWARE ENGINEERING INSTITUTE MATERIAL IS FURNISHED ON AN “AS-IS” BASIS. CARNEGIE MELLON UNIVERSITY MAKES NO WARRANTIES OF ANY KIND, EITHER EXPRESSED OR IMPLIED, AS TO ANY MATTER INCLUDING, BUT NOT LIMITED TO, WARRANTY OF FITNESS FOR PURPOSE OR MERCHANTABILITY, EXCLUSIVITY, OR RESULTS OBTAINED FROM USE OF THE MATERIAL. CARNEGIE MELLON UNIVERSITY DOES NOT MAKE ANY WARRANTY OF ANY KIND WITH RESPECT TO FREEDOM FROM PATENT, TRADEMARK, OR COPYRIGHT INFRINGEMENT.

Use of any trademarks in this report is not intended in any way to infringe on the rights of the trademark holder.

Internal use. Permission to reproduce this document and to prepare derivative works from this document for internal use is granted, provided the copyright and "No Warranty" statements are included with all reproductions and derivative works.

External use. This document may be reproduced in its entirety, without modification, and freely distributed in written or electronic form without requesting formal permission. Permission is required for any other external and/or commercial use. Requests for permission should be directed to the Software Engineering Institute at permission@sei.cmu.edu.

This work was created in the performance of Federal Government Contract Number FA8721-05-C-0003 with Carnegie Mellon University for the operation of the Software Engineering Institute, a federally funded research and development center. The Government of the United States has a royalty-free government-purpose license to use, duplicate, or disclose the work, in whole or in part and in any manner, and to have or permit others to do so, for government purposes pursuant to the copyright license under the clause at 252.227-7013.

For information about SEI publications, please visit the library on the SEI website (www.sei.cmu.edu/library). 


\section{Table of Contents}

Acknowledgments $\quad$ v

Abstract vii

1 Introduction 1

$\begin{array}{ll}1.1 \text { Audience } & 1\end{array}$

1.2 Why Mentoring? 1

1.3 Mentor and Mentee 2

1.3.1 What is a Mentor? $\quad 2$

1.3.2 What is a Mentee?

1.4 TSP Coach and Mentor Coach Qualification Overview 3

1.5 Similarities and Differences between Coaching and Mentoring 4

$2 \quad$ Mentoring Concepts $\quad 7$

$\begin{array}{ll}2.1 \text { What is Mentoring? } & 7\end{array}$

$\begin{array}{lll}2.1 .1 & \text { The Mentoring Process } & 7\end{array}$

$\begin{array}{ll}2.1 .2 & \text { Mentoring Relationships }\end{array}$

$\begin{array}{ll}2.1 .3 & \text { Mentoring Objectives }\end{array}$

2.1.4 Types of Mentoring $\quad 8$

$\begin{array}{lll}2.2 & \text { Stages in a Mentoring Relationship } & 8\end{array}$

2.2.1 The Preparation/Prescriptive Stage 9

2.2.2 The Persuasive Stage 9

2.2.3 The Enabling/Collaborative Stage $\quad 10$

2.2.4 The Closure/Confirmative Stage 10

$\begin{array}{ll}2.3 & \text { The Mentor and Mentee Roles } \\ \end{array}$

2.3.1 The Mentor Role 10

2.3.2 The Mentee Role 11

$\begin{array}{lll}2.4 & \text { Obstacles to Successful Mentorships } & 11\end{array}$

$3 \quad$ Mentoring TSP Coaches $\quad 13$

$\begin{array}{lll}3.1 & \text { Overview } & 13\end{array}$

3.1.1 Why is Mentoring Needed in the TSP Coach Qualification Model?

3.2 The TSP Coach Qualification Model 15

3.2.1 The Provisional Coach 16

3.2.2 The SEI-Certified TSP Coach 17

3.2.3 The Provisional TSP Mentor Coach 18

$\begin{array}{ll}\text { 3.2.4 The SEI-Certified TSP Mentor Coach } & 20\end{array}$

$4 \quad$ The TSP Mentoring Program $\quad 21$

$\begin{array}{lll}4.1 & \text { TSP Mentoring Phases } & 21\end{array}$

$\begin{array}{lll}4.2 & \text { Conducting Mentoring Sessions } & 24\end{array}$

$\begin{array}{lll}4.3 & \text { Guidance for Mentors and Provisional Coaches } & 24\end{array}$

4.3.1 General Guidance on Answering Questions $\quad 14$

$\begin{array}{lll}4.4 & \text { TSP Coach Mentoring Roadmap } & 26\end{array}$

4.5 Communication and Record Keeping 26

4.5.1 Becoming an SEl-Certified TSP Coach $\quad 27$

4.5.2 Provisional Coach Evaluation and Data Submission 28

4.5.3 Becoming a Mentor Coach $\quad 29$

4.5.4 TSP Coach Mentoring Program Evaluations $\quad 29$ 
References

Appendix A Targeted Questions

A-1

Appendix B TSP Coach Job Analysis Report

B-1

Appendix C Forms

C-1 


\section{List of Figures}

Figure 1: TSP Coach and Mentor Coach Qualification Overview 4

Figure 2: Mentoring Relationship Stages 9

Figure 3: $\quad$ Multi-Tiered Qualification Model $\quad 14$

Figure 4: Steps to Becoming an SEI-Certified TSP Coach 16

Figure 5: Steps to Becoming an SEI-Certified TSP Mentor Coach 20

Figure 6: TSP Mentoring Program - Preparation/Prescriptive and Persuasive Phases 22

Figure 7: TSP Mentoring Program - Enabling/Collaborative and Closure/Confirmation Phases 23 
iv | CMU/SEI-2010-SR-016 


\section{Acknowledgments}

In creating this mentoring program, the authors consulted with several individuals who provided ideas and helped to shape the program. In particular, we want to acknowledge Kimberley Campbell, Anita Carleton, and Tracey Kelly for helping us out when we needed a new perspective, and our editors William Thomas and Barbara White for catching defects and dealing with formatting issues. Finally, the authors would like to thank the SEI-Certified TSP Coaches who contributed by reviewing the content and clarity of the report: Yoshi Akiyama, Lana Cagle, Luis Castro, Hazel Crofts, Ahmed El-Shikh, Bradley Hodgins, Michelle Jurkouich, Delwyn Kellogg, Juan Lopez, Andy Oughton, Rafael Salazar, and Jim Van Buren. 
vi | CMU/SEI-2010-SR-016 


\section{Abstract}

This guidebook is designed to explain the steps for becoming an SEI-Certified Team Software Process (TSP) Coach or SEI-Certified TSP Mentor Coach, with emphasis on guiding individuals through the mentoring process. This guidebook defines the structure and format of the mentor and provisional coach relationship, and explains the process steps and evaluation criteria for becoming an SEI-Certified TSP Coach or Mentor Coach. 
viii | CMU/SEI-2010-SR-016 


\section{Introduction}

This guidebook is designed to explain the steps for becoming an SEI-Certified Team Software Process (TSP) Coach or SEI-Certified TSP Mentor Coach, with emphasis on guiding individuals through the mentoring process. This guidebook defines the structure and format of the mentor and provisional coach relationship, and explains the process steps and evaluation criteria for becoming an SEI-Certified TSP Coach or Mentor Coach. It is recommended that all mentors (SEI-Certified TSP Mentor Coaches) and provisional TSP coaches (SEI-Certified TSP Coach candidates) read all sections of the guidebook at least once, and then refer to the guidebook whenever necessary.

\section{$1.1 \quad$ Audience}

This document is intended for

- individuals who are interested in becoming SEI-Certified TSP Coaches

- individuals who are interested in becoming SEI-Certified TSP Mentor Coaches

- SEI-Authorized Personal Software Process (PSP) Instructors

- change agents who are responsible for transitioning and sustaining TSP in their organizations

- individuals who are responsible for administering the SEI-Certified TSP Coach and SEICertified Mentor Coach program in their organizations

\section{$1.2 \quad$ Why Mentoring?}

The SEI has begun transitioning the TSP technology from early adopters to the early majority by "crossing the chasm," which Regis McKenna explains as "the gulf between two distinct marketplaces for technology products - the first, an early market dominated by early adopters and insiders who are quick to appreciate the nature and benefits of the new development, and the second a mainstream market representing 'the rest of us,' people who want the benefits of new technology but who do not want to 'experience' it in all its gory details" [Moore 2002]. To help facilitate this transition, the SEI has begun modifying the TSP product suite in order to meet the market's growing need for qualified TSP coaches. Prior to the creation of the SEI-Certified TSP Coach and SEI-Certified TSP Mentor Coach certification tracks, the SEI conferred coach status to individuals using the SEI-Authorized TSP Coach process. While the SEI-Authorized TSP Coach program met the needs of TSP's early adopters, some of the authorization requirements created barriers to the early majority. These barriers included some of the following factors.

- Candidate coaches often did not follow through with authorization, resulting in unqualified users attempting to implement the TSP.

- The qualification process placed too much emphasis on the mechanics of the team launch and not enough emphasis on other important aspects of process implementation, such as

1 | CMU/SEI-2010-SR-016 
conducting weekly team meetings, assisting the team leader with management, doing cycle and project postmortems, and developing repeatable core skills.

- Lack of continuing engagements with other experienced TSP practitioners created the potential for insufficient and/or inconsistent coach development after authorization.

- TSP coach training was available only through the SEI.

- SEI authorization required candidates for coach authorization to conduct a launch or relaunch while being observed by an authorized member of the SEI TSP Initiative Team.

- All training was conducted in English only, and observations were limited to Englishspeaking coaches and teams.

The SEI-Certified TSP Coach and SEI-Certified TSP Mentor Coach programs are designed to eliminate the need for observation by SEI personnel (and the associated costs) by enabling the transfer of knowledge from experienced TSP coaches to new TSP coaches through mentoring, while still maintaining the high standard of quality that organizations, teams, and individuals have come to expect from TSP coaches.

The SEI-Certified TSP Coach and SEI-Certified TSP Mentor Coach programs also enable the expansion of TSP implementation to non-English-speaking teams and organizations. This expanded capacity for qualifying candidate coaches will enable the available supply of qualified TSP coaches to keep better pace with market demand. In addition to overcoming the transition barriers, the new qualification footprint for the TSP coach provides a revised set of standards, processes, and procedures for producing highly qualified TSP coaches. The qualification activities also give candidates a chance to gain real-world experience as they proceed through the steps needed to become SEI-Certified TSP Coaches.

\subsection{Mentor and Mentee}

\subsubsection{What is a Mentor?}

In Greek mythology, Mentor was the wise old family friend to whom Odysseus entrusted his son's education and development and the oversight of his lands while Odysseus was away in the Trojan War. Mentor's wisdom, experience, and protective guidance are now embodied in the name of the centuries-old practice of pairing newcomers to a discipline with a more experienced person who will help the learners to master the needed skills and knowledge in that domain. Mentoring is effectively used in many organizations, not only as a way of developing knowledge, but also to impart the values, beliefs, and practices that compose the organizational culture [U. S. Navy 2009].

Further definition is provided by the People Capability Maturity Model (PCMM): "The purpose of mentoring is to transfer the lessons of greater experience in a workforce competency to improve the capability of other individuals or workgroups" [Curtis 2002]. 


\subsubsection{What is a Mentee?}

A mentee is, very simply, a person who is being mentored. In the SEI-Certified TSP Coach program, the candidate ("provisional") coach is the mentee who learns from the more experienced mentor coach. The provisional coach must be committed to learning and taking responsibility for his or her own personal development. This commitment must include a willingness to make ongoing and accurate assessments of current skills and competencies, participating in the development and execution of a mentoring action plan, and working with a mentor to achieve the agreed-upon goals.

The U.S. Department of Transportation, Departmental Office of Human Resource Management [DoT 2009] describes the various roles of a mentee as follows.

- The mentee must act as his or her own gauge for measuring how interactive the mentoring relationship will be. It is up to the mentee to determine the amount of dependence and guidance that he or she requires. The mentee must take the initiative to ask for help or advice, and to take on more challenging work as the relationship progresses.

- The mentee is a student who needs to grasp the mentor's knowledge and have the ambition to know what to do with the knowledge. The mentee must practice and demonstrate what he or she has learned.

- The mentee is a trainee who should blend mentoring with other approaches to learning. The mentee should seek out other opportunities to grow and learn from people other than the mentor, and not be overly dependent on the mentor's professional advice. Opportunities such as conferences or continuing education courses related to the professional domain can provide mentees with additional perspectives from which to learn about the profession and its practices.

\subsection{TSP Coach and Mentor Coach Qualification Overview}

Figure 1 outlines the SEI-Certified TSP Coach and SEI-Certified TSP Mentor Coach qualification tracks. The process begins with successful completion of the PSP training courses from the SEI, an SEI-Authorized PSP Instructor, or an accredited university, after which, the prospective TSP coach must earn the SEI-Certified Personal Software Process (PSP) Developer certification (www.sei.cmu.edu/certification/process/psp/index.cfm) as proof of mastery of the knowledge and skills required to deliver quality software within a predictable schedule and budget. Next, the SEICertified PSP Developer must successfully complete the TSP Coach Training course (www.sei.cmu.edu/training/p21.cfm). At this point, the individual becomes a provisional TSP coach and enters into the mentoring process. The provisional coach has up to 18 months to complete the mentoring process and pass the TSP coach certification exam. Upon successful completion of these requirements, the provisional coach becomes an SEI-Certified TSP Coach (www.sei.cmu.edu/certification/process/tsp/index.cfm).

In order for an individual to become an SEI-Certified TSP Mentor Coach, a candidate must be an SEI-Certified TSP Coach and must also complete the PSP Instructor Training course 
(www.sei.cmu.edu/training/p20.cfm). (NOTE: This course can be taken at any time before or after completion of the TSP Coach Training course.) The SEI-Certified TSP Coach must also meet all of the other TSP Mentor Coach Training course entry requirements, as outlined in subsequent sections of this guidebook. Upon completion of all requirements, the prospective mentor coach should submit an application for admittance into the TSP Mentor Coach Training course and provide the required supporting data. Upon successful completion of the TSP Mentor Coach Training course, the applicant will become a provisional mentor coach. The provisional mentor coach will be then provided guidance and oversight by an SEI-Certified TSP Mentor Coach from the SEI staff. After successfully mentoring a mentee, the provisional mentor coach will become an SEI-Certified TSP Mentor Coach (sei.cmu.edu/certification/process/tsp/TSP-Mentor-

\section{Coach.cfm).}
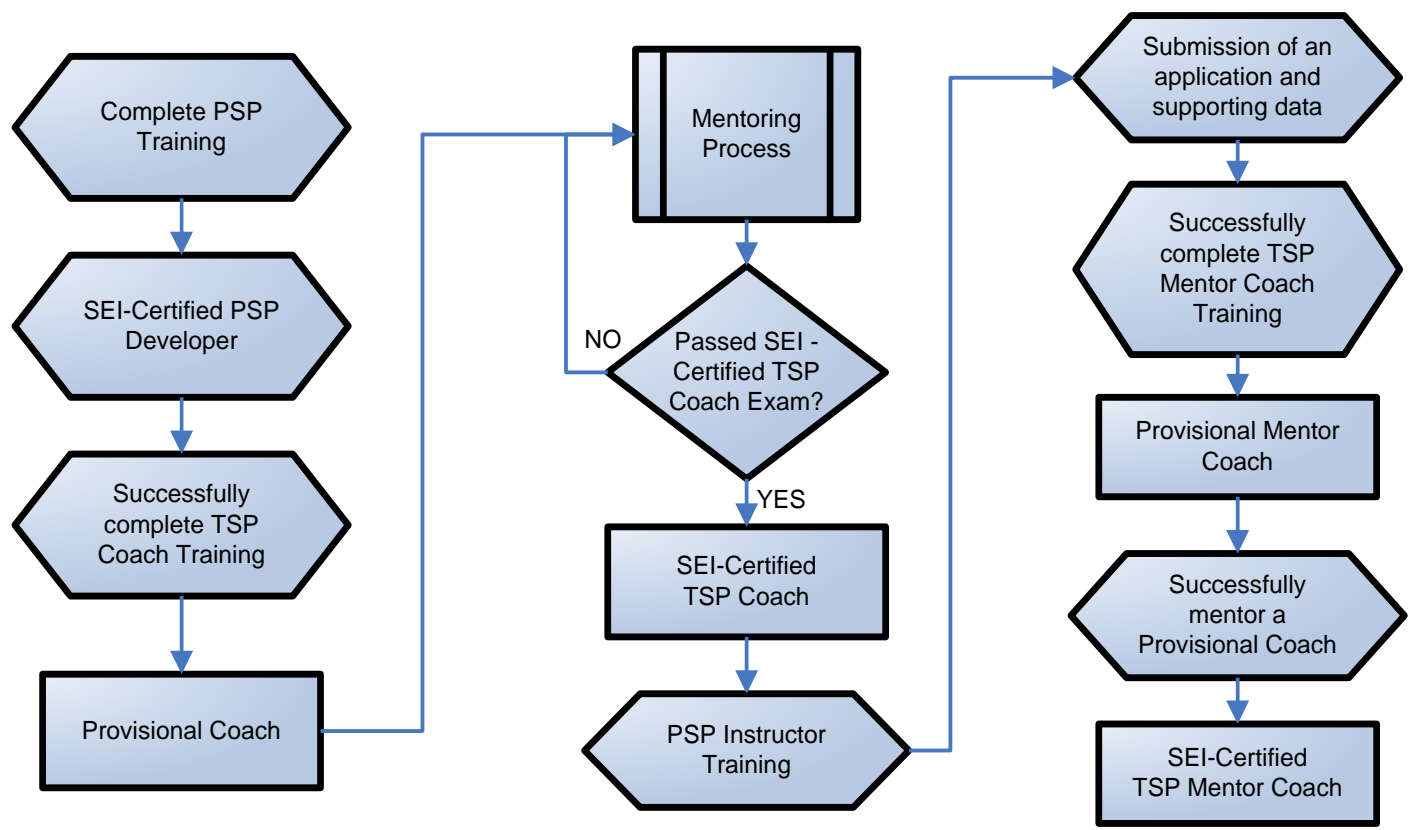

Figure 1: TSP Coach and Mentor Coach Qualification Overview

\subsection{Similarities and Differences between Coaching and Mentoring}

Coaching and mentoring are not the same. However, these terms often are used interchangeably, partly due to the fact that coaches and mentors often perform similar roles using similar skills and techniques. Because the TSP coach mentoring process is designed to create better coaches, it is important to clearly delineate the similarities and differences between these two roles.

A coach is a person who instructs individuals in the knowledge and skills needed to gain proficiency in a specific domain. Coaches help individuals to achieve extraordinary results by helping them to focus on mastery of specific processes and procedures and encouraging them to set and achieve goals by enacting a series of action steps that produce the desired results quickly and easily. Coaching helps to sustain progress towards the desired goals by helping people to learn from setbacks, turn problems into opportunities, and achieve positive results even in difficult 
circumstances. Coaches have a set agenda to reinforce, and seek to change the skills and behaviors of others to enable realization of that agenda. Coaches work with individuals or teams to achieve a finite set of objectives in a defined timeframe. Studies show that when a professional coach is hired to work with individuals or teams, specific goals and measurable outcomes can be achieved in a shorter period of time than could have been done without the coach's guidance. In other words, "While all of the steps of teambuilding, training, goal setting and feedback are needed to produce a high-performing team, they are not sufficient. The final key ingredient is leadership and coaching" [Humphrey 2006].

As with a coach, a mentor is an experienced person who helps less experienced people to gain proficiency in a particular domain. However, in addition to providing instruction, the mentor also acts as a trusted counselor, role model, and guide to the less experienced person or newcomer who is the mentee. Mentoring involves a two-way, mutually beneficial learning situation in which the mentor provides advice, shares knowledge and experiences, and teaches using a low-pressure approach that enables the mentee to discover his or her own particular strengths and areas for improvement. The mentor's role is to help shape and guide an individual's development in both professional and general life skills. Good communication and coaching skills are vital in fulfilling the role of a mentor.

Coaching and mentoring share many similarities. The roles of both mentors and coaches are filled by individuals who possess a great deal of experience in and knowledge about the domain in which they are working, and who have the job of helping less experienced individuals to improve their knowledge and performance in that domain. Both roles require the coach or mentor to act as guide and role model to the individual being coached or mentored, and both help their lessexperienced charges to view setbacks as lessons that will help them to learn from their own mistakes.

There are also several important differences that delineate coaching and mentoring as separate functions. Coaches often receive some sort of formal training in the skills required for effective coaching; mentors generally do not receive formal mentor training, but they usually possess the same skills and abilities as coaches, both in domain-specific skills and knowledge and in the communication and instructional skills needed for effective mentor-mentee relationships. The goals and outcomes for coaches and mentors also differ: coaching relationships usually have set goals and measurable outcomes, which, when met, result either in the termination of the relationship or a renewal of the relationship based on a new set of goals and desired outcomes. Mentoring relationships typically do not have clearly stated learning goals or measurable outcomes, and tend to endure over time, even after the mentee has gained sufficient skills to perform independently and proficiently in the domain. Coaches can work either with individuals or teams, whereas mentors work one-on-one with a single mentee. Coaches have more of an authoritative role, and provide direct instruction in which learning flows in one direction only, from coach to learner. Mentors act more like facilitators or guides than instructors, and when instruction is needed, it is often done through counseling or discovery activities from which both the mentor and the mentee may learn. The major similarities and differences between coaches and mentors are summarized in the table on the following page. 


\begin{tabular}{|c|c|}
\hline Coaches & Mentors \\
\hline Coaches work with teams or individuals. & Mentors work with individuals only. \\
\hline $\begin{array}{l}\text { Coaches help teams and individuals to improve } \\
\text { performance. }\end{array}$ & $\begin{array}{l}\text { Mentors help individuals to improve } \\
\text { performance. }\end{array}$ \\
\hline $\begin{array}{l}\text { Coaches aid learners to achieve specific objectives } \\
\text { or performance levels. }\end{array}$ & $\begin{array}{l}\text { Mentors guide learners according to changing } \\
\text { needs; there is no set learning agenda or } \\
\text { specified performance objective. }\end{array}$ \\
\hline $\begin{array}{l}\text { Involvement comes as part of the job for which the } \\
\text { coach was hired. }\end{array}$ & $\begin{array}{l}\text { Involvement comes through self-selection by } \\
\text { both mentor and mentee. }\end{array}$ \\
\hline Authority is inherent in the coaching position. & $\begin{array}{l}\text { Authority comes from the mentee's perceived } \\
\text { value of the mentor's influence. }\end{array}$ \\
\hline $\begin{array}{l}\text { Relationships have a finite time span based on the } \\
\text { achievement of learning or the fulfillment of } \\
\text { contractual specifications. }\end{array}$ & $\begin{array}{l}\text { Relationships have no set time frame and may } \\
\text { persist even after the mentee achieves } \\
\text { proficiency in the desired knowledge or skills. }\end{array}$ \\
\hline $\begin{array}{l}\text { The coach's relationship with the learner is primarily } \\
\text { authoritative. }\end{array}$ & $\begin{array}{l}\text { The mentor's relationship with the mentee is } \\
\text { collaborative. }\end{array}$ \\
\hline $\begin{array}{l}\text { Instruction is one-way; coaches transfer knowledge } \\
\text { to teams and individuals. }\end{array}$ & $\begin{array}{l}\text { Instruction can be two-way; mentors may learn } \\
\text { from mentees while providing the mentee with } \\
\text { skills, knowledge, and guidance. }\end{array}$ \\
\hline $\begin{array}{l}\text { Instruction is usually limited to domain-specific skills } \\
\text { and knowledge. }\end{array}$ & $\begin{array}{l}\text { Instruction is often applicable to general life } \\
\text { skills, not just a specific domain. }\end{array}$ \\
\hline $\begin{array}{l}\text { Coaches usually receive formal training in coaching } \\
\text { skills. }\end{array}$ & $\begin{array}{l}\text { Mentors usually do not receive formal training } \\
\text { in mentoring or coaching skills. }\end{array}$ \\
\hline Coaches sometimes act as mentors. & Mentors usually act as coaches. \\
\hline
\end{tabular}




\section{Mentoring Concepts}

Mentoring is a process by which an experienced person provides advice, support, and training to a less experienced person to enhance personal and professional growth to both parties in the relationship. This section describes the fundamental concepts relevant to creating an effective mentor-mentee relationship.

\subsection{What is Mentoring?}

\subsubsection{The Mentoring Process}

Mentoring is a developmental process in which a more experienced individual commits to working and learning with a less experienced individual for the purpose of improving the professional development of both individuals [CIO 2002]. The mentoring process includes a series of stages (described below in Section 2.2), in which the mentor's leadership in the process is adapted to support the developing strengths and meet the changing needs of the mentee. The desired outcome of an effective mentoring process is a self-confident and competent professional who has become prepared to mentor others.

\subsubsection{Mentoring Relationships}

A successful relationship between a mentor and a mentee is characterized by confidentiality, trust, caring, mutual support, and challenges for growth. The mentoring relationship creates the necessary context of safety and confidence in which the mentor and mentee both can take the risks of trying new work strategies and learning from each other. This context is necessary for encouraging the professional growth of both individuals.

\subsubsection{Mentoring Objectives}

Mentoring can achieve many objectives. In addition to providing the mentee with opportunities for success and further growth, mentoring is also a means for accomplishing the following desired outcomes.

- Achieve scalability of a profession in a global environment. In many professions, the need for qualified practitioners is growing so rapidly that the capacity of academic institutions or training programs is unable to meet the demand for practica or internships that enable learners to gain needed experience. Mentoring provides a cost-effective way to facilitate the transfer of practical skills and knowledge from experienced professionals to new professionals, while still maintaining the high standard of quality needed for proficiency in a discipline. In the case of TSP, having qualified mentors within an organization allows the 
organization to train and assess coaches without the need for costly travel by candidate coaches or external observers. Mentorships also allow training and observations to be conducted outside the United States and in languages other than English.

- Strengthen the culture of a profession. Mentoring allows less experienced individuals to develop relationships with established professionals in their field who can provide advice on personal and career goals, introduce them to other practitioners in the professional community, and provide positive examples of ethical and masterful professional behavior. In turn, mentees can provide their mentors with fresh perspectives and new ways of approaching established problems in the profession.

- Plan for individual transition (prepare professionals for greater responsibilities). Mentoring provides a mechanism for new practitioners to transfer the knowledge and skills learned in the classroom to real-world practice under the tutelage of an experienced professional. Mentorships allow new practitioners to set and achieve goals that build on what they already know but cannot yet achieve alone, gradually increasing their proficiency in practice until they are able to capably perform all required functions without guidance or supervision.

\subsubsection{Types of Mentoring}

Although there are numerous types of mentoring, the SEI-Certified TSP Coach and SEI-Certified TSP Mentor Coach qualification tracks follow the formal/planned mentoring approach, which is described by the U.S. Department of Transportation Departmental Office of Human Resource Management as follows.

Formal or planned mentoring focuses on enabling the mentee to develop skills based on the needs of the profession, usually resulting in benefits to both the profession and the mentee. This type of mentoring promotes a "formal" approach to the relationship, with little social interaction between mentor and mentee; the mentor and mentee rarely (if ever) see each other outside the office. The mentor and mentee are more interested in meeting the needs of the profession than in developing a friendship; the basis for their relationship is professional commitment. Planned mentoring follows a predefined track that ends when the professional goals are reached. This type of mentoring takes a systematic approach to ensure that the mentee develops the skill set needed to benefit the profession.

\subsection{Stages in a Mentoring Relationship}

Numerous models of mentorship describe the process as having four distinct stages through which the mentor-mentee relationship evolves; the evolutionary sequence of stages is based on the changing knowledge levels of the mentee. The sequence of stages (depicted in Figure 2) is generally a forward progression (as in a pure waterfall model), but as with software, a stage sometimes must be revisited before moving forward again. 


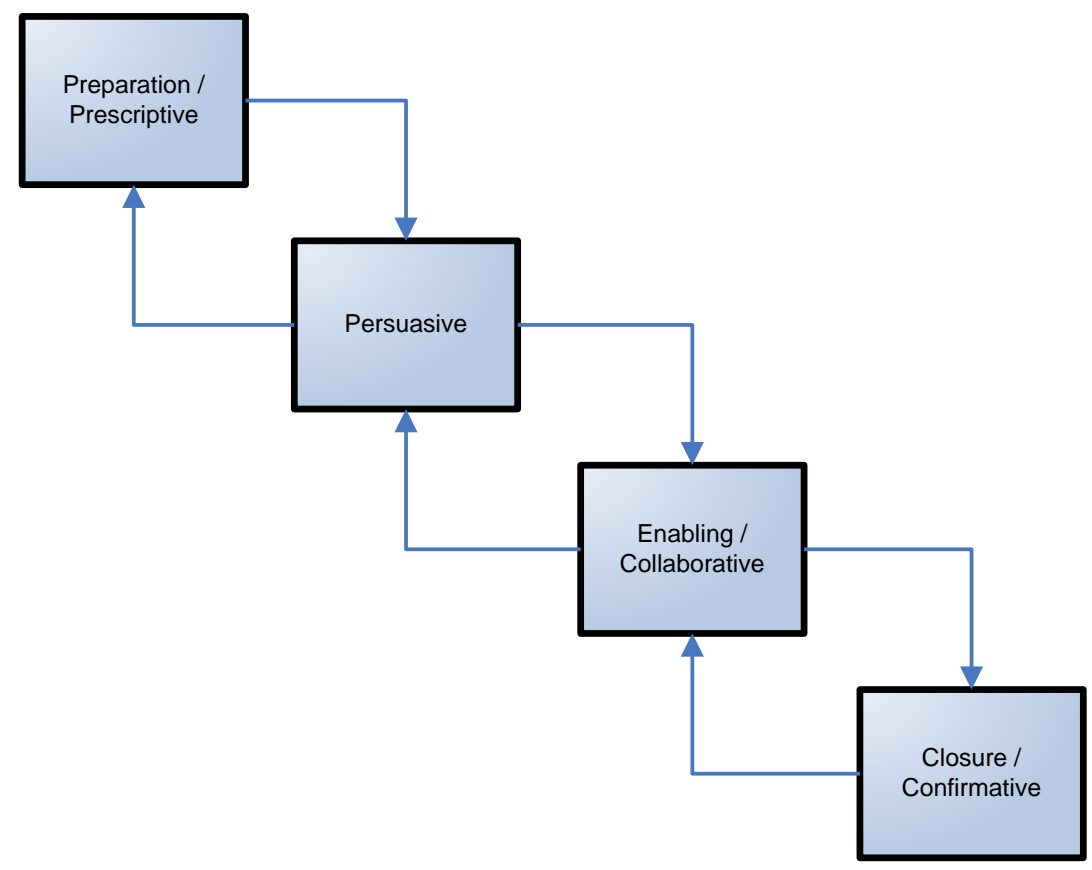

Figure 2: Mentoring Relationship Stages

\subsubsection{The Preparation/Prescriptive Stage}

The initial stage of the mentor-mentee relationship establishes the foundation upon which all progress will be measured and sets the ground rules under which the relationship will operate. During this phase, the mentor and mentee engage in discussion(s) to establish a sense of common purpose, as well as to develop a mutual understanding of the guidance that will be provided and to establish the expected outcomes of the process. In this stage, the mentee generally has little or no experience in the organization or the professional domain, so the mentor must assume a more proactive role in guiding, directing, and advising the mentee. This stage is generally the most demanding on the mentor because he or she must share a tremendous amount of information, and the mentee's ability to function successfully depends in large part on the extent to which active guidance and in-depth advice is forthcoming from the mentor.

\subsubsection{The Persuasive Stage}

The second stage requires the mentor to take a strong approach in persuading the mentee to begin taking risks and acting more autonomously, with less direction and motivation provided from the mentor. The mentor must actively persuade the mentee to seek challenges and find answers. The mentee has begun to gain some experience in the organization or professional domain, but still needs some active direction from the mentor to be completely successful. The mentor may begin to help the mentee to develop and grow by suggesting new strategies, raising challenging questions, and pushing the mentee into making new discoveries. 


\subsubsection{The Enabling/Collaborative Stage}

During the enabling/collaborative stage, the mentor allows the mentee to experience both successes and failures, while still guarding the mentee from total failure. The mentor persuades the mentee to consider problems and discuss solutions openly and without fear of embarrassment. The mentor uses feedback as the primary mechanism for communication.

During this stage, the mentor should purposely move the relationship from mentor-oriented to mentee-oriented. The mentor becomes a sounding board for questions and advice rather than the source of all information, and begins to use probing or evaluative questions to study the mentee's grasp of the skills and concepts being mastered. At some point during this stage, the mentor will become satisfied that the mentee has crossed the acceptable threshold for competent and autonomous performance in the professional domain or organization.

\subsubsection{The Closure/Confirmative Stage}

The final stage of the mentor-mentee relationship commences when the mentee successfully meets the criteria needed for successful autonomous performance of a particular job function or professional skill set. The mentee is able to work independently of the mentor. Communications at this stage take place on a more equal level, often with the mentor and mentee working to solve problems together. As the mentee begins to function at a higher level of understanding in the professional domain or organization, the mentor gradually withdraws support and will eventually, by mutual consent, exit the relationship altogether.

\subsection{The Mentor and Mentee Roles}

\subsubsection{The Mentor Role}

Mentors facilitate personal, educational, and professional growth in another individual by sharing the knowledge and insights that they have gathered through years of experience. Successful mentors are characterized as supportive, patient, and respected, among other positive personality traits. Mentors have several responsibilities, including the following.

- Helping the mentee to develop an appropriate learning plan/mentoring agreement, including goals that build on what the mentee knows and can do already, but cannot yet achieve alone

- Providing guidance based on the mentee's learning and development needs

- Helping the mentee to access appropriate expert advice to extend knowledge and skills

- Creating a learning environment that supports risk-taking and innovation, and encouraging the mentee to expand his or her abilities

- Listening actively, being accommodating, and using silence as a tool

- Providing feedback as necessary, such as relating guidance from personal past experiences 
Some of the attributes and roles that a mentor may need to employ are as follows.

- Teacher - sharing knowledge and experience in the mentored domain

- Problem solver - referring the mentee to resources and options

- Motivator - utilizing encouragement, support, and positive feedback when a mentee is facing a challenge

- Coach - helping the mentee to overcome performance difficulties through positive feedback and constructive feedback

- Guide - helping the mentee to set realistic goals

\subsubsection{The Mentee Role}

A mentee is an individual who is protected or trained, or whose career is furthered by a mentor or a person of greater experience, prominence, or influence. A mentee is a professional who needs to learn from the mentor and to practice and demonstrate what has been learned. A mentee is also a "trainee" who should blend mentoring with other training approaches. The mentee has several responsibilities, including the following.

- Taking learning opportunities seriously

- Preparing and completing each assignment according to the action plan that was negotiated with the mentor

- Expressing needs clearly

- Helping to identify development goals

- Seeking input from the mentor

- Demonstrating commitment through action

- Maintaining confidentiality

- Maintaining a positive attitude

- Keeping an open mind when receiving feedback, whether positive or negative

\subsection{Obstacles to Successful Mentorships}

Mentor-mentee relationships are like any other situations that involve interpersonal interactions. The following list outlines some of the more common problems that are specific to a mentorship arrangement.

- Differences in learning/mentoring styles. A mentoring style may not meet the mentee's learning needs or feel comfortable to the mentor. After evaluating the mentee to determine the required amount of guidance, the mentor can determine the mentoring style that is most appropriate. Both the mentor and the mentee need to be flexible in adjusting the amount and direction of "give-and-take" in their interactions. As the relationship evolves and the mentee's skill level and confidence grow, the mentor may need to adjust mentoring 
techniques to stay synchronized with the mentee's development. Typically, as the mentorship evolves and moves toward conclusion, the mentor tends to give less advice and accepts more input from the mentee, until the mentee is capable of fully autonomous performance.

- Time required for mentoring activities. Schedule commitments may prevent a mentor from spending sufficient or high-quality time with a mentee. If a mentor starts to sacrifice mentorship time because of other commitments, the mentee may lose faith in the mentor, and the mentoring relationship will suffer. The same is true if the situation is reversed, with the mentee failing to devote adequate time for interacting with and learning from the mentor.

- Inappropriate expectations. A common problem with mentors is that they may expect too much progress from the mentee in an unrealistically short time. Mentors must allow their mentees to have sufficient time to grow professionally and to make mistakes along the way. Because of their greater knowledge and experience, mentors may have difficulty reining in their impatience with a mentee from whom they are expecting too much too soon. Conversely, some mentees may expect too much from their mentors, such as demanding more time than is realistic. Or, mentees may expect or ask for more attention than they actually need.

- Control. A mentor should try to avoid the two extremes that may arise in a mentor-mentee relationship - either exerting too much control over the learning situation and smothering the mentee's attempts to act alone, or paying so little attention to the mentee that it amounts to neglect and leaves the mentee open to failure. Both parties should understand that this kind of relationship requires a firm time commitment from both parties and, if these commitments are not honored, the relationship will not meet its goals. Time constraints on both sides should be acknowledged and then managed effectively.

Other obstacles encountered in mentoring efforts may include the following.

- Attempts by either party to control the relationship (instead of cooperating)

- Manipulation by either party (instead of mutual respect)

- Inadequate attention to the preparation stage (for example, failing to set clear goals or to develop an action plan to meet desired goals)

- A casual approach to meetings or other forms of contact with a mentee (for example, unilateral changes to meeting times without good reason and not making further arrangements immediately)

- Lack of organization or preparation for meetings with a mentee

- Overstepping the boundaries of the agreed-to mentorship style; for example, straying into tutoring or direct training 


\section{Mentoring TSP Coaches}

\subsection{Overview}

The Team Software Process (TSP) has grown and transitioned through the technology adoption life-cycle curve from early adoption to the early majority phase [Moore 2002]. In response, the SEI has changed the TSP introduction strategy to better support the needs of a different category of technology adaptors. An essential element in this strategy is the inclusion of a formal mentoring program for TSP coaches. This program expands the coach training (which, in its initial stages, focused primarily on preparing and conducting the TSP team launch) to include other aspects, such as overseeing the associated meetings conducted during the projectdevelopment cycle, helping teams to collect and interpret data, and providing guidance on appropriate and effective interactions with TSP team sponsors, leaders, and members.

The TSP coach training program also reflects a response to comments received from the SEI's TSP Users Survey conducted in 2006. Community input, as reflected in the following survey findings, is a vital element influencing the growth of TSP into wider adoption in software engineering practice.

- A majority of the survey respondents agreed that the 2006 coach training model needed revision and that adding several levels of coach qualification was necessary.

- Feedback described the 2006 coach qualification track as a hindrance to the growth of TSP use in organizations, especially to widespread transition across an organization.

- Survey respondents noted in the write-in comments that a key area of concern was the need to implement coach qualification tracks that better suited the scalability needs of the customer.

- Respondents agreed that adding mentoring to the qualification track would benefit both individuals and organizations.

The previous (2006) training model resulted in successful candidates receiving the designation of SEI-Authorized TSP Coach. The authorization requirements were as follows.

- Successful completion of the PSP for Engineers course, or the PSP Fundamentals and PSP Advanced courses

- Successful completion of the SEI-Certified PSP Developer credential

- Sponsorship by an SEI Partner

- Successful completion of the TSP Coach Training course

- Successful performance as a coach in at least one TSP team launch (with successful performance determined through observations conducted by qualified SEI personnel)

The qualification model detailed in this guidebook describes four levels of qualification, each with definitive entry and exit gates. These levels are Provisional TSP Coach, SEI-Certified TSP Coach, Provisional TSP Mentor Coach and SEI-Certified TSP Mentor Coach. This four-tiered 
model provides organizations with more scalability and decreased costs when broadening the implementation of TSP across multiple sectors of the organization, and provides individuals with more options to apply their TSP experiences as coaches within the organization.

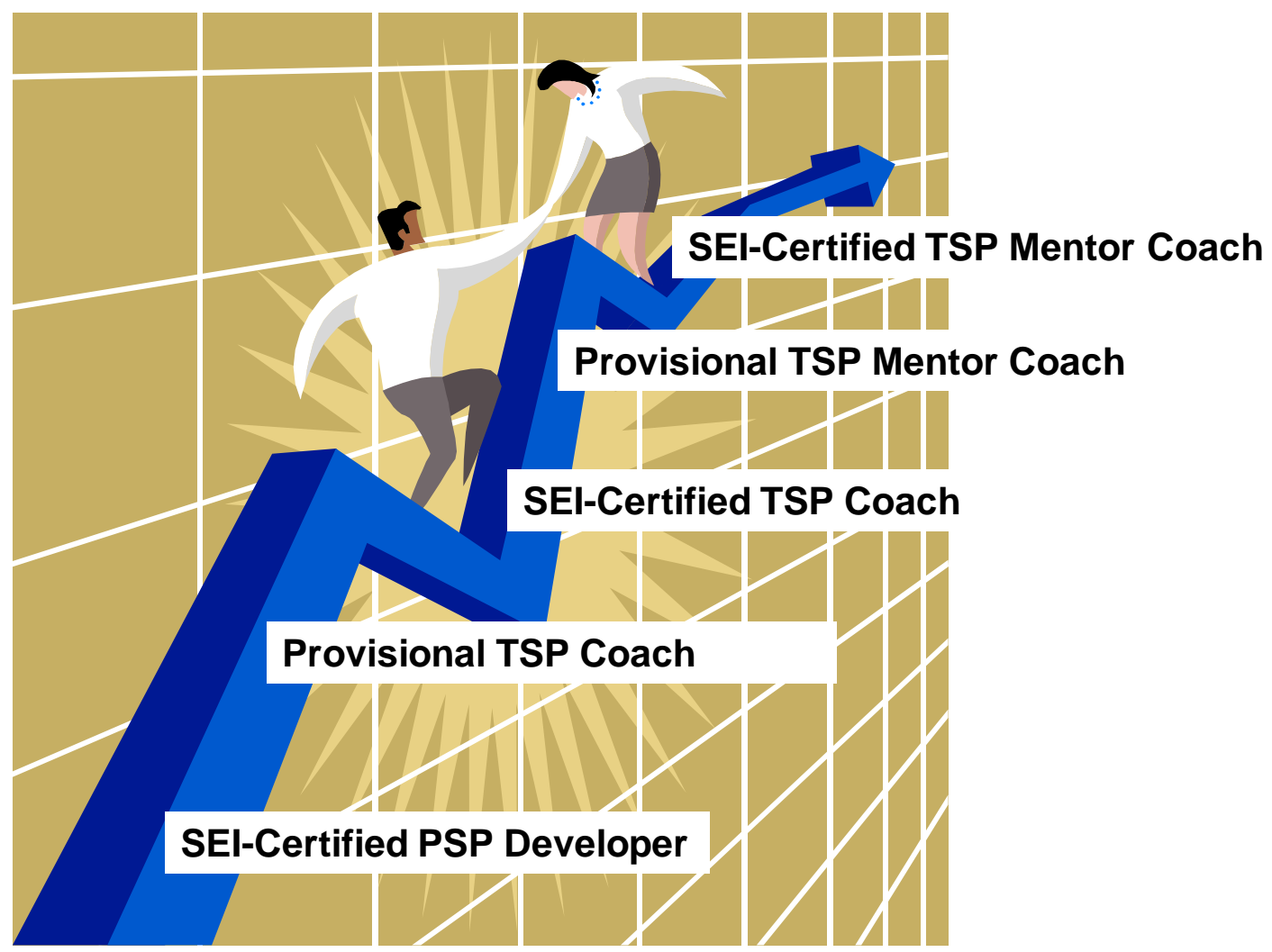

Figure 3: Multi-Tiered Qualification Model

\subsubsection{Why is Mentoring Needed in the TSP Coach Qualification Model?}

Recent studies and workforce research indicate that additional on-the-job training is needed to increase employee productivity and decrease the time needed to produce quality work. A study performed by the American Society of Training and Development found that while training alone increased manager productivity by $24 \%$, productivity was increased by $88 \%$ when training was combined with coaching and mentoring support strategies [Sweeny 2003]. The study defined mentoring as

- a series of tasks that effective mentors must do to promote the professional development of others

- the intense, trusting, supportive, positive, confidential, low-risk relationship within which the partners can try ways of working and relating, make mistakes, gain feedback, accept challenges, and learn in front of each other 
- the complex developmental process that mentors use to support and guide their mentees through the necessary career transitions that are part of learning how to be an effective, reflective professional and a career-long learner

The TSP coach qualification model includes mentoring in order to provide new coaches with guidance and support in a controlled environment that allows new coaches to implement the skills and knowledge gained through PSP/TSP training. The mentorship structure gives new coaches an opportunity to practice and gain feedback on performance, thereby optimizing the learning experiences gained through interactions with TSP teams and a qualified mentor coach.

\subsection{The TSP Coach Qualification Model}

The TSP coach qualification model accounts for the needs of a newly-trained coach to implement the knowledge and skills learned in the classroom into real-world practice under the tutelage of an experienced coach. The mentoring element in this model replaces the former requirement for an on-site observation by SEI personnel and allows written evaluations (such as the final evaluation of data and the written exam) to be accomplished remotely, thus eliminating the need for costly travel by either the new coach or the coach evaluators.

The inclusion of mentoring in the qualification model also provides a path for continued personal and professional growth by providing the opportunity for qualified and interested TSP coaches to become SEI-Certified TSP Mentor Coaches.

An outline of the TSP coach qualification model is shown on the next page in Figure 4. 


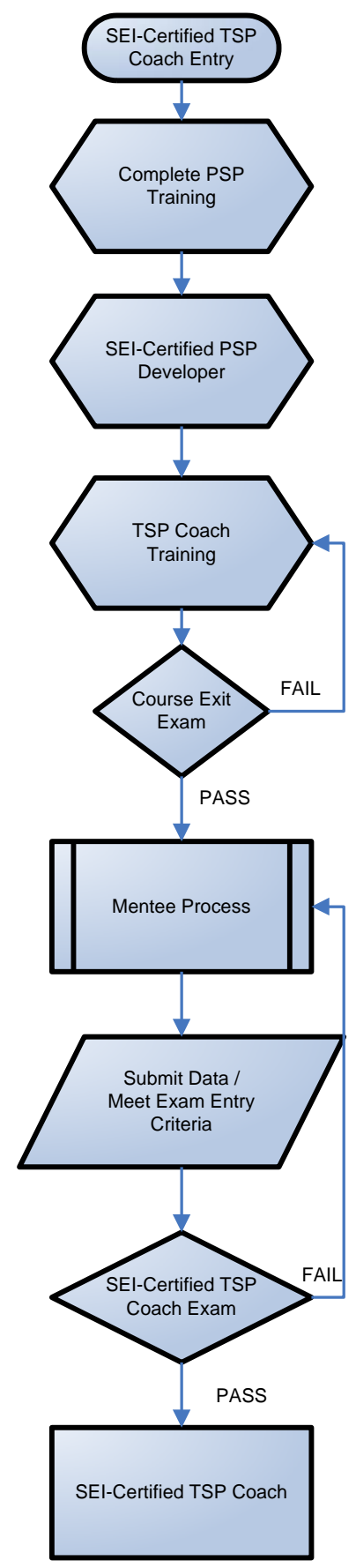

Figure 4: Steps to Becoming an SEI-Certified TSP Coach

\subsubsection{The Provisional Coach}

A provisional coach has received training in PSP and TSP and is ready to apply his or her skills and knowledge under the supervision of a mentor coach. A provisional coach must satisfy the following criteria before the mentoring phase can begin.

16 | CMU/SEI-2010-SR-016 
- Successfully complete the PSP coursework delivered by the SEI, an SEI-Authorized PSP Instructor, or an accredited university

- Be recommended by the PSP instructor who taught the provisional coach's PSP courses

- Hold the SEI-Certified PSP Developer credential

- Be sponsored by an SEI Partner

- Sign the SEI Code of Professional Conduct

- Successfully complete the TSP Coach Training course

To become certified, a provisional coach must complete the following activities while under the supervision of an SEI-Certified Mentor Coach.

- As a provisional coach, successfully complete at least one each of the TSP events listed below within 18 months of entering provisional coach status.

- TSP launch or relaunch

- $\quad$ TSP checkpoint

- TSP project or cycle postmortem

- Successfully complete all associated responsibilities of a TSP coach as outlined in tasking areas C through G of the TSP Coach Job Analysis Report (see Appendix B). Successful completion must be confirmed by an SEI-Certified TSP Mentor Coach, or a Provisional Mentor Coach under the guidance of an SEI-Certified TSP Mentor Coach, via the final assessment report. The mentor coach must also provide a recommendation that the provisional coach be allowed to become an SEI-Certified TSP Coach.

- Successfully complete the TSP Coach Certification written exam. (NOTE: the provisional coach is allowed a maximum of three attempts at passing the exam. Failure to pass the exam on the third attempt will disqualify the individual from becoming an SEI-Certified TSP Coach.)

A provisional coach has permission to use the TSP tool and intellectual property under the sponsor's license agreement for the duration of the provisional period; the supervising mentor coach will provide access to the tool and intellectual property on an as-needed basis. The provisional coach is also subject to annual support payments, as outlined in the partner agreement. The maximum completion time for the provisional coach period is 18 months, with an option to apply for an extension (subject to approval by the SEI).

\subsubsection{The SEI-Certified TSP Coach}

The designation of SEI-Certified TSP Coach is conferred upon individuals who have completed all training and testing requirements as outlined in Figure 4. These individuals are fully qualified to coach a TSP team. An SEI-Certified TSP Coach has been mentored by an SEI-Certified TSP Mentor Coach, was evaluated against a standard in the form of a written examination, and has demonstrated the skills necessary to successfully coach a TSP team. The SEI-Certified TSP Coach can apply PSP/TSP principles in ill-defined team and organizational situations and is able 
to guide teams toward superior performance. The SEI-Certified TSP Coach also acts as a champion for PSP/TSP, motivating new developers, managers, and executives to adopt these technologies.

SEI-Certified TSP Coaches must renew their certification every two years. Renewal criteria are as follows.

- Maintain currency of the SEI-Certified PSP Developer credential

- Hold a current SEI-Certified TSP Coach credential

- At a minimum, submit data for one complete TSP cycle, which includes at least one each of the following events.

- Launch or relaunch

- workbooks (overall, consolidated, and individual) or equivalent

- questionnaires (site, project, and team member)

- evaluations (launch and relaunch)

- presentations from launch meetings 1 and 9

- Checkpoint

- report of findings and recommendations

- workbooks (consolidated and individual) or equivalent

- Project or cycle postmortem

- postmortem report

- workbooks (consolidated and individual) or equivalent

\subsubsection{The Provisional TSP Mentor Coach}

A mentor coach is responsible for providing provisional coaches with the guidance and support necessary to effectively coach TSP teams. A mentor coach is an experienced person who acts as a trusted counselor, role model, and guide to a less experienced person or a newcomer into the practice. A mentor coach has completed the required training and has gained sufficient experience in coaching successful TSP teams to counsel and mentor provisional coaches. A mentor coach also prepares provisional coaches for their final evaluations to become SEI-Certified TSP Coaches. In order to provide each provisional coach with the attention needed for success, a mentor coach is permitted to mentor no more than four provisional coaches at any given time.

In order to become a provisional mentor coach, an applicant must be an SEI-Certified TSP Coach in good standing and must also successfully complete the TSP Mentor Coach Training course offered by the SEI. The TSP Mentor Coach Training course prerequisites are as follows.

- Submit an application with all required supporting data

- Be an SEI-Authorized PSP Instructor

- Teach or co-teach three of the courses from the TSP product suite as outlined on the SEI website (www.sei.cmu.edu/partners/tsp/materials/); these courses must be any one PSP course and any two non-PSP courses listed in the product suite 
- Launch (or relaunch) a minimum of four different teams during the five-year period immediately preceding the mentor coach application; the launch or relaunch to postmortem cycles must total at least 52 team-weeks of coaching experience, and evidence must be available from data submissions made to the SEI

- Complete a minimum of four TSP checkpoints and four TSP project or cycle postmortems associated with the aforementioned (re)launched teams, as evidenced with reports and actual data submitted to the SEI

- Provide at least one of the following sets of recommendations.

- Letters of recommendation to be a mentor coach from all team leaders of the aforementioned (re)launched teams, and at least two of the associated team members

- Launch Participant Feedback Forms and a Launch Coach Feedback Form for each of the aforementioned (re)launched teams

A provisional mentor coach must successfully mentor a provisional coach candidate through the process of becoming an SEI-Certified TSP Coach (see certification requirements listed above), under the guidance of an SEI-Certified TSP Mentor Coach. The SEI-Certified TSP Mentor Coach from the SEI will guide the provisional mentor coach through the following activities.

- Completion of the Provisional Coach Mentoring Program Application (Form MPA), which includes the completion of a Provisional Coach Developmental Needs Self-Assessment (Form DNSA) and the development of Mentoring Goals (Form MG) and a Mentoring Action Plan (Form MAP)

- Completion of Mentoring Artifact Evaluations (Form MAE) of the data and information provided at (re)launches, checkpoints, and postmortems

- If part of the mentor and mentee's MAP, conducting (re)launch observations (Forms LOE and LOS)

- Periodic assessment of the mentoring being provided to the provisional coach

- Submission of TSP data to the SEI (Form DSF)

- Submission of a final assessment report (Form FAR) 


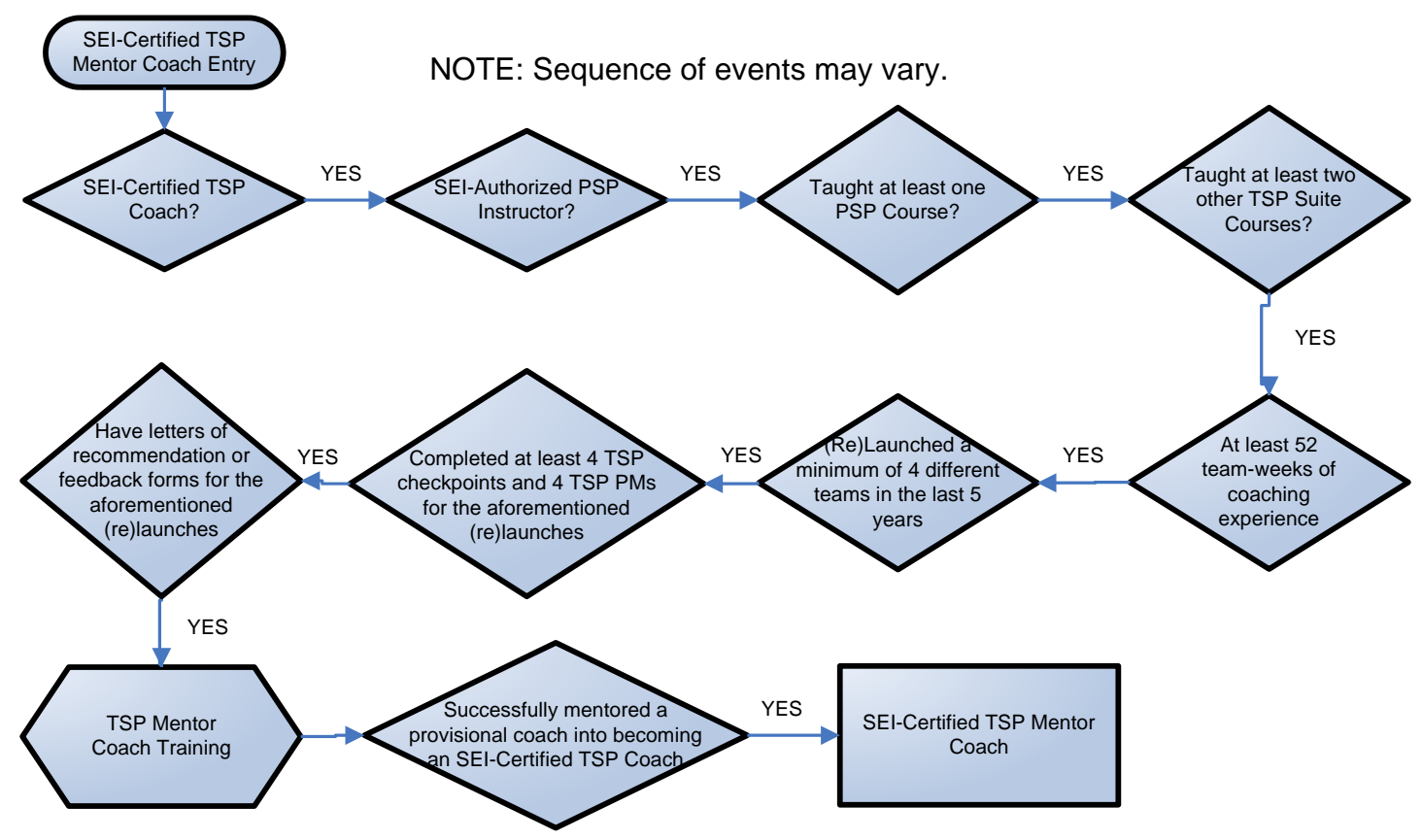

Figure 5: Steps to Becoming an SEI-Certified TSP Mentor Coach

\subsubsection{The SEI-Certified TSP Mentor Coach}

An SEI-Certified TSP Mentor Coach is capable of meeting all the responsibilities outlined in the provisional mentor coach section above without the direct guidance of the SEI and is capable of providing a provisional coach with all the skills needed in order to successfully coach a TSP team.

- An SEI-Certified TSP Mentor Coach must renew his or her certification every four years. Renewal criteria are as follows.

- Be an SEI-Certified PSP Developer in good standing

- Be an SEI-Certified TSP Coach in good standing

- Be an SEI-Authorized PSP Instructor in good standing

- Successfully mentor at least two provisional coaches through the complete process of becoming an SEI-Certified TSP Coach 


\section{The TSP Mentoring Program}

This guidebook will help mentors and provisional coaches to set achievable goals and to assess areas in which growth and development are needed to complete the qualification track. This section defines the TSP mentoring program and provides guidelines to be used while executing the mentoring program.

\subsection{TSP Mentoring Phases}

Figure 6 and Figure 7 outline the TSP mentoring phases. These phases are expansions of the mentoring relationship phases shown in Figure 2. Depending on the provisional coach's developmental goals and the action plan developed by the mentor and provisional coach during the Preparation/Prescriptive phase, the next step in the developmental progression could be the Persuasive phase, the Enabling/Collaborative phase, or a combination of both.

During the Persuasive phase, there are many meetings throughout the TSP cycle that the mentor should attend. For these events, the mentor may attend in person or remotely via video teleconference or similar means. It is important that the mentor take the role of a silent observer during these events, as it is the provisional coach's job to coach the team, not the mentor's job. The mentor must refrain from correcting or evaluating the provisional coach during these events. The mentor should hold any comments or recommendations until after the event or during a break. The mentor is present mainly to ensure that the provisional coach is successful. Therefore, the mentor should remain as invisible as possible to allow the provisional coach to learn and gain experience and to maintain credibility with the team being coached.

The mentoring artifacts and the TSP cycle events outlined in Figure 6 and Figure 7 are designed to guide the mentor and provisional coach through the many duties and skills expected for a certified coach, as outlined in Appendix B (the TSP Coach Job Analysis Report). As the mentor and provisional coach work their way through the TSP cycle events, they should use the questions contained in Appendix A to stimulate thinking and to help guide the interaction between them successfully. The mentor is not expected to be an expert in every subject area, but mentors are expected to utilize their network of resources to augment their own skill set. The mentor should also review and provide feedback to the provisional coach on all mentoring artifacts as they are produced, using Forms LOE, LOS, and MAE as appropriate. 


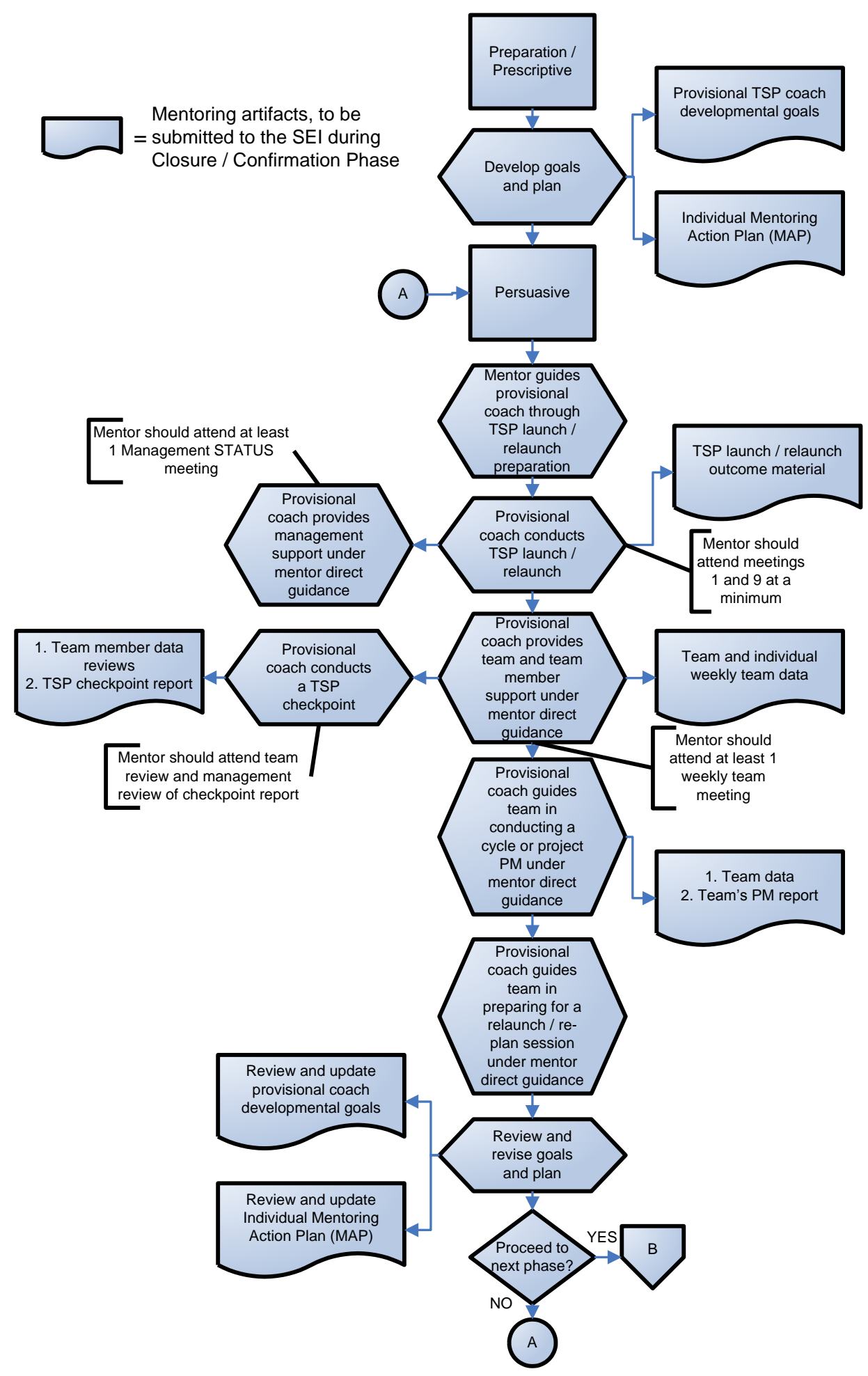

Figure 6: TSP Mentoring Program - Preparation/Prescriptive and Persuasive Phases 


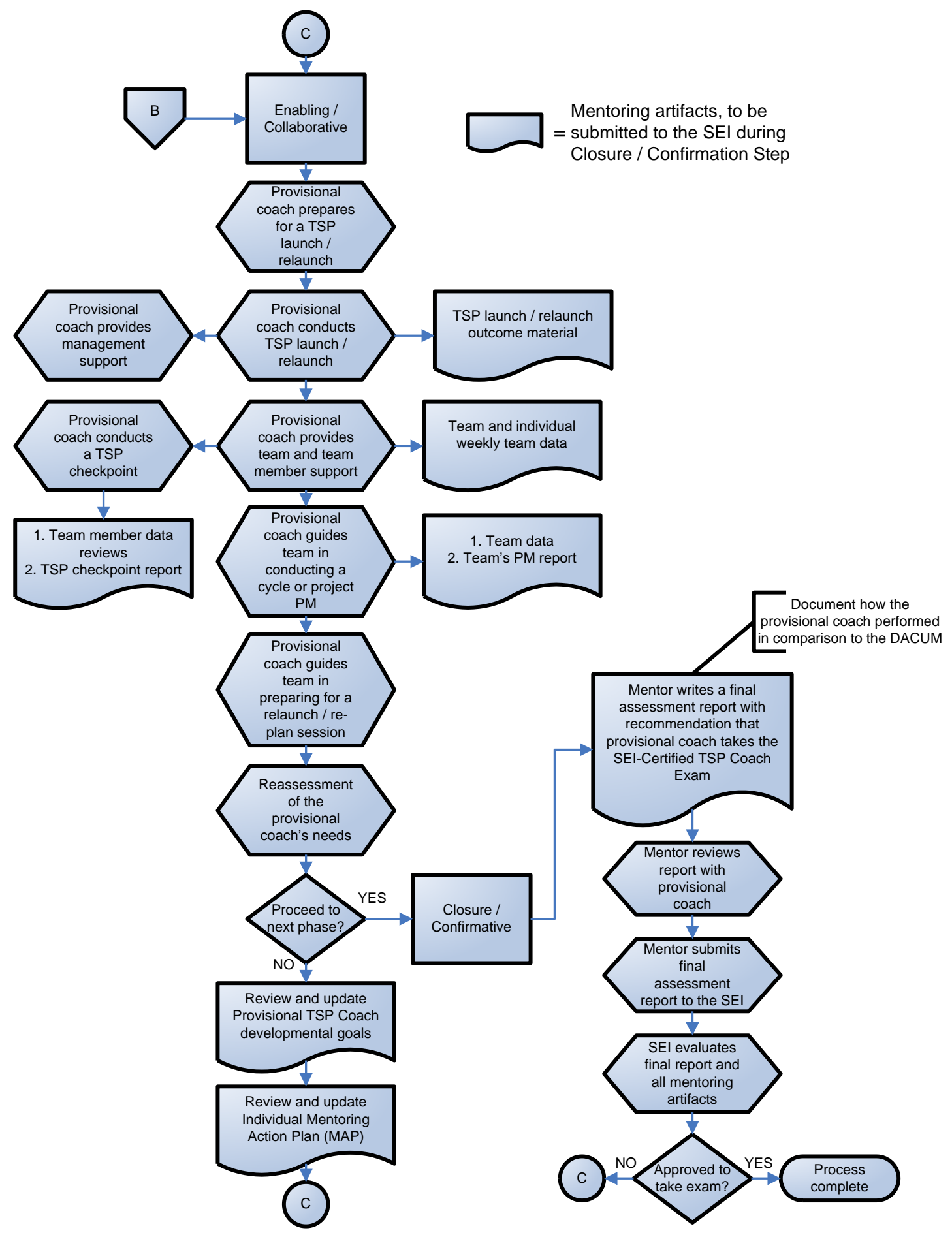

Figure 7: TSP Mentoring Program - Enabling/Collaborative and Closure/Confirmation Phases 


\subsection{Conducting Mentoring Sessions}

The following list outlines suggestions that can help to ensure that the mentor and the provisional coach have productive mentoring sessions.

- The first meeting or conference call should be long enough to complete planning goals and expectations and scheduling needs. This meeting generally can be expected to take about two hours.

- Both mentor and provisional coach should review this guide before their first meeting. It should be used as a reference for future meetings.

- The provisional coach should be ready to discuss the project status during the mentor meeting, and should be able to easily access needed details. Mentoring artifacts should be readily available to both parties.

- Mitigation steps should be identified for any identified areas for improvement.

- The mentor should provide copies of all mentoring reports to the provisional coach. This includes a copy of the final assessment report.

- A date and time for the next mentoring session should be set before each meeting ends. It is recommended that the mentor and provisional coach spend at least 30 minutes each week reviewing and updating their Mentoring Action Plan.

\subsection{Guidance for Mentors and Provisional Coaches}

A mentor may be able to judge the provisional coach's progress from reviewing only the mentoring artifacts, as outlined in Figure 6 and Figure 7. However, it is more likely that the mentor will require additional information to assess whether the provisional coach is preparing properly for his or her coaching work. This section discusses areas in which the mentor needs to ensure that the provisional coach is progressing in the development track. We have designated specific areas of tasking where a provisional coach should show competency of knowledge and skills to be a successful TSP coach.

Key Question: What should the mentor be asking/doing to ensure that the provisional coach can be successful?

Mentors should ask the questions that lead the provisional coach to function successfully in coaching their provisional team and, more importantly, that will ensure that the provisional coach masters the skills needed to coach future projects once the mentoring relationship has concluded. For example, when validating the required mentoring artifacts, the mentor should ask questions about how the information was obtained and what information might have been missed.

\subsubsection{General Guidance on Answering Questions}

Provisional coaches are very likely to ask lots of questions of the mentor. The mentor should use careful judgment about whether to answer the question immediately, or to lead the provisional 
coach to derive his or her own answer. The mentor may reasonably respond by repeating the question for the provisional coach to answer, or may ask other questions in lieu of providing an answer. Such questions could include the following.

- Why did you ask that question?

- What do you think the options are?

- Which option would you pick and why?

- Why would you be nervous about that option?

After having a dialogue around those topics, if the original question is still unanswered, the mentor may provide a personal opinion or point the provisional coach to another person or resource. The mentor coach can also draw guidance from the information in the various appendices of this document.

- Appendix A contains questions that a mentor may ask of a provisional coach to determine knowledge and/or skill competency levels in the required topic areas.

- Appendix B is a TSP coach job-task analysis conducted in 2006 by the SEI and the Ohio State University, and is drawn from the expertise of TSP professionals in government, academia, and industry. The resulting information was segmented into the following core areas in which it was deemed that TSP coaches must be competent; Sections C through G (listed below in bold font) are areas that should be of particular interest for potential SEICertified TSP Coaches and Mentor Coaches, as these are the areas in which they are expected to demonstrate mastery.
A. Prepare Organization for Initial TSP Usage
B. Provide TSP Domain Training
C. Facilitate TSP Team Launch
D. Guide Personal Process Usage
E. Guide Team Process Usage
F. Guide Management in TSP Usage
G. Support Data Analysis and Usage
H. Support Organizational TSP Infrastructure
I. Perform Administrative Activities
J. Pursue Professional Development

Competence in all of these coaching task areas is important in the development of a TSP provisional coach. However, during the early training stages, it is critical to a new TSP coach's success to understand and perform well in the specific task areas highlighted above (items $\mathrm{C}$ through G).

- Appendix $\mathbf{C}$ contains the relevant forms that are kept during the provisional qualification process. These forms must be completed, with the original sent to the SEI as part of the TSP coach mentoring program. 


\subsection{TSP Coach Mentoring Roadmap}

In general, the mentoring process for TSP provisional coaches includes the following five steps.

1. Assigning mentors and provisional coaches. Mentors and provisional coaches are paired based on availability, location, and experience in the TSP environment. If necessary, the SEI will assist provisional coaches in locating suitable SEI-Certified TSP Mentor Coaches. The Provisional Coach Mentoring Program Application (see Section 4.5.1.1) is used in the assignment of mentors and provisional coaches.

2. Creating the Mentoring Action Plan (MAP). A successful mentorship outcome depends on setting goals, expectations, and timetables. The Mentoring Goals form (see Section 4.5.1.3) provides guidance to the mentor coach in outlining specific short- and long-term goals with the provisional coach. These goals are based on an individual assessment of the provisional coach's needs (see Section 4.5.1.2) and are supported by an active mentoring partnership. Once the mentor and provisional coach have determined the mentorship goals, they can prepare the MAP (see Section 4.5.1.4). The MAP is the tangible output of the first meeting or conference call, and records the timetable of events for reaching the identified goals, as well as the objectives and tasks associated with each event.

3. Following the MAP. The mentor is responsible for ensuring that the steps in the qualification track are completed according to the plan developed with the provisional coach.

4. Evaluating Progress. The questions listed in Appendix A provide an excellent tool for the mentor to use in evaluating and guiding a provisional coach's progress. Just as TSP teams are advised to conduct weekly meetings, mentors and provisional coaches must regularly communicate with each other and share progress and obstacles. Mentors and provisional coaches are advised to spend at least 30 minutes each week updating the MAP.

5. Assessing performance. At the conclusion of the mentoring relationship, the mentor coach evaluates the provisional coach. The mentor coach completes the final assessment report (see Section 4.5.2.4) and submits it to the SEI for review and validation. The final report contains the information needed to verify that the provisional coach has successfully worked through the TSP cycle and is ready to take the TSP Coach Certification Exam and become an SEICertified TSP Coach.

\subsection{Communication and Record Keeping}

Several forms have been created to support the communication and record-keeping needs of the SEI-Certified TSP Coach Mentoring Program. The forms are contained in Appendix C, with a brief description of each form provided in the sections below. 


\subsubsection{Becoming an SEl-Certified TSP Coach}

\subsubsection{Provisional Coach Mentoring Program Application-Form MPA}

Before a provisional TSP coach can enter the SEI-Certified TSP Coach Mentoring Program, the candidate first must find an SEI-Certified TSP Mentor Coach to serve as mentor. After securing a mentor, the provisional coach completes the Provisional Coach Developmental Needs SelfAssessment form, meets with the mentor coach to discuss developmental goals and create an individual mentoring action plan. The results of the initial meeting are captured in the Mentoring Goals and Mentoring Action Plan forms. The provisional coach then completes the Provisional Coach Mentoring Program Application form and submits it to the SEI for approval, along with the completed Provisional Coach Developmental Needs Self-Assessment, Mentoring Goals, and Mentoring Action Plan forms.

If a provisional coach applicant is unable to find an SEI-Certified TSP Mentor Coach, the applicant may request the SEI to provide assistance in finding a suitable mentor. This is done by submitting such a request to the SEI along with the Provisional Coach Mentoring Program Application. When a mentor is found, the provisional coach must complete the Provisional Coach Developmental Needs Self-Assessment, Mentoring Goals, and Mentoring Action Plan as described above and submit them with a revised Provisional Coach Mentoring Program Application.

\subsubsection{Provisional Coach Developmental Needs Self-Assessment-Form DNSA}

One of the objectives of an SEI-Certified TSP Mentor Coach is to provide guidance based on the provisional coach's learning and development needs and objectives. To accomplish this, the provisional coach must provide input about the personal development goals and work with the mentor to identify the developmental goals and desired results of the mentoring process. The Provisional Coach Developmental Needs Self-Assessment is intended to facilitate this process. The provisional coach should complete this assessment prior to the initial meeting with the mentor to provide a starting point for identifying developmental goals and creating an individual mentoring action plan. This form is submitted to the SEI as part of the Provisional Coach Mentoring Program Application.

\subsubsection{Mentoring Goals-Form MG}

One of the first steps in creating a mentoring relationship is to create the mentoring goals. The Mentoring Goals form is used to document the provisional coach's developmental goals that should be accomplished as a result of the mentoring relationship and that were agreed to by both the mentor and provisional coach. The goals and objectives should be in line with the provisional coach's developmental needs and should be reviewed and updated as the provisional coach progresses through the TSP mentoring process. This form is submitted to the SEI as part of the Provisional Coach Mentoring Program Application.

\subsubsection{Mentoring Action Plan-Form MAP}

The Mentoring Action Plan (MAP) is prepared during the first meeting with the mentor coach. The MAP records the timetable of events and the objectives and tasks associated with each event. 
It is a dynamic document that is updated periodically to reflect reality. The mentor is responsible for ensuring that the steps in the qualification track (as outlined above in Section 3.2.1) are completed according to the MAP. The original MAP is submitted to the SEI as part of the Provisional Coach Mentoring Program Application.

\subsubsection{Provisional Coach Evaluation and Data Submission \\ 4.5.2.1 Mentoring Artifact Evaluation-Form MAE}

The Mentoring Artifact Evaluation form is used by the mentor to review and provide feedback to the provisional coach on all mentoring artifacts (as outlined in Figure 6 and Figure 7) during the provisional coach's progress through the mentoring program. The mentor must provide feedback in a timely manner if the evaluation is to be effective. The evaluation forms are submitted to the SEI as part of the final assessment report.

\subsubsection{TSP (Re)Launch Observation Evaluation (Form LOE) and Summary Forms (Form LOS)}

The provisional coach's developmental goals and MAP may require the mentor to attend the provisional coach's (re)launch as an observer. It is recommended, but not required, that the mentor attend the provisional coach's first (re)launch in its entirety. At the very least, the mentor should attend meetings 1 and 9. The mentor coach should follow these guidelines when observing the provisional coach.

- The provisional coach conducts the (re)launch.

- The mentor coach observes and evaluates the candidate's performance.

- The mentor coach should refrain from participating in the (re)launch.

- The mentor coach should promptly and privately discuss the provisional coach's performance whenever the mentor identifies problems.

During the observation, the mentor observes and evaluates the provisional coach's performance using the (Re)Launch Observation Evaluation form, then summarizes the observation on the (Re)Launch Observation Summary form. The mentor coach also evaluates the (re)launch artifacts using the Mentoring Artifact Evaluation form and provides feedback to the provisional coach at the end of the (re)launch. The provisional coach submits the (re)launch artifacts to the SEI using the TSP Data Submission form, via the SEI Partner Resource Center website (https://partnerresources.sei.cmu.edu/). All evaluation forms are submitted to the SEI as part of the final assessment report. Upon approval as an SEI-Certified TSP Coach, the individual will be given full access to the SEI Partner Resource Center, which will provide a mechanism for submitting all required data to the SEI and also allows coaches to access the TSP tool and intellectual property, as outlined in their sponsor's license agreement.

\subsubsection{TSP Data Submission Form—Form DSF}

The TSP Data Submission form is used to submit all TSP cycle data to the SEI. It is used by both provisional coaches and SEI-Certified TSP Coaches. A separate form must be used for each TSP cycle event. The form, along with the associated data, must be submitted to the SEI using the SEI 
Partner Resource Center website or by mailing an electronic copy of the data and associated form to the SEI via a CD. No emailed data submissions will be accepted due to Internet security restrictions.

\subsubsection{Final Assessment Report-Form FAR}

When the provisional coach has worked through the entire TSP cycle at least once and the mentor is satisfied with the provisional coach's performance, the mentor submits a final assessment report to the SEI with a recommendation for the provisional coach to become an SEI-Certified TSP Coach. The SEI will review the final assessment report, validate the results, and, if all entry criteria have been fulfilled, will notify the provisional coach of his/her eligibility to take the TSP Coach Certification Exam. If the entry criteria were not met or the mentor coach does not recommend the provisional coach for certification, the SEI will notify the provisional coach of any outstanding issues that must be remediated.

\subsubsection{Becoming a Mentor Coach}

\subsubsection{Mentor Coach Application-Form MCA}

A candidate for the SEI-Certified TSP Mentor Coach credential must meet all prerequisites as outlined in Section 3.2.3 above, complete the Mentor Coach Application, and submit it to the SEI. The SEI will verify that the applicant has met all requirements, before accepting the applicant into the Mentor Coach Qualification track. Upon successful completion of mentor coach training and completing a mentoring cycle (under the guidance of an SEI-Certified TSP Mentor Coach from the SEI) to help a provisional coach become an SEI-Certified TSP Coach, the applicant will be awarded the SEI-Certified TSP Mentor Coach credential.

\subsubsection{Mentor Recommendation-Form MR}

As part of the SEI-Certified TSP Mentor Coach Application, the mentor coach applicant may provide a recommendation from multiple leaders and members of TSP teams coached by the applicant as an SEI-Certified TSP Coach. The applicant must complete the Applicant's Section of the Mentor Recommendation form before providing it to the TSP team leaders and members, who will complete the remainder of the recommendation form and submit it to the SEI.

\subsubsection{TSP Coach Mentoring Program Evaluations}

\subsubsection{Provisional Coach Mentoring Evaluation-Form PCME}

As a way to assess the effectiveness of the SEI-Certified TSP Coach Mentoring Program and to provide feedback to SEI-Certified TSP Mentor Coaches on their performance, the SEI will collect certain information from provisional coaches. When a provisional coach submits a final assessment report to the SEI, he or she will receive a Coach Mentoring Evaluation form to be completed and returned by the provisional coach. Once the mentor has mentored several provisional coaches, the provisional coach's comments will be compiled and sent to the mentor. 


\subsubsection{Mentor Coach's Mentoring Program Evaluation-Form MPE}

Upon receipt of the first provisional coach's final assessment report, the mentor will receive a Mentor Coach's Mentoring Program Evaluation form that will ask for information about the mentor's experiences and opinions about the mentorship and the mentoring program. Information from these evaluations will be used to improve the SEI-Certified TSP Coach Mentoring Program. After the receipt of the first evaluation, the mentor coach will be asked to complete the evaluation form on an annual basis, rather than after the completion of every mentoring relationship. 


\section{References}

[CIO 2002]

Federal Chief Information Officers Council. "Federal CIO Council Mentoring Guide." www.cio.gov

\section{[Curtis 2002]}

Bill Curtis, William E. Hefley, \& Sally A. Miller. The People Capability Maturity Model: Guidelines for Improving the Workforce. Boston: Addison-Wesley, 2002 (ISBN: 0201604450). www.loc.gov/catdir/toc/fy031/2001134026.html

\section{[DoT 2009]}

Departmental Office of Human Resource Management, Department of Transportation, "Mentoring Handbook." Retrieved June 3, 2010 from Maxwell-Gunter AFB:

www.au.af.mil/au/awc/awcgate/mentor/mentorhb.htm\#Mentor\%20Directions

\section{[Ensher 2005]}

Ellen A. Ensher \& Susan E. Murphy. Power Mentoring: How Successful Mentors and Protégés Get the Most Out of Their Relationships. San Francisco, CA: Jossey-Bass, 2005 (ISBN:

9780787979522). www.loc.gov/catdir/toc/ecip0513/2005015654.html

\section{[Humphrey 2006]}

Watts S. Humphrey. TSP: Coaching Development Teams. Upper Saddle River, NJ: AddisonWesley Publishers, 2006 (ISBN: 0201731134).

www.sei.cmu.edu/library/abstracts/books/201731134.cfm

\section{[Klasen 2001]}

Nadine Klasen \& David Clutterbuck. Implementing Mentoring Schemes: A Practical Guide to Successful Programs. Boston: Butterworth-Heinemann, 2001 (ISBN: 0750654309). www.loc.gov/catdir/description/els031/2001043846.html

\section{[Moore 1999]}

Geoffrey A. Moore. Crossing the Chasm: Marketing and Selling High-Tech Products to Mainstream Customers. New York: HarperBusiness, 1999 (ISBN: 0066620023).

\section{[Murray 2001]}

Margo Murray. Beyond the Myths and Magic of Mentoring: How to Facilitate an Effective Mentoring Process. San Francisco: Jossey-Bass, 2001 (ISBN: 0787956759).

www.loc.gov/catdir/bios/wiley043/00012933.html

\section{[Sweeny 2003]}

B. Sweeny. "Frequently Asked Questions." Retrieved June 3, 2010 from International Mentoring Association: http://mentoring-association.org/FAQs.html 


\section{[U.S. Navy 2009]}

U.S. Navy Medical Corps. "Abbreviated Mentoring Guide.” Retrieved June 3, 2010 from Maxwell-Gunter AFB: www.au.af.mil/au/awc/awcgate/mentor/mentor.htm\#Introduction 


\section{Appendix A Targeted Questions}

The TSP Coach Job Analysis (contained in Appendix B) identifies the seven major task areas in which successful TSP coaches are expected to attain proficiency. The provisional coach in the SEI-Certified TSP Coach qualification track should concentrate his or her initial efforts on mastering skills from Tasking Areas $\mathrm{C}$ through $\mathrm{G}$. The tables below provide subtopic divisions with associated targeted questions that a mentor can use to gauge the knowledge, skills, or abilities of a provisional coach. These questions are not required, nor should the list of questions be considered complete; rather, they provide a representative sample of open-ended questions that can help to clarify the topic scope and challenge a provisional coach's understanding. The forms in Appendix $\mathrm{C}$ can be used to record the evaluation findings elicited by these questions and to record any necessary mitigation steps. 


\section{Task Area C: Facilitate TSP Team Launch}

C-1 Prepare management for launch
1. Describe the history of the project.

2. What work has already been done?

3. Who are the key management people and customers who care about this project?

4. Have the key project stakeholders provided a presentation to kick off the project and launch?

5. If this project has failed in the past, what led to its failure?

6. When the team presents the final plan to management with alternatives, will management be prepared?

7. Is it clear who has the decision authority to approve the plan or select an alternative?

8. Does the decision authority know what questions to ask?

9. Has the decision authority formulated a response in case the team says that the plan will take significantly longer than management anticipated?
C-2 Prepare TSP team lead for launch

1. Does it seem to you (the provisional coach) that the team leader understands how a self-directed work team should function?

2. Does the team leader seem willing to work in that way?

3. Do all team members have the TSP launch scripts?

4. Describe the room where you're having the launch.

5. What is your schedule for the launch?

6. Are there any unusual circumstances that you think will affect the launch?

7. Have you confirmed management availability for meeting 9 ?

C-3 Prepare TSP team for launch

1. Who are the presenters for meeting 1 ?
2. How did you get this list of presenters? Who could be missing from the list?

3. Have all of the key stakeholders for the project agreed on the content of the meeting 1 presentation?

4. Does the meeting 1 presentation clearly answer the big questions of what is the content and when is it needed?

5. Is management prepared to answer the question, "What is the top priority between resources, schedule, cost, and content?"

C-4 Arrange for TSP launch
logistics

1. Where will the launch take place?

2. Will this be on or off site?

3. What catering or alternatives will be arranged?

C-5 Guide creation of draft conceptual design (prior to launch)
1. How many components does the conceptual design contain?

2. How are they similar to or different from previously developed components?

How might you need to customize the launch scripts?

What do you think would be the most effective thing you could do to help a team jell?

1. Are you prepared to describe team roles, if asked?

2. Have you and the team leader discussed whether the team leader wants to give any guidance regarding team roles?

3. If this is a relaunch, have you talked with the team leader about whether the same roles will continue? 
C-9 Guide TSP team in establishing goals (e.g., management, project, team)
1. What are some coaching suggestions you would give to the team leader prior to meeting 2?

2. How do you intend to lead the team in establishing goals?

3. What's an example of an implied goal?

4. What would you do if the team's goals are not measurable?

5. What would you do if the team's goals are not achievable?

6. How do you prevent the team from taking management goals as their only goals?

7. How would you ensure that there's an adequate record of actions taken during the meeting?

8. How would you conduct a meeting postmortem?

9. What is a suitable number of goals for this team?

1. What general guidelines would you give to the team leader prior to meeting 3 ?

2. What general guidelines would you give to the design manager prior to meeting 3 ?

3. What (if anything) would you do if the team struggles with its conceptual design?

4. What (if anything) would you do if the conceptual design appears to be too sketchy?

5. What (if anything) would you do if the conceptual design appears to be overly detailed?

6. What (if anything) would you do if meeting 3 is lasting much longer than anticipated?

7. Can you give an example of a Product Breakdown Structure if you need to?

8. Can you explain why there are three different "passes" at establishing an estimate (meetings $3,4,6)$ ?

9. NOTE: Questions such as these should be asked in such a way that the provisional coach does not think that he or she should play an active role in the team's decision process.

C-11 Guide TSP team in determining development strategy

1. What are the issues that should drive the team's selection of a development strategy?

2. What do we mean by strategy? How does it relate to conceptual design?

3. Are there any external factors that could affect the strategy, other than the end date?

C-12 Guide TSP team in defining work processes
1. Have you talked to the team leader about the processes (if any) that the team already has?

2. What are some examples of processes that you can describe if someone on the team asks what is supposed to happen here?

3. What is the granularity of process steps that the team should attempt to achieve?

4. What are some examples of process elements that a new team might typically be missing?

5. Who should lead this meeting? Coach? Design manager? Planning manager?

6. Have we looked at any standard company processes that can be tailored to fit the project? 


\begin{tabular}{|c|c|}
\hline $\begin{array}{l}\text { C-13 Guide TSP team in } \\
\text { developing process support and } \\
\text { role plans }\end{array}$ & $\begin{array}{l}\text { 1. What are some key activities that should be in the role plan for the XXX } \\
\text { manager? (You don't need to do all eight-but enough to feel confident } \\
\text { that the provisional coach understands what should be in a role plan.) } \\
\text { 2. How much effort is planned for their roles? }\end{array}$ \\
\hline $\begin{array}{l}\text { C-14 Develop TSP coaching } \\
\text { plans }\end{array}$ & $\begin{array}{l}\text { 1. Does your coaching plan deviate from the standard coaching plan? If } \\
\text { there is no deviation, why not? If there is a deviation, why was it } \\
\text { necessary? } \\
\text { 2. How experienced is the team in using TSP? } \\
\text { 3. What specific coaching do you expect the team to need? }\end{array}$ \\
\hline $\begin{array}{l}\text { C-15 Guide TSP team in } \\
\text { developing overall plan (top- } \\
\text { down plan) }\end{array}$ & $\begin{array}{l}\text { 1. What general guidelines would you give to the team leader prior to } \\
\text { meeting } 4 \text { ? Or, what guidelines have you given to the team leader? } \\
\text { 2. What general guidelines would you give to the planning manager prior to } \\
\text { meeting } 4 \text { ? Or, what guidelines have you given to the planning manager? } \\
\text { 3. How do you intend to introduce the TSP planning tool to the planning } \\
\text { manager? } \\
\text { 4. How do you intend to make the planning manager the primary tool user? } \\
\text { 5. Can you give an example of how to derive a Work Breakdown Structure } \\
\text { from a Product Breakdown Structure? } \\
\text { 6. What (if anything) would you do if meeting } 4 \text { is lasting much longer than } \\
\text { anticipated? } \\
\text { 7. What can you do to keep team members focused during meeting } 4 \text { ? } \\
\text { 8. What periods do "short term" and "long term" refer to? } \\
\text { 9. What would you do if a team has no data on what to base size or effort } \\
\text { estimates? } \\
\text { 10. What would you do if everyone on the team appears to be estimating a } \\
\text { very high number of task hours per week? Low task hours? } \\
\text { 11. Do you have a plan for dealing with the "dead-time" while data is being } \\
\text { entered into the tool? } \\
\text { 12. How are you going to build the TSP Size Summary (SUMS) and enter it } \\
\text { into the tool? } \\
\text { 13. How do you plan to build the tasks from SUMS? }\end{array}$ \\
\hline $\begin{array}{l}\text { C-16 Provide early warning to } \\
\text { senior management if their goals } \\
\text { cannot be met }\end{array}$ & $\begin{array}{l}\text { 1. At what stage in the launch would you be able to provide information to } \\
\text { management that the team is having difficulty meeting the desired } \\
\text { management goals? } \\
\text { 2. What information would you provide to management? } \\
\text { 3. How would you provide the information to management? } \\
\text { 4. What information would you not provide to management? } \\
\text { 5. After providing an early warning to management about the team's ability to } \\
\text { meet management goals, would you take any messages back to the } \\
\text { team? } \\
\text { 6. How do you deal with potential denial problems? }\end{array}$ \\
\hline
\end{tabular}


C-17 Guide TSP team in creating quality plan
1. What general guidelines would you give to the quality manager prior to meeting 5 ?

2. Would you suggest to the team that it use the quality guidelines that are available in the TSP tool?

3. Would you encourage the team to visit/revisit their quality goals during this meeting?

4. How can you use the tool to demonstrate the effect of various assumptions about defect injection and removal rates?

5. What (if anything) would you do if the team appears to be making unrealistic assumptions about defect injections and/or removals?

6. What problems do you expect to encounter and how do you anticipate mitigating them using the tool?

C-18 Guide team in creating individual TSP plans

1. What general guidelines would you give to the planning manager prior to meeting 6 ?

C-19 Guide TSP team in balancing workload

C-20 Guide TSP team in consolidating individual TSP plans

C-21 Guide TSP team in reviewing plans

2. How can you help the team to achieve a balanced plan?

3. How do you intend to introduce the TSP planning tool to the planning manager?

1. How will you know that the team has a plan that satisfies management's goals?

2. Is there something that you would expect management to ask for?

3. How are you going to handle those goals that your plan doesn't address?

C-22 Guide TSP team in creating alternative plans

1. At what time in the launch would you begin to discuss alternative plans?

2. How will the team determine whether alternative plans are needed?

3. How many alternative plans do you think a team should prepare?

4. What alternatives should they consider?

5. Why not more (or fewer)?

6. How can you use the TSP tool to develop alternative plans?

7. How can the team estimate the effects of alternative assumptions?

C-23 Guide TSP team in creating summary project plan

1. What are the essential elements of the team's summary project plan?

2. Who should take the lead in preparation of the summary project plan?

C-24 Guide TSP team to identify and mitigate risks

1. How can you ensure that the team is focusing on the right kinds of risks?

2. What examples of risks could you present that would help the team to then distinguish between risks and issues?

3. What techniques can you use to elicit legitimate risks?

C-25 Guide TSP team in preparing management briefing
1. What are some elements of the management briefing that you think are essential?

2. What template will the team use?

3. Describe how the team will present the plan.

4. Does the briefing cover all the topics?

5. Does it answer likely management questions?

6. Does it tell management at the beginning what the punch line is? 
C-26 Guide TSP team in brainstorming questions management is likely to ask
1. What are some examples of questions that you might suggest if no team member comes forward with questions?

2. What is most important to management?

3. What is likely to surprise them?

4. What will management ask about
a. Assumptions?
b. Products?
c. Dates?
d. Milestones?

C-27 Guide TSP team leader in preparing for management meeting

1. Do you think there are any special circumstances involving the management team or the development team that would call for additions or deletions to the suggested format?
2. Have you had a "dry run" of the presentation?

3. Are there any significant issues with this plan that warrant going to management prior to the meeting?

4. What are your primary plan assumptions?

5. How did you come to those assumptions? In what way (if any) does the main plan not fully satisfy management goals?

6. How will alternate plans address the main plan shortcomings?

7. Why did the team select these specific alternates?

8. How will you respond if management proposes something not considered in your alternative plans?

9. How will you handle the situation if management asks for a commitment to a plan that is not your proposal or one of your alternates?

10. If management agrees to your main plan or an alternate, are you ready to begin work?

11. What are your greatest plan risks and how will you address them?

12. What do you require from management to enact your plan or an alternative?

13. Are you fully committed to the plan and the alternates?

14. Are you convinced that the team is committed to the plan?

Would you ever step in and take a larger role in the management briefing?

conducting the management briefing

C-29 Obtain management approval for team plan

C-30 Guide TSP team in providing outbrief to technical stakeholders

C-31 Guide TSP team in conducting launch Postmortem (PM)

C-32 Train new TSP teams in tool usage

How do you ensure that the team and management will leave the meeting with the same understanding of meeting 9 outcomes?

1. Who are the technical stakeholders for this project?

2. What are the essential elements of the outbrief for each of them?

1. How can the team benefit from the launch PM?

2. How can you benefit from the launch PM?

1. What tool will the team use? Are you familiar with that tool?

2. Are most members of the team familiar with the tool?

3. How do you intend to train team members who are not familiar with the tool? 


\begin{tabular}{l|l}
\hline $\begin{array}{l}\text { C-33 Facilitate the use of launch } \\
\text { scripts }\end{array}$ & $\begin{array}{l}\text { 1. Will all members of the team have the launch scripts at hand during the } \\
\text { launch? } \\
\text { 2. What will you do during the launch to ensure that team members are } \\
\text { aware that the launch is following a script? }\end{array}$ \\
\hline $\begin{array}{l}\text { C-34 Coordinate cross-team } \\
\text { involvement }\end{array}$ & $\begin{array}{l}\text { 1. Is more than one team involved in this project? } \\
\text { 2. Have you and the team leader talked to the coaches and team leaders of } \\
\text { the other teams? }\end{array}$ \\
$\begin{array}{ll}\text { 3. What role managers will coordinate with other teams? } \\
\text { 4. How does your coaching role differ when a project involves multiple } \\
\text { teams? }\end{array}$
\end{tabular}

Task Area D: Guide Personal Process Usage

D-1 Conduct individual data review
1. How have you prepared to conduct the reviews?

2. What data are you reviewing? Why did you choose that data at this time?

3. When are you reviewing the data (the data that should be going into the weekly consolidation)?

D-2 Identify individual strengths and weaknesses

1. What individual strengths and weaknesses do you see in the team members?

2. What data led you to these conclusions?

D-3 Guide individuals with improvement goals

1. How did you identify improvement goals?
2. Who identified these improvement goals?

3. What problems did the individuals have in establishing these goals?

4. What is your role in helping individuals to develop these goals?

D-4 Guide individuals' process improvement plans (PIPs)

1. Where are PIPs stored?

2. How often are they reviewed? In what order?

3. How are they acted on?

D-5 Guide individuals in presenting their status present their status?
1. What do you want to make sure that team members include when they

2. What information should always be presented? Or, what does the rest of the team need to know?

3. How long should each team member take to review his/her status?

4. When might the planning manager or team leader ask for additional review of data?

5. How will team members present their reviews?

D-6 Guide individuals in fulfilling team member roles

1. How much time in the meetings is devoted to role reports?

2. Describe the team's various team role activities.

3. How much time are role managers spending per week?

4. Describe problems or issues that the team has in implementing roles.

D-7 Provide individual remedial PSP training
1. Have your team members finished their PSP training? If not, what will be done to finish the training?

2. Have you identified any problems or misunderstandings in this area? 


\section{Task Area E: Guide Team Process Usage}

E-1 Guide team in assessing quality status
1. How much meeting time is devoted to quality issues?

2. How does quality data compare to the plan?

3. Who is the team's quality manager? Is this individual leading the discussion?

\section{E-2 Guide team in assessing} process status
1. Who is the team's process manager?

2. How does the team evaluate process fidelity?

3. What suggestions have you made to the team regarding process usage?

4. Is the team developing process elements that were identified in the launch?

E-3 Guide team in assessing schedule status

1. Does the team review the schedule status in the weekly meeting? How much time do they spend discussing schedule?

2. How does the team know whether they are ahead of or behind schedule? (CPI? Hours? EV?)

E-4 Guide team in dynamic plan adjustments (e.g., load balancing, task management)

1. Why is the team ahead or behind?

2. What are they doing about it?

3. What guidance have you provided?

4. How is the team handling workload imbalance?

E-5 Identify team strengths and weaknesses

1. How did you identify the team's strengths and weaknesses?

2. How did you come to that conclusion?

E-6 Guide team in setting improvement goals

1. What are the team's improvement goals?

2. Why did they choose those goals?

3. Are the goals achievable?

4. How will the team measure these goals?

E-7 Guide team in developing improvement plan

1. What improvement actions does the team plan?

2. Why did they select these actions?

3. What do they expect the effect to be?

E-8 Guide team in presenting its status to management

1. How often does the team report to management?

2. What information do they report?

3. What help do they ask for when preparing or presenting the report?

4. What level of management needs to be present?

5. Are written reports prepared for these meetings?

E-9 Guide team in fulfilling TSP team roles

1. Which roles are most active? Or inactive? Why?

2. Are any of those a problem?

3. What tasks does the team assign the role managers?

4. Are these tasks being completed?

E-10 Guide team with remedial TSP training

1. What TSP issues has the team encountered?

2. What have you reviewed in the workbooks?

3. Has the team encountered any tool issues? What were they? How did you address them? 
E-11 Attend weekly team meetings

1. How many weekly meetings have you attended? Was it in person or remotely?

2. Are minutes taken?

3. Who leads the meeting?

4. What coaching advice have you provided to the team leader? Preparation? Follow up?

5. What advice have you provided to the team members?

6. Are team members following the scripts? Are they skipping over any parts?

E-12 Guide team through initial inspections
1. Have you attended an inspection?

2. What kinds of help did the team require?

3. Are the inspections effective?

4. Is the team following the scripts? Are they skipping over any parts?
1. How much time did you spend with individual interviews?

2. What kinds of comments did you receive?

3. How did this affect your data review?

4. What were your findings? How were the findings presented to management and the team?

5. Did you use a template?

E-14 Guide team to conduct cycle and project PM

1. Did everyone participate? If not, why?
2. What are the PIPs?

3. Were there any data problems?

4. How can the results be used to plan future projects or cycles?

5. Were the goals measurable (SMART: specific-measurable-attainablerealistic-time-bound)? Were they achieved?

6. Were planned risks realized? Was mitigation effective? Were any new risks identified?

E-15 Guide team to conduct replanning and relaunch sessions

1. Why was a relaunch/replan needed? How did you decide?

2. Describe the preparations.

3. How long did the relaunch/replan take?

4. Describe the result. Did any goals or the commitments change? If so, how was this addressed?

E-16 Guide team in managing inter/intra team dependencies

1. How did the team identify and handle team dependencies?

2. Describe cross-team dependencies.

3. What guidance have you provided?

E-17 Guide team in managing risks and issues

1. What major risks and issues did the team have coming out of launch?

2. How frequently do they review the status?

3. What is the current status?

4. Is the team reviewing risks in the weekly meetings?

E-18 Guide team in achieving management goals

1. What are management's primary goals?

2. What are the team's primary goals?

3. How do the team goals support management goals?

4. Is the team reviewing goals in weekly meetings? 


\begin{tabular}{l|l}
$\begin{array}{l}\text { E-19 Guide team in developing } \\
\text { new process elements (e.g., } \\
\text { design standards, review } \\
\text { checklist) }\end{array}$ & $\begin{array}{l}\text { 1. What process elements might the team need to develop? } \\
\text { 2. How did they determine that new process elements would be needed? } \\
\text { 3. When do they need them? } \\
\text { 4. Which ones do they need first? } \\
\text { 5. Who is responsible for developing them? }\end{array}$ \\
\hline $\begin{array}{l}\text { E-20 Show team leader (and } \\
\text { team members) how to use TSP } \\
\text { tools }\end{array}$ & $\begin{array}{l}\text { 1. Which TSP tools does the team use? } \\
\text { 2. What help has the team leader needed with the tools? } \\
\text { 3. What help has the planning manager needed with the tools? }\end{array}$ \\
\hline $\begin{array}{l}\text { E-21 Coordinate changes in } \\
\text { team membership }\end{array}$ & $\begin{array}{l}\text { 1. Has there been any turnover in team membership? } \\
\text { 2. Have new members received any required training? }\end{array}$ \\
\hline $\begin{array}{l}\text { E-22 Guide team in correcting } \\
\text { identified problems }\end{array}$ & $\begin{array}{l}\text { 3. What assistance have you provided? } \\
\text { 2. Wave any problems arisen that need further attention? }\end{array}$ \\
\hline
\end{tabular}

\section{Task Area F: Guide Management in TSP Usage}

F-1 Guide management in assessing quality status

F-2 Guide management in assessing process status
1. What data should management look at in terms of quality?

2. Does management understand the data being presented to them?

3. What questions should management ask the team?

1. What should management look at in terms of process status?

2. How should management respond to process shortcomings?

3. What questions should management ask the team?

4. Does management understand the information being presented to them?

5. Does management understand the difference between team and organizational processes?

6. What would you recommend that management address first from an organizational perspective in order to improve the team's effectiveness?

F-3 Guide management in assessing schedule status

1. Does management understand the EV being presented to them?
2. Are you prepared to explain how to interpret the EV data?

3. What should management look at in addition to EV and EV projections?

4. What questions should management ask when EV and projections look good? Look bad?

5. What can management do to address task hour problems?

6. What kinds of decisions should management be making in response to schedule problems? What information does management need to make these decisions?

7. How would you explain the difference between task time and staff hours?

8. Are you prepared to explain how the predicted EV is calculated?

F-4 Guide management in dynamic plan adjustments (e.g., load balancing, task management)

F-5 Guide management in identifying organizational process strengths and weaknesses
2. How should management assign work to a team?

Advanced (beyond the scope for provisional coaches) 


\begin{tabular}{|c|c|}
\hline $\begin{array}{l}\text { F-6 Guide management in } \\
\text { developing organizational } \\
\text { improvement plan }\end{array}$ & Advanced (beyond the scope for provisional coaches) \\
\hline $\begin{array}{l}\text { F-7 Guide management in } \\
\text { communicating success }\end{array}$ & $\begin{array}{l}\text { 1. Has management defined what a successful project looks like? } \\
\text { 2. How would management define a successful TSP team? } \\
\text { 3. How would you help management define success? } \\
\text { 4. What are the different ways management could communicate success? } \\
\text { 5. How could you help management communicate success? }\end{array}$ \\
\hline $\begin{array}{l}\text { F-8 Guide management in } \\
\text { reviewing and rewarding } \\
\text { success }\end{array}$ & $\begin{array}{l}\text { 1. What are some of the different ways management could review and } \\
\text { reward success? } \\
\text { 2. What are some approaches that might result in unintended negative } \\
\text { results? } \\
\text { 3. Are you prepared to provide management with some productive ways for } \\
\text { reviewing and rewarding success? } \\
\text { 4. How would you address management's desire to use personal TSP data } \\
\text { in reviewing and rewarding individual success? }\end{array}$ \\
\hline $\begin{array}{l}\text { F-9 Guide management in data } \\
\text { privacy practices }\end{array}$ & $\begin{array}{l}\text { 1. Are you prepared to discuss the different levels of data privacy? } \\
\text { 2. How would you discourage management from using data inappropriately? } \\
\text { 3. What data should be shared between management and the team? } \\
\text { 4. What data should be shared among individuals and the team? } \\
\text { 5. What data should be shared among individuals and different role } \\
\text { managers? }\end{array}$ \\
\hline $\begin{array}{l}\text { F-10 Guide linkages to } \\
\text { organizational level business } \\
\text { goals }\end{array}$ & Advanced (beyond the scope for provisional coaches) \\
\hline $\begin{array}{l}\text { F-11 Guide management in } \\
\text { developing and improving teams } \\
\text { as organizational assets }\end{array}$ & Advanced (beyond the scope for provisional coaches) \\
\hline F-12 Sustain TSP sponsorship & Advanced (beyond the scope for provisional coaches) \\
\hline $\begin{array}{l}\text { F-13 Guide management in } \\
\text { developing and improving teams } \\
\text { as organizational assets }\end{array}$ & Advanced (beyond the scope for provisional coaches) \\
\hline
\end{tabular}

Task Area G: Support Data Analysis and Usage

G-1 Support organizational software development final analysis

G-2 Support defect prevention
analysis

G-3 Support handling of system test defects
Advanced (beyond the scope for provisional coaches)

1. Have you conducted a TestD or root cause analysis? Describe it.

2. How did the team come to its conclusions?

3. What were the PIPs? Were any implemented?

1. Does the team have a process for handling system test defects?

2. Did they follow their process? What do they do?

3. Do they perform TestD?

Have you conducted a cycle postmortem?
G-4 Support establishment of benchmarks (e.g., yield, quality, productivity, task hours)

G-5 Support conducting TSP usage opinion survey
Advanced (beyond the scope for provisional coaches) 


\begin{tabular}{l|l}
$\begin{array}{l}\text { G-6 Support selection and } \\
\text { recommendation of data } \\
\text { analysis tools }\end{array}$ & Advanced (beyond the scope for provisional coaches) \\
\hline $\begin{array}{l}\text { G-7 Support reconciling data } \\
\text { from multiple sources (e.g., } \\
\text { system test defects, production } \\
\text { defects, configuration }\end{array}$ & $\begin{array}{l}\text { 1. Did the team understand how to combine data from different sources? } \\
\text { 2. What difficulties did they encounter? }\end{array}$ \\
3. What guidance did you provide?
\end{tabular}

management tools) 


\section{Appendix B TSP Coach Job Analysis Report}


B-2 | CMU/SEI-2010-SR-016 


\section{DACUM Research Chart for \\ Team Software Process ${ }^{\text {SM }}\left(\right.$ TSP $\left.^{S M}\right)$ Coach}

\section{DACUM Panel}

Dan Burton

Software Engineering Institute

Robert Cannon

Software Engineering Institute

Noopur Davis

Software Engineering Institute

Ellen George

PS \& J Consulting Services, Inc.

Julia L. Mullaney

Software Engineering Institute

William R. Nichols

Software Engineering Institute

Marsha Pomeroy-Huff

Software Engineering Institute

Jeffrey Smith

Microsoft, Inc.

Dan Wall

Vicarious Visions, Inc.

Allen Willett

Software Engineering Institute

\section{SEI Coordinators:}

Jefferson Welch

Mary Ellen Rich

Valerie Chilson

\section{DACUM Facilitator}

Robert E. Norton

CETE/OSU
Sponsored by

\section{Software Engineering Institute $\mid$ CarnegieMellon}

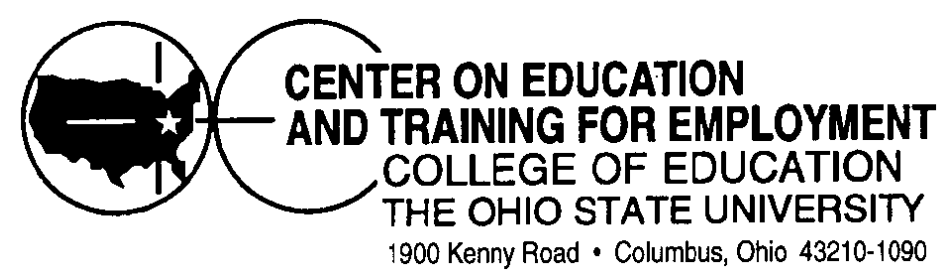

June 1-2, 2006 


\begin{tabular}{|c|c|c|c|c|c|c|c|c|c|c|}
\hline & Duties & & & & & & & & & Tasks \\
\hline $\mathbf{A}$ & $\begin{array}{l}\text { Prepare } \\
\text { Organization for } \\
\text { Initial TSP Usage }\end{array}$ & $\begin{array}{l}\text { A-1 Secure } \\
\text { executive } \\
\text { sponsor for } \\
\text { TSP }\end{array}$ & $\begin{array}{l}\text { A-2 } \\
\text { TSP } \\
\text { semil }\end{array}$ & exect & & $\begin{array}{l}\text { A-3 Con } \\
\text { organiza } \\
\text { needs an }\end{array}$ & $\begin{array}{l}\text { nduct } \\
\text { ational } \\
\text { alysis }\end{array}$ & $\begin{array}{l}\text { A-4 Es } \\
\text { criteria } \\
\text { ROI) }\end{array}$ & e.g & $\begin{array}{l}\text { pilot success } \\
\text { benchmark data, }\end{array}$ \\
\hline B & $\begin{array}{l}\text { Provide TSP } \\
\text { Domain } \\
\text { Training }\end{array}$ & $\begin{array}{l}\text { B-1 Handle } \\
\text { course } \\
\text { logistics }\end{array}$ & $\begin{array}{l}\text { B-2 } \\
\text { for c } \\
\text { deliv }\end{array}$ & $\begin{array}{l}\text { urse } \\
\text { ery }\end{array}$ & & $\begin{array}{l}\text { B-3 Dev } \\
\text { supplem } \\
\text { training } \\
\text { materials }\end{array}$ & $\begin{array}{l}\text { velop } \\
\text { lental } \\
\text { s }\end{array}$ & $\begin{array}{l}\text { B-4 De } \\
\text { Executi } \\
\text { Trainin } \\
\text { Introdu }\end{array}$ & $\begin{array}{l}\text { g, PS } \\
\text { ction }\end{array}$ & $\begin{array}{l}\text { course (e.g., } \\
\text { minar, Management } \\
\text { for Engineers, } \\
\text { o the PSP Process) }\end{array}$ \\
\hline $\mathrm{C}$ & $\begin{array}{l}\text { Facilitate TSP } \\
\text { Team } \\
\text { Launch }\end{array}$ & $\begin{array}{l}\text { C-1 Prepare } \\
\text { management } \\
\text { for launch }\end{array}$ & $\begin{array}{l}\text { C-2 } \\
\text { TSP } \\
\text { for la }\end{array}$ & unch & & $\begin{array}{l}\text { C-3 Prep } \\
\text { TSP tean } \\
\text { launch }\end{array}$ & $\begin{array}{l}\text { pare } \\
\text { m for }\end{array}$ & $\begin{array}{l}\text { C-4 } \\
\text { Arrange } \\
\text { TSP lau } \\
\text { logistic }\end{array}$ & $\begin{array}{l}\text { e for } \\
\text { anch } \\
\text { s }\end{array}$ & $\begin{array}{l}\text { C-5 Guide } \\
\text { creation of draft } \\
\text { conceptual design } \\
\text { (prior to launch) }\end{array}$ \\
\hline & & $\begin{array}{l}\text { C-12 Guide } \\
\text { TSP team in } \\
\text { defining work } \\
\text { processes }\end{array}$ & $\begin{array}{l}\text { C-13 } \\
\text { deve } \\
\text { role } 1\end{array}$ & $\begin{array}{l}\text { oping } \\
\text { lans }\end{array}$ & & $\begin{array}{l}\text { team in } \\
\text { ss suppor }\end{array}$ & rt and & $\begin{array}{l}\text { C-14 D } \\
\text { TSP co } \\
\text { plans }\end{array}$ & $\begin{array}{l}\text { evelo } \\
\text { aching }\end{array}$ & \begin{tabular}{l|l}
$\mathrm{p}$ & C-15 Guide \\
TSP team in \\
developing top \\
level plan
\end{tabular} \\
\hline & & \begin{tabular}{l|l} 
C-21 Guide & \multicolumn{1}{c}{} \\
TSP team in & 7 \\
reviewing & plans
\end{tabular} & $\begin{array}{l}\text { C-22 } \\
\text { TSP te } \\
\text { creatin } \\
\text { native }\end{array}$ & $\begin{array}{l}\text { am in } \\
\text { g alte } \\
\text { plans }\end{array}$ & & $\begin{array}{l}\text { C-23 Guid } \\
\text { reating su } \\
\text { lan }\end{array}$ & $\begin{array}{l}\text { le TSP te } \\
\text { ummary }\end{array}$ & $\begin{array}{l}\text { eam in } \\
\text { project }\end{array}$ & $\begin{array}{l}\text { C-24 } \\
\text { to id } \\
\text { risks }\end{array}$ & $\begin{array}{l}\text { Guide TSP team } \\
\text { entify and mitigate }\end{array}$ \\
\hline & & $\begin{array}{l}\text { C-30 Guide tean } \\
\text { in providing out } \\
\text { brief to technical } \\
\text { stakeholders }\end{array}$ & \begin{tabular}{l|l}
$\mathrm{n}$ & $\mathrm{C}-$ \\
tec \\
co \\
lau
\end{tabular} & $\begin{array}{l}31 \mathrm{G} \\
\mathrm{m} \text { in } \\
\text { nducti }\end{array}$ & & $\begin{array}{l}\text { C-32 } \mathrm{Tr} \\
\text { new tean } \\
\text { tool usag }\end{array}$ & $\begin{array}{l}\text { rain } \\
\text { ms in } \\
\text { ge }\end{array}$ & $\begin{array}{l}\text { C-33 } \\
\text { Facilita } \\
\text { use of } 1 \\
\text { scripts }\end{array}$ & $\begin{array}{l}\text { te the } \\
\text { aunch }\end{array}$ & $\begin{array}{l}\text { C-34 } \\
\text { Coordinate } \\
\text { cross-team } \\
\text { involvement }\end{array}$ \\
\hline D & $\begin{array}{l}\text { Guide Personal } \\
\text { Process } \\
\text { Usage }\end{array}$ & $\begin{array}{l}\text { D-1 Conduct } \\
\text { individual data } \\
\text { review }\end{array}$ & \begin{tabular}{|l} 
D-2 \\
indiv \\
stren \\
weak
\end{tabular} & $\begin{array}{l}\text { Identi } \\
\text { idual } \\
\text { gths a }\end{array}$ & & $\begin{array}{l}\text { D-3 Gui } \\
\text { individua } \\
\text { with imp } \\
\text { ment goa }\end{array}$ & $\begin{array}{l}\text { ide } \\
\text { als } \\
\text { prove- } \\
\text { als }\end{array}$ & $\begin{array}{l}\text { D-4 Gu } \\
\text { individe } \\
\text { improve } \\
\text { plan }(\mathrm{Pl}\end{array}$ & $\begin{array}{l}\text { dide } \\
\text { uals } \\
\text { ement } \\
\text { IP) }\end{array}$ & $\begin{array}{l}\text { D-5 Guide } \\
\text { individuals in } \\
\text { presenting } \\
\text { their status }\end{array}$ \\
\hline $\mathbf{E}$ & $\begin{array}{l}\text { Guide Team } \\
\text { Process } \\
\text { Usage }\end{array}$ & $\begin{array}{l}\text { E-1 Guide } \\
\text { team in } \\
\text { assessing } \\
\text { quality status }\end{array}$ & $\begin{array}{l}\text { E-2 } \\
\text { team } \\
\text { asses } \\
\text { proce }\end{array}$ & $\begin{array}{l}\text { Guide } \\
\text { in } \\
\text { sing } \\
\text { ss sta }\end{array}$ & & $\begin{array}{l}\text { E-3 Gui } \\
\text { team in } \\
\text { assessing } \\
\text { schedule }\end{array}$ & $\begin{array}{l}\text { ide } \\
\text { g status }\end{array}$ & $\begin{array}{l}\mathrm{E}-4 \mathrm{Gu} \\
\text { adjustm } \\
\text { balancir }\end{array}$ & $\begin{array}{l}\text { de t } \\
\text { ents }\end{array}$ & $\begin{array}{l}\text { am in dynamic plan } \\
\text { e.g., load } \\
\text { k management) }\end{array}$ \\
\hline & & $\begin{array}{l}\text { E-12 Guide } \\
\text { team through } \\
\text { initial } \\
\text { inspections }\end{array}$ & $\begin{array}{l}\text { E-13 } \\
\text { Cond } \\
\text { checl } \\
\text { revie }\end{array}$ & $\begin{array}{l}\text { uct } \\
\text { point } \\
\text { w }\end{array}$ & & $\begin{array}{l}14 \text { Guide } \\
\mathrm{m} \text { to } \\
\text { Aduct cycl } \\
\text { project PN }\end{array}$ & \begin{tabular}{l|l} 
& E- \\
& tec \\
le & re \\
M & rel \\
\end{tabular} & $\begin{array}{l}15 \text { Guide } \\
\text { am to con } \\
\text { planning } \\
\text { aunch }\end{array}$ & duct & $\begin{array}{l}\text { E-16 Guide team } \\
\text { in managing } \\
\text { inter/intra team } \\
\text { dependencies }\end{array}$ \\
\hline & $\begin{array}{l}\text { Guide } \\
\text { Management in } \\
\text { TSP Usage }\end{array}$ & $\begin{array}{l}\text { F-1 Guide } \\
\text { management in } \\
\text { assessing } \\
\text { quality status }\end{array}$ & $\begin{array}{l}\text { F-2 } \\
\text { mana } \\
\text { asses } \\
\text { proce }\end{array}$ & $\begin{array}{l}\text { Guide } \\
\text { geme } \\
\text { sing } \\
\text { ss sta }\end{array}$ & & $\begin{array}{l}\text { F-3 Guic } \\
\text { managen } \\
\text { assessing } \\
\text { schedulir }\end{array}$ & $\begin{array}{l}\text { ide } \\
\text { ment in } \\
\text { ing statu }\end{array}$ & \begin{tabular}{|l|l} 
F-4 \\
dyna \\
(e.g. \\
man
\end{tabular} & $\begin{array}{l}\text { Guic } \\
\text { amic } \\
\text {., loa }\end{array}$ & $\begin{array}{l}\text { management in } \\
\text { lan adjustments } \\
\text { balancing, task } \\
\text { ent) }\end{array}$ \\
\hline & & $\begin{array}{l}\text { F-10 Guide link: } \\
\text { to organizational } \\
\text { level business go }\end{array}$ & & $\begin{array}{l}\text { F-11 } \\
\text { mana } \\
\text { integ } \\
\text { organ }\end{array}$ & & $\begin{array}{l}\text { e } \\
\text { nt in TSP } \\
\text { with } \\
\text { nal goals }\end{array}$ & \begin{tabular}{|l} 
F-12 \\
TSP \\
spons
\end{tabular} & $\begin{array}{l}\text { Sustain } \\
\text { orship }\end{array}$ & $\begin{array}{l}\text { F-1? } \\
\text { men } \\
\text { imp } \\
\text { org. }\end{array}$ & $\begin{array}{l}\text { Guide manage- } \\
\text { t in developing and } \\
\text { roving teams as } \\
\text { anizational assets }\end{array}$ \\
\hline $\boldsymbol{C}$ & $\begin{array}{l}\text { Support Data } \\
\text { Analysis and } \\
\text { Usage }\end{array}$ & $\begin{array}{l}\text { G-1 Support } \\
\text { organizational } \\
\text { software develop } \\
\text { final analysis }\end{array}$ & oment & $\begin{array}{l}\text { G-2 } \\
\text { defe } \\
\text { prev } \\
\text { anal }\end{array}$ & & & $\begin{array}{l}\text { G-3 Sup } \\
\text { handling } \\
\text { system t } \\
\text { defects }\end{array}$ & $\begin{array}{l}\text { port } \\
\text { of } \\
\text { est }\end{array}$ & $\begin{array}{l}\text { G-4 } \\
\text { ment } \\
\text { (e.g. } \\
\text { prod }\end{array}$ & $\begin{array}{l}\text { Support establish- } \\
\text { of benchmarks } \\
\text { yield, quality, } \\
\text { uctivity, task hours) }\end{array}$ \\
\hline
\end{tabular}




\begin{tabular}{|c|c|c|c|c|c|c|c|c|c|c|c|c|c|}
\hline $\begin{array}{l}\text { A-5 Define } \\
\text { TSP pilot } \\
\text { selection } \\
\text { criteria }\end{array}$ & \multicolumn{2}{|c|}{$\begin{array}{l}\text { A-6 } \\
\text { Identify } \\
\text { TSP pilot } \\
\text { projects }\end{array}$} & \multicolumn{2}{|c|}{$\begin{array}{l}\text { A-7 } \\
\text { Develop } \\
\text { TSP intro- } \\
\text { duction plan }\end{array}$} & \multicolumn{2}{|c|}{$\begin{array}{l}\text { A-8 } \\
\text { Identify TSP } \\
\text { coach } \\
\text { candidates }\end{array}$} & \multicolumn{2}{|c|}{$\begin{array}{l}\text { A-9 Establish } \\
\text { pilot project } \\
\text { reward system }\end{array}$} & \multicolumn{2}{|c|}{$\begin{array}{l}\text { A-10 Deliver } \\
\text { PSP/TSP } \\
\text { awareness } \\
\text { presentation }\end{array}$} & \multicolumn{2}{|c|}{$\begin{array}{l}\text { A-11 } \\
\text { Evaluate } \\
\text { TSP pilot } \\
\text { projects } \\
\end{array}$} & $\begin{array}{l}\text { A-12 Set } \\
\text { data } \\
\text { privacy } \\
\text { standards }\end{array}$ \\
\hline $\begin{array}{l}\text { B-5 Evaluate } \\
\text { TSP/PSP } \\
\text { course } \\
\text { outcomes }\end{array}$ & \multicolumn{5}{|c|}{\begin{tabular}{l|l} 
B-6 & \\
Implement & \\
training PIPs &
\end{tabular}} & & & & & & & & \\
\hline $\begin{array}{l}\text { C-6 Plan for } \\
\text { departures } \\
\text { from the norm }\end{array}$ & \multicolumn{2}{|c|}{$\begin{array}{l}\text { C-7 Provide } \\
\text { conditions } \\
\text { for TSP team } \\
\text { to jell }\end{array}$} & \multicolumn{3}{|c|}{$\begin{array}{l}\text { C-8 Guide TSP } \\
\text { team in selecting } \\
\text { appropriate roles }\end{array}$} & \multicolumn{3}{|c|}{$\begin{array}{l}\text { C-9 Guide TSP team in } \\
\text { establishing goals (e.g., } \\
\text { management, project, } \\
\text { team) }\end{array}$} & \multicolumn{3}{|c|}{$\begin{array}{l}\text { C-10 Guide TSP } \\
\text { team in defining } \\
\text { conceptual } \\
\text { design }\end{array}$} & \multicolumn{2}{|c|}{$\begin{array}{l}\text { C-11 Guide TSP } \\
\text { team in determining } \\
\text { development } \\
\text { strategy }\end{array}$} \\
\hline \multicolumn{3}{|c|}{$\begin{array}{l}\text { C-16 Provide early warning } \\
\text { to senior management if } \\
\text { their goals cannot be met }\end{array}$} & \multicolumn{3}{|c|}{$\begin{array}{l}\text { C-17 Guide } \\
\text { TSP team in } \\
\text { creating quality } \\
\text { plan }\end{array}$} & \multicolumn{2}{|c|}{$\begin{array}{l}\text { C-18 Guide team } \\
\text { in creating } \\
\text { individual TSP } \\
\text { plans }\end{array}$} & \multicolumn{2}{|c|}{$\begin{array}{l}\text { C-19 Guide } \\
\text { TSP team in } \\
\text { balancing } \\
\text { workload } \\
\end{array}$} & \multicolumn{4}{|c|}{$\begin{array}{l}\text { C-20 Guide TSP team in } \\
\text { consolidating individual TSP } \\
\text { plans }\end{array}$} \\
\hline $\begin{array}{l}\text { C-25 Guide TSP } \\
\text { team in preparing } \\
\text { management } \\
\text { briefing }\end{array}$ & \multicolumn{4}{|c|}{$\begin{array}{l}\text { C-26 Guide TSP team } \\
\text { in brainstorming } \\
\text { questions management } \\
\text { is likely to ask }\end{array}$} & \multicolumn{3}{|c|}{$\begin{array}{l}\text { C-27 Guide TSP team } \\
\text { leader in preparing for } \\
\text { management meeting }\end{array}$} & \multicolumn{4}{|c|}{$\begin{array}{l}\text { C-28 Guide TSP team in } \\
\text { conducting the } \\
\text { management briefing }\end{array}$} & \multicolumn{2}{|c|}{$\begin{array}{l}\text { C-29 Obtain } \\
\text { management } \\
\text { approval for team } \\
\text { plan }\end{array}$} \\
\hline $\begin{array}{l}\text { D-6 Guide } \\
\text { individual in } \\
\text { fulfilling team } \\
\text { member roles }\end{array}$ & \multicolumn{2}{|c|}{$\begin{array}{l}\text { D-7 Provide } \\
\text { individual } \\
\text { remedial PSP } \\
\text { training }\end{array}$} & & & & & & & & & & & \\
\hline \begin{tabular}{l|} 
E-5 Identify \\
team \\
strengths and \\
weaknesses
\end{tabular} & \multicolumn{2}{|c|}{$\begin{array}{l}\text { E-6 Guide } \\
\text { team in setting } \\
\text { improvement } \\
\text { goals }\end{array}$} & \multicolumn{3}{|c|}{$\begin{array}{l}\text { E-7 Guide team } \\
\text { in developing } \\
\text { improvement } \\
\text { plan }\end{array}$} & \multicolumn{2}{|c|}{$\begin{array}{l}\text { E-8 Guide team } \\
\text { in presenting its } \\
\text { status to } \\
\text { management }\end{array}$} & \multicolumn{2}{|c|}{$\begin{array}{l}\text { E-9 Guide } \\
\text { team in } \\
\text { fulfilling TSP } \\
\text { team roles }\end{array}$} & \multicolumn{2}{|c|}{$\begin{array}{l}\text { E-10 Guide } \\
\text { team with } \\
\text { remedial TSP } \\
\text { training }\end{array}$} & \multicolumn{2}{|c|}{$\begin{array}{l}\text { E-11 Attend } \\
\text { weekly team } \\
\text { meetings }\end{array}$} \\
\hline $\begin{array}{l}\text { E-17 Guide } \\
\text { team in } \\
\text { managing risks } \\
\text { and issues }\end{array}$ & \multicolumn{3}{|c|}{$\begin{array}{l}\text { E-18 Guide team } \\
\text { in achieving } \\
\text { management goals }\end{array}$} & \multicolumn{4}{|c|}{$\begin{array}{l}\text { E-19 Guide team in } \\
\text { developing new process } \\
\text { elements (e.g., design } \\
\text { standards, review checklist) }\end{array}$} & $\begin{array}{l}\text { E-20 S } \\
\text { team le: } \\
\text { how to } \\
\text { TSP toc }\end{array}$ & & $\begin{array}{l}\text { E-21 Co } \\
\text { dinate ch } \\
\text { in team } \\
\text { members }\end{array}$ & $\begin{array}{l}\text { or- } \\
\text { anges } \\
\text { hip }\end{array}$ & $\begin{array}{l}\text { E-22 } \\
\text { in cc } \\
\text { iden } \\
\text { prob }\end{array}$ & $\begin{array}{l}\text { Guide team } \\
\text { recting } \\
\text { fied } \\
\text { ms }\end{array}$ \\
\hline \multicolumn{2}{|c|}{$\begin{array}{l}\text { F-5 Guide management } \\
\text { in identifying } \\
\text { organizational process } \\
\text { strengths \& weaknesses }\end{array}$} & \multicolumn{4}{|c|}{$\begin{array}{l}\text { F-6 Guide management } \\
\text { in developing } \\
\text { organizational } \\
\text { improvement plan }\end{array}$} & \multicolumn{2}{|c|}{$\begin{array}{l}\text { F-7 Guide } \\
\text { management in } \\
\text { communicating } \\
\text { successes }\end{array}$} & \multicolumn{3}{|c|}{\begin{tabular}{l|l} 
F-8 Guide \\
management in \\
reviewing and \\
rewarding success
\end{tabular}} & \multicolumn{3}{|c|}{$\begin{array}{l}\text { F-9 Guide } \\
\text { management in data } \\
\text { privacy practices }\end{array}$} \\
\hline $\begin{array}{l}\text { G-5 Support } \\
\text { conducting TSP } \\
\text { usage opinion } \\
\text { survey }\end{array}$ & $\begin{array}{l}\text { G-6 Sup } \\
\text { recomme } \\
\text { analysis }\end{array}$ & $\begin{array}{l}\text { oort s } \\
\text { ndati } \\
\text { ools }\end{array}$ & $\begin{array}{l}\text { olectic } \\
\text { on of }\end{array}$ & $\begin{array}{l}\text { ond } \\
\text { lata }\end{array}$ & & $\begin{array}{l}-7 \text { Suppor } \\
\text { lultiple sou } \\
\text { efects, prod } \\
\text { onfiguratio }\end{array}$ & $\begin{array}{l}\text { reconcil } \\
\text { ces (e.g. } \\
\text { uction de } \\
\text { manage }\end{array}$ & $\begin{array}{l}\text { Ing data } \\
\text { system } \\
\text { fects, } \\
\text { ment too }\end{array}$ & & & & & \\
\hline
\end{tabular}




\section{DACUM Research Chart for Team Software Process ${ }^{\text {SM }}$ (TSP $\left.^{\text {SM }}\right)$ Coach}

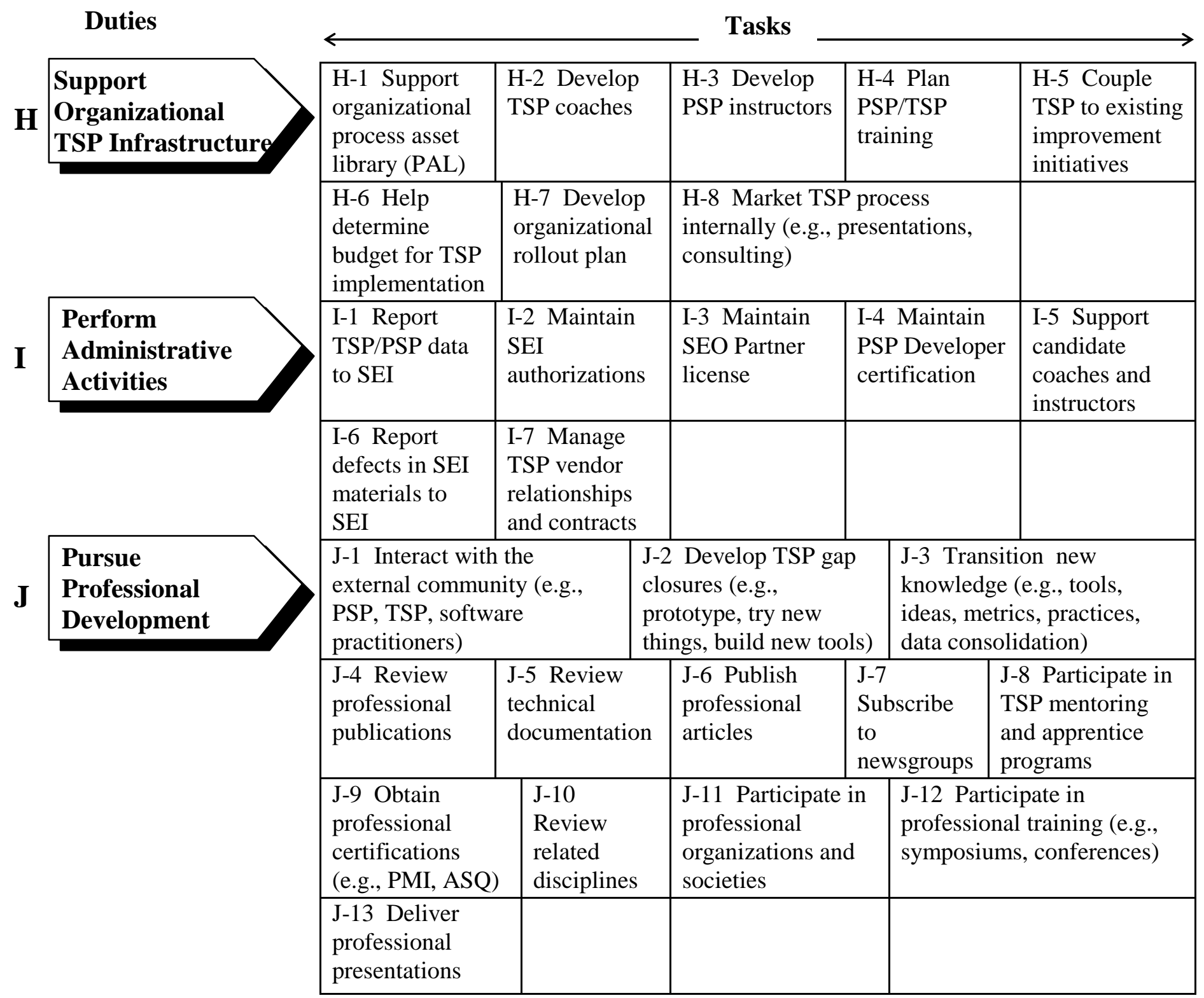

\section{Tools, Equipment, Supplies and Materials}

TSP tools:

SEI tools

Solonsys

Dashboard

LOC counting tools

Defects tracking tools

Project mgmt tools

Presentation tools

Analysis tools (e.g. EXCEL, Minitab, SAS)

Design tools (e.g. Rationale)

Microsoft Office (e.g. Access, Word, Excel, PowerPoint)

\section{Worker Behaviors}

$\begin{array}{ll}\text { Reliable } & \text { Courageous } \\ \text { Flexible } & \text { Truth teller } \\ \text { Patient } & \text { Self-Confident } \\ \text { Positive } & \text { Exemplary } \\ \text { Trustworthy } & \text { Quick learner } \\ \text { Credible } & \text { Prescient } \\ \text { Diplomatic } & \text { Tactful } \\ \text { Good listener } & \text { Humble } \\ \text { Resourceful } & \text { Analytical } \\ \text { Principled } & \text { Motivational } \\ \text { Disciplined } & \text { Convincing } \\ \text { Professional } & \text { Confidant } \\ \text { Knowledgeable } & \text { Informed }\end{array}$




\section{General Knowledge and Skills}

PSP/TSP

People skills

Mgmt skills

Ability to pick up domain knowledge quickly

Software design skills

Process definition skills

Ability to see big picture (trees \& forest)

Technical skills:

Software development

Testing

Project mgmt

Data analysis

Quality mgmt

Systems analysis

Presentation skills

Facilitation skills

Negotiation skills

Organization skills

Process improvement

Ability to follow a process

Logistics

Consulting skills

Analytical skills

Knowledge of PSP tools \& analysis tools

Training skills

Communication skills

Time management skills

Problem solving

Change management

Meeting management

Process technology knowledge

CMMI

Agile method

LEAN

Six Sigma

Function points

Conflict resolution

Using historical data

Recognizing individual improvement

Staying at appropriate level of detail

Coaching skills

Data privacy/ability to protect

Motivate high performance

Handling difficult people

\section{Future Trends and Concerns}

Applying TSP to non software domains

Scalability:

Scaling process to fit large teams

Increased demand for coaching services (demand more than supply)

Need to address coaching progression (levels)

Ability to maintain coaching quality

SEI ability to provide new materials (e.g., courses)

Processes, course materials, and examples based on older research in the technology

More TSP tools need to be available

New TSP licensing strategy to amplify transition

Extending TSP into college curriculum

Broader issue of TSPm \& TSPd

\section{Acronyms}

CM Configuration Management

CMM Capability Maturity Model

CMMI Capability Maturity Model Integration

JIT Just In Time

PAL Process Asset Library

PIP Process Improvement Proposal

PM Postmortem

PSP Personal Software Process

ROI Return on Investment

SEI Software Engineering Institute

SEPG Software Engineering Process Group

TSP Team Software Process 


\section{Appendix C Forms}


C-2 | CMU/SEI-2010-SR-016 


\section{Provisional Coach Mentoring Program Application - Form MPA}

\section{SEI-Certified TSP Coach Mentoring Program}

\section{Personal Information (Please use the exact name that appears on your identification documents.)}

\begin{tabular}{lll}
\hline Last Name (Family Name) & First Name (Given Name) & Middle Name(s)
\end{tabular}

\begin{tabular}{ll}
\hline Primary Language & Secondary Language
\end{tabular}

\footnotetext{
Job/Position
}

\section{Partner Sponsor}

\section{Personal Contact Information}

\begin{tabular}{lll}
\hline Street Address (Home) & & Zip Code \\
\hline City & State or Country & \\
\hline Mailing Address (If Different from Above Address) & Zip Code \\
\hline City & State or Country & \\
\hline Daytime Phone Number & Evening Phone Number & \\
\hline Email Address & Fax Number
\end{tabular}

\section{Request for Mentor Assignment}

Visit the following website to find a list of SEI-Certified TSP Mentor Coaches:

http://www.sei.cmu.edu/certification/

Please note that mentors are limited to the number of provisional coaches that they can mentor at any given time.

Do you need help from SEI to find an SEl-Certified TSP Mentor $\quad \square$ Yes $\square$ No Coach?

If yes, who have you contacted unsuccessfully as a possible mentor?

If no, who will be your SEI-Certified TSP Mentor Coach? 
Once a mentoring coach has been established, the following forms must be submitted to the SEI:

\section{Provisional Coach Developmental Needs Self-Assessment}

Mentoring Goals

Mentoring Action Plan

\section{Statement of Accuracy}

I certify that all of the information included in my application packet is true, complete, and accurate. I understand that all components of my application are subject to verification, and I give my permission for any person or entity to provide the Software Engineering Institute, Carnegie Mellon University, with information relevant to such verification. I understand that all components of my application packet become the property of the Software Engineering Institute and that they will not be returned to me or duplicated for me. I understand that the application fee is not refundable.

\begin{tabular}{lc}
\hline Signature & Date
\end{tabular}

\section{Submission Instructions}

Please email this form as an attachment, along with the Provisional Coach Developmental Needs SelfAssessment, Mentoring Goals, and Mentoring Action Plan forms, to certification-info@sei.cmu.edu.

Or mail your application to:

Software Engineering Institute

Carnegie Mellon University

Attn: Certifications

4500 Fifth Avenue

Pittsburgh, PA 15213-2612

Direct any questions to the SEI Certification Manager:

Phone: 412-268-5800 or email: certification-info@sei.cmu.edu 


\section{Provisional Coach Developmental Needs Self- Assessment - Form DNSA}

SEI-Certified TSP Coach Mentoring Program

\section{Provisional Coach's Name:}

Mentor's Name:

Assessment Date:

One of the objectives of an SEI-Certified TSP Mentor Coach is to provide guidance to provisional coaches based on their individual learning and development needs and objectives. To accomplish this, the provisional coach must provide input about personal development goals and work with the mentor to identify the developmental goals and desired results of the mentoring process. The Provisional Coach Developmental Needs Self-Assessment is intended to facilitate this process. The provisional coach should complete this assessment prior to the initial meeting with the mentor to provide a starting point for identifying developmental goals and creating an individual mentoring action plan (MAP).

\section{Briefly describe your task and role assignment on your TSP teams.}




\section{Software Engineering Institute}

CarnegieMellon

List any papers or presentations you have done and describe any professional activities you have participated in.

\section{Why do you want to be a TSP coach?}

What are your goals as a TSP coach? 


\section{Software Engineering Institute}

\section{CarnegieMellon}

For statement numbers 1 through 38 below, please check the box that best describes your current level of performance in each of the following areas.

\begin{tabular}{ccccc} 
Communication & $\begin{array}{c}\text { Needs } \\
\text { Significant } \\
\text { Improvement }\end{array}$ & $\begin{array}{c}\text { Could Benefit } \\
\text { from } \\
\text { Development }\end{array}$ & $\begin{array}{c}\text { Capable } \\
\text { and } \\
\text { Effective }\end{array}$ & $\begin{array}{c}\text { Role } \\
\text { Model }\end{array}$ \\
\hline 1.
\end{tabular}

1. I listen before speaking.

2. I demonstrate persuasiveness in my objectives.

3. When needed, I clarify statements to gain better understanding.

4. I am able to convey my priorities with a sense of urgency and importance.

5. I speak clearly, fluently, and in a compelling manner.

6. I consider others' points of view when responding.

7. I am effective in gaining commitment by persuasion.

8. I am open and approachable.

9. I am able to communicate the vision and need for using TSP.

10. I am effective in communicating TSP ideas and concepts.

11. I am open to suggestions from others.

12. I am able to bring clarity to discussions.

13. I am able to give honest feedback to others.

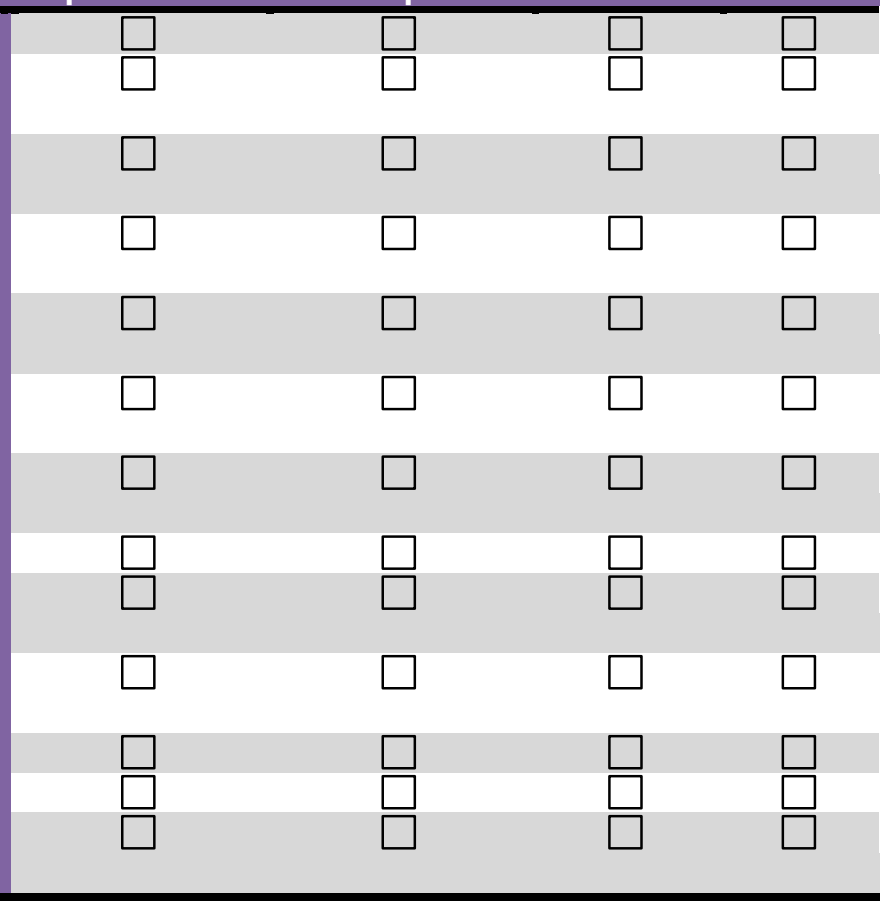

Action

\begin{tabular}{|c|c|c|}
\hline $\begin{array}{l}\text { Needs } \\
\text { Significant } \\
\text { mprovement }\end{array}$ & $\begin{array}{l}\text { Could Benefit } \\
\text { from } \\
\text { Development }\end{array}$ & $\begin{array}{l}\text { Capable } \\
\text { and } \\
\text { Effective }\end{array}$ \\
\hline
\end{tabular}

14. I take corrective action when necessary.

15. I usually make effective decisions.

16. I can positively motivate and support others in their development.

$\begin{array}{llll}\square & \square & \square & \square \\ \square & \square & \square & \square \\ \square & \square & \square & \square\end{array}$

\begin{tabular}{|c|c|c|c|c|}
\hline Flexibility & $\begin{array}{l}\text { Needs } \\
\text { Significant } \\
\text { Improvement }\end{array}$ & $\begin{array}{l}\text { Could Benefit } \\
\text { from } \\
\text { Development }\end{array}$ & $\begin{array}{l}\text { Capable } \\
\text { and } \\
\text { Effective }\end{array}$ & $\begin{array}{l}\text { Role } \\
\text { Model }\end{array}$ \\
\hline $\begin{array}{l}\text { 17. I am creative in finding ways to get things } \\
\text { done. }\end{array}$ & $\square$ & $\square$ & $\square$ & $\square$ \\
\hline $\begin{array}{l}\text { 18. I can adapt to meet the needs of a } \\
\text { frequently changing and uncertain } \\
\text { environment }\end{array}$ & $\square$ & $\square$ & $\square$ & $\square$ \\
\hline 19. I am effective in incorporating new ideas. & $\square$ & $\square$ & $\square$ & $\square$ \\
\hline 20. I readily implement proposed changes. & $\square$ & $\square$ & $\square$ & $\square$ \\
\hline $\begin{array}{l}\text { 21. I willingly incorporate feedback from } \\
\text { others. }\end{array}$ & $\square$ & $\square$ & $\square$ & $\square$ \\
\hline
\end{tabular}




\section{Software Engineering Institute}

\section{CarnegieMellon}

\begin{tabular}{|c|c|c|c|c|}
\hline Analytical & $\begin{array}{l}\text { Needs } \\
\text { Significant } \\
\text { Improvement }\end{array}$ & $\begin{array}{l}\text { Could Benefit } \\
\text { from } \\
\text { Development }\end{array}$ & $\begin{array}{l}\text { Capable } \\
\text { and } \\
\text { Effective }\end{array}$ & $\begin{array}{l}\text { Role } \\
\text { Model }\end{array}$ \\
\hline $\begin{array}{l}\text { 22. I am able to analyze data and develop } \\
\text { effective presentations and explanations. }\end{array}$ & $\square$ & $\square$ & $\square$ & $\square$ \\
\hline $\begin{array}{l}\text { 23. I am able to reduce problems to their root } \\
\text { causes. }\end{array}$ & $\square$ & $\square$ & $\square$ & $\square$ \\
\hline $\begin{array}{l}\text { 24. I understand and use appropriate } \\
\text { methods for analyzing different sources } \\
\text { of data. }\end{array}$ & $\square$ & $\square$ & $\square$ & $\square$ \\
\hline $\begin{array}{l}\text { 25. I am able to organize and compile data } \\
\text { from multiple sources. }\end{array}$ & $\square$ & $\square$ & $\square$ & $\square$ \\
\hline $\begin{array}{l}\text { 26. I am able to identify opportunities for } \\
\text { improvement. }\end{array}$ & $\square$ & $\square$ & $\square$ & $\square$ \\
\hline Problem Solving & $\begin{array}{l}\text { Needs } \\
\text { Significant } \\
\text { Improvement }\end{array}$ & $\begin{array}{l}\text { Could Benefit } \\
\text { from } \\
\text { Development }\end{array}$ & $\begin{array}{l}\text { Capable } \\
\text { and } \\
\text { Effective }\end{array}$ & $\begin{array}{l}\text { Role } \\
\text { Model }\end{array}$ \\
\hline $\begin{array}{l}\text { 27. I can identify potential problems and } \\
\text { develop appropriate solutions. }\end{array}$ & & $\square$ & $\square$ & $\square$ \\
\hline $\begin{array}{l}\text { 28. I try to solve problems at the root level } \\
\text { instead of just addressing the symptoms. }\end{array}$ & $\square$ & $\square$ & $\square$ & $\square$ \\
\hline Performance & $\begin{array}{l}\text { Needs } \\
\text { Significant } \\
\text { Improvement }\end{array}$ & $\begin{array}{l}\text { Could Benefit } \\
\text { from } \\
\text { Development }\end{array}$ & $\begin{array}{l}\text { Capable } \\
\text { and } \\
\text { Effective }\end{array}$ & $\begin{array}{l}\text { Role } \\
\text { Model }\end{array}$ \\
\hline $\begin{array}{l}\text { 29. I work with a high standard of quality. } \\
\text { 30. I am able to prioritize work in order to } \\
\text { meet commitments and help teams and } \\
\text { individuals to obtain their goals. }\end{array}$ & $\square$ & $\square$ & $\square$ & $\square$ \\
\hline $\begin{array}{l}\text { 31. I have high personal standards. } \\
\text { 32. I follow up on the ideas of other people. }\end{array}$ & $\square$ & $\square$ & $\square$ & $\square$ \\
\hline Other & $\begin{array}{l}\text { Needs } \\
\text { Significant } \\
\text { Improvement }\end{array}$ & $\begin{array}{l}\text { Could Benefit } \\
\text { from } \\
\text { Development }\end{array}$ & $\begin{array}{l}\text { Capable } \\
\text { and } \\
\text { Effective }\end{array}$ & $\begin{array}{l}\text { Role } \\
\text { Model }\end{array}$ \\
\hline $\begin{array}{l}\text { 33. I am able to influence and persuade } \\
\text { others. }\end{array}$ & $\square$ & $\square$ & $\square$ & $\square$ \\
\hline $\begin{array}{l}\text { 34. I am able to facilitate teams in achieving } \\
\text { results. }\end{array}$ & $\square$ & $\square$ & $\square$ & $\square$ \\
\hline 35. I am effective in planning (re)launches. & $\square$ & $\square$ & $\square$ & $\square$ \\
\hline 36. I am attentive to the needs of others. & $\square$ & $\square$ & $\square$ & $\square$ \\
\hline $\begin{array}{l}\text { 37. I am able to show individuals how their } \\
\text { role supports the team. }\end{array}$ & & ᄃ & $\square$ & $\square$ \\
\hline $\begin{array}{l}\text { 38. I understand how change affects } \\
\text { individuals and teams. }\end{array}$ & $\square$ & $\square$ & $\square$ & $\square$ \\
\hline
\end{tabular}


Of the following TSP coaching areas, which topics are your top priorities for improvement during

the mentoring process? Please check all that apply. (See Appendix B of the TSP Mentor Coach

Guidebook for more details regarding the topics.)

$\begin{array}{ll}\square & \text { Prepare organizations for initial TSP usage } \\ \square & \text { Provide TSP domain } \\ \square \quad \text { Facilitate TSP team } \\ \square \quad \text { Guide personal process uses } \\ \square \quad \text { Guide team process uses } \\ \square \quad \text { Guide management in TSP usage } \\ \square \quad \text { Support data analysis and usage }\end{array}$

Strengths: Please describe your coaching strengths.

Opportunities for development: Please describe areas which you would like to work on so as to become a better coach.

\section{Submission Instructions}

Please email this form as an attachment, along with the Provisional Mentoring Goals, Provisional Coach Mentoring Program Application, and Mentoring Action Plan forms, to certification-info@sei.cmu.edu.

Or mail your forms to:

Software Engineering Institute

Carnegie Mellon University

Attn: Certifications

4500 Fifth Avenue

Pittsburgh, PA 15213-2612

Direct any questions to the SEI Certification Manager:

Phone: 412-268-5800 or email: certification-info@sei.cmu.edu 


\section{Mentoring Goals - Form MG}

\section{SEI-Certified TSP Coach Mentoring Program}

\section{Provisional Coach's Name: \\ Mentor's Name: \\ Date:}

Mentoring Process Phase:
Preparation/Prescriptive

Enabling/Collaborative
Persuasive

Closure/Confirmation

Goals should always be: $\mathbf{S}$ - Specific, $\mathbf{M}$ - Measurable, A - Achievable, $\mathbf{R}$ - Realistic, $\mathbf{T}$ - Time-bound

1. Goal/Objective - Briefly describe each goal/objective and when the goal/objective should be met or accomplished.

2. Measurement - How will the goal/objective be evaluated?

3. Importance - Rank the goal as Essential, Important, or Desirable, as follows:

- Essential - required for TSP coaching

- Important - helpful for TSP coaching

- Desirable - asset for TSP coaching

Goals should be established and agreed to by both the mentor and provisional coach. This is one of the first steps in creating a mentoring relationship. The goals and objectives should be in line with the provisional coach's developmental needs, and should be reviewed and updated as the provisional coach progresses through the TSP mentoring process phases.

\section{$1^{\text {st }}$ Goal / Objective}

Description:

Measurement:

Importance: $\square$ Essential $\square$ Important $\square$ Desirable

$2^{\text {na }}$ Goal / Objective

Description:

Measurement:

Importance:

Essential

Important

Desirable 
$3^{\text {ra }}$ Goal / Objective

Description:

Measurement:

Importance: $\square$ Essential $\square$ Important $\square$ Desirable

\section{$4^{\text {th }}$ Goal / Objective}

Description:

Measurement:

Importance: $\square$ Essential $\square$ Important $\square$ Desirable

\section{Signed Agreement}

We mutually agree to work towards accomplishing the aforementioned goals/objectives of our mentoring relationship.

\begin{tabular}{ll}
\hline Mentor Coach Signature & Date
\end{tabular}

\section{Submission Instructions}

Please email this form as an attachment, along with the Provisional Coach Developmental Needs SelfAssessment, Provisional Coach Mentoring Program Application, and Mentoring Action Plan forms, to certification-info@sei.cmu.edu.

Or mail your forms to:

Software Engineering Institute

Carnegie Mellon University

Attn: Certifications

4500 Fifth Avenue

Pittsburgh, PA 15213-2612

Direct any questions to the SEI Certification Manager:

Phone: 412-268-5800 or email: certification-info@sei.cmu.edu 


\section{Mentoring Action Plan - Form MAP \\ SEI-Certified TSP Coach Mentoring Program}

\section{Provisional Coach Information}

\begin{tabular}{lc}
\hline Last Name (Family Name) & First Name (Given Name) \\
\hline Daytime Phone Number & Evening Phone Number \\
\hline Email Address & Mobile Phone Number \\
\hline Organization Name & Organization's Location \\
\hline & \\
\hline Mentor Coach Information & \\
\hline
\end{tabular}

\begin{tabular}{lc}
\hline Last Name (Family Name) & First Name (Given Name) \\
\hline Daytime Phone Number & Evening Phone Number \\
\hline Email Address & Mobile Phone Number \\
\hline Organization Name & Organization's Location \\
\hline & \\
\hline Action Plan & \\
\hline
\end{tabular}

\begin{tabular}{|l|l|l|l|}
\hline $\begin{array}{l}\text { Time } \\
\text { Frame } \\
\text { (Week \#) }\end{array}$ & Objective and Task(s) & $\begin{array}{l}\text { Goal / } \\
\text { Objective } \\
\text { Number }\end{array}$ & $\begin{array}{l}\text { Mentor Physical } \\
\text { Location } \\
\text { (Rete or On- } \\
\text { Site) }\end{array}$ \\
\hline & & & \\
\hline & & & \\
\hline & & & \\
\hline & & & \\
\hline & & \\
\hline
\end{tabular}




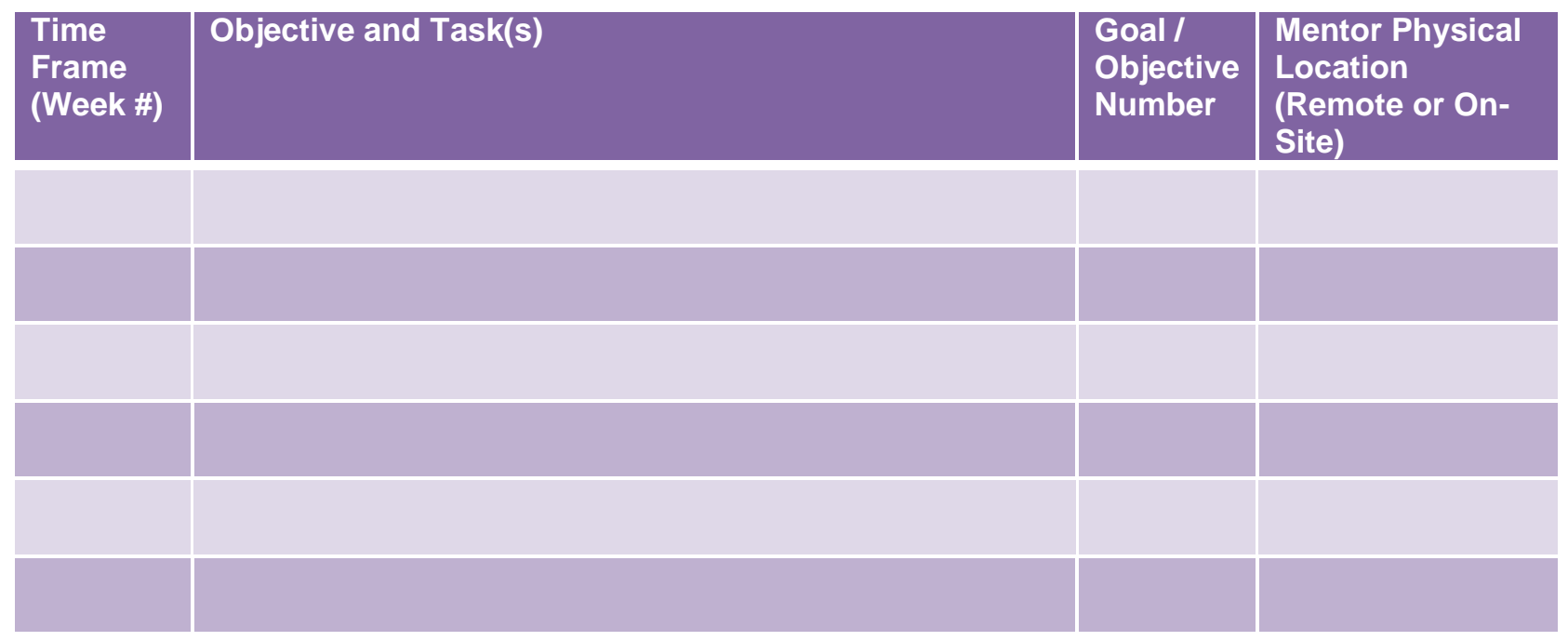

\section{Signed Agreement}

We agree that, to the best of our ability, we will work towards the aforementioned objectives and time frame in order to accomplish the agreed-to goals of our mentoring relationship.

\section{Submission Instructions}

Please email this form as an attachment, along with the Provisional Coach Developmental Needs SelfAssessment, Mentoring Goals, and Provisional Coach Mentoring Program Application forms, to certification-info@sei.cmu.edu.

Or mail your forms to:

Software Engineering Institute

Carnegie Mellon University

Attn: Certifications

4500 Fifth Avenue

Pittsburgh, PA 15213-2612

Direct any questions to the SEI Certification Manager:

Phone: 412-268-5800 or email: certification-info@sei.cmu.edu 


\title{
Mentoring Artifact Evaluation - Form MAE
}

\section{SEI-Certified TSP Coach Mentoring Program}

\author{
Provisional Coach's Name: \\ Mentor's Name: \\ Evaluation Date:
}

\section{Guidebook for more details regarding the topics.

\begin{tabular}{ll}
$\square$ & Prepare organizations for initial TSP usage \\
$\square \quad$ & Provide TSP domain training \\
$\square \quad$ Facilitate TSP team launch \\
$\square \quad$ Guide personal process usage \\
$\square \quad$ Guide team process usage \\
$\square \quad$ Guide management in TSP usage \\
$\square \quad$ Support data analysis and usage \\
\hline
\end{tabular}

Select TSP coaching area(s) being evaluated. See Appendix B of the TSP Mentor Coach

\section{Select artifacts included in evaluation.}

\begin{tabular}{|c|c|c|c|}
\hline & & & $\begin{array}{l}\text { (Re)Launch preparations } \\
\square \text { Meeting } 1 \text { presentation material } \\
\square \text { Previous cycle or project PM data } \\
\square \text { Pre (re)launch meeting agendas and presentations } \\
\square \text { PSP/TSP training records for all relevant (re)launch stakeholders } \\
\square \\
\text { Other }\end{array}$ \\
\hline & & $\square$ & $\begin{array}{l}\text { (Re) Launch output material } \\
\square \text { Team consolidated plan } \\
\square \text { Individual plans } \\
\square \text { Meeting } 9 \text { presentation(s) } \\
\square \text { Risk analysis } \\
\square \text { Other }\end{array}$ \\
\hline & & . & $\begin{array}{l}\text { Weekly team meeting } \\
\square \text { Agenda } \\
\square \text { Meeting minutes } \\
\square \text { Team consolidated plan and actual } \\
\square \text { Individual plan and actual } \\
\square \text { Manager role reports } \\
\square \text { Other }\end{array}$ \\
\hline & & $\square$ & $\begin{array}{l}\text { Management STATUS meeting } \\
\square \text { Agenda } \\
\square \text { Meeting minutes } \\
\square \text { STATUS report } \\
\square \text { Team consolidated plan and actual (source of report) } \\
\square \text { Individual plan and actual (source of team's consolidated plan) } \\
\square \text { Other }\end{array}$ \\
\hline & & $\square$ & $\begin{array}{l}\text { Checkpoint } \\
\square \text { Checkpoint report } \\
\square \text { Checkpoint team member data review } \\
\square \text { Team consolidated plan and actual (source of report) } \\
\square \text { Individual plan and actual (source of team's consolidated plan) } \\
\square \text { Other }\end{array}$ \\
\hline
\end{tabular}


\begin{tabular}{ll}
\hline$\square$ Cycle or project postmortem \\
$\square$ PM report \\
$\square$ Team consolidated plan and actual (source of report) \\
$\square$ Individual plan and actual (source of team's consolidated plan) \\
$\square$ Other \\
\hline
\end{tabular}

Based on the TSP coaching area(s) being evaluated and the artifacts under review, list any questions or comments you have for the provisional coach. 


\section{What information might have been missed?}

What areas of the TSP BOK should the provisional coach review in preparation of the next TSP activity?

Other observations and questions for the provisional coach:

Does it appear that the provisional coach is guiding the team to meet management's goal(s)?
$\square$ Yes $\square$ No $\square$ Unclear

Why?

If the team is off-track, is the provisional coach taking appropriate action(s)?

Yes $\square$ No $\square$ Unclear $\square$ N/A

Why?

Do these artifacts satisfy the associated TSP cycle requirements for a TSP coach? $\square \quad$ Yes $\square$ No If no, explain: 


\section{Submission Instructions}

Please email this form along with any supporting artifacts to the provisional coach in order to provide immediate feedback. Depending on the nature of the feedback the mentor coach may also need to followup with a phone call or meeting to discuss the evaluation results and needed steps to correct any identified issues.

Please email a copy of all completed Mentoring Evaluation Artifact forms along with the Final Assessment Report as supporting evidence, to certification-info@sei.cmu.edu.

Or mail your Final Assessment Report along with these completed forms to:

Software Engineering Institute

Carnegie Mellon University

Attn: Certifications

4500 Fifth Avenue

Pittsburgh, PA 15213-2612

Direct any questions to the SEI Certification Manager:

Phone: 412-268-5800 or email: certification-info@sei.cmu.edu 


\section{(Re)Launch Observation Evaluation - Form LOE}

\section{SEI-Certified TSP Coach Mentoring Program}

\section{Provisional Coach's Name:}

Mentor's Name:

TSP Team's Name:

Project Name:

Company/Organization:

Observation Dates:

Coach Performance Evaluations for the $(\mathbf{R e})$ Launch Meetings - Consider each characteristic on the left. For each meeting, enter an $\mathrm{X}$ for each characteristic that was properly handled in the box that corresponds to the meeting number. If there was a problem, enter a number instead of an X (in sequence, as if you were adding a footnote). In the comments section, reference any numbers that you used in the table and explain the problem.

\begin{tabular}{|l|l|l|l|l|l|l|l|l|l|l|}
\hline Meeting Number & $\mathbf{1}$ & $\mathbf{2}$ & $\mathbf{3}$ & $\mathbf{4}$ & $\mathbf{5}$ & $\mathbf{6}$ & $\mathbf{7}$ & $\mathbf{8}$ & $\mathbf{9}$ & PM \\
\hline \begin{tabular}{l} 
Mechanics: agenda, roles, summary \\
\hline Followed script steps
\end{tabular} & & & & & & & & & & \\
\hline Maintained effective communication & & & & & & & & & \\
\hline Effectively handled issues \\
\hline $\begin{array}{l}\text { Kept team focused on meeting } \\
\text { objective }\end{array}$
\end{tabular}

\section{Meeting 1}

Evaluation Topics

Did management explain the importance of the project?

Were management's goals for the team clearly communicated?

Were team questions encouraged and answered?

Was the team satisfied with the meeting outcome?

Was the coach effective in guiding management and the team in a successful

meeting?

Comments: 


\section{Software Engineering Institute}

CarnegieMellon

Meeting 2

Evaluation Topics

Did all team members participate in defining the team's goals?

Did all team members agree with the goals that were finally selected?

Did all team members select their own roles and alternate roles?

Were the team members and team leader satisfied with the final role assignments?

Was the coach effective in guiding the team to a successful meeting outcome?

Comments:

\section{Meeting 3}

Evaluation Topics

Did the team agree on the product's conceptual design and overall size estimates?

Did all team members participate in producing the team's development strategy?

Did all team members participate in producing the team's development process?

Did the team identify and assign responsibility for other additional team processes?

Was the team satisfied with the meeting outcome?

Was the coach effective in guiding the team to a successful meeting outcome?

Comments:

\section{Meeting 4}

Evaluation Topics

Did all team members participate in identifying the project's tasks?

Did all team members participate in estimating the effort required for each task?

Did all team members participate in estimating the team's weekly task hours?

Were the team members and team leader satisfied with the resulting overall team

plan?

Was the coach effective in guiding the team to a successful meeting outcome?

Comments: 


\section{Software Engineering Institute}

CarnegieMellon

\section{Meeting 5}

Evaluation Topics

Did the team define and agree on an aggressive set of measurable quality goals?

Did the team use available data to establish realistic defect injection rates?

Did the team use personal and other available data to establish realistic yield values?

Did the team review and agree on the final quality plan?

Was the coach effective in guiding the team to a successful meeting outcome?

Comments:

\section{Meeting 6}

Evaluation Topics

Did all team members agree with the tasks they were assigned to do?

Did all team members produce their own detailed personal plans?

Did the entire team participate in producing a balanced team plan?

Were the team members and team leader satisfied with the final consolidated team

plan?

Was the coach effective in guiding the team to a successful meeting outcome?

Comments:

\section{Meeting 7}

Evaluation Topics

Did the team leader lead the team in identifying a comprehensive set of project risks?

Did all team members participate in identifying and evaluating these risks?

Was responsibility for each significant risk assigned to a team member to track?

Were mitigation actions defined for the key risks?

Was the team satisfied with the meeting outcome?

Was the coach effective in guiding the team to a successful meeting outcome?

Comments: 


\section{Meeting 8}

Evaluation Topics

Did the team leader define the format and content of the meeting 9 presentation?

Did the team leader obtain team member input in defining this format and content?

Did all team members participate in producing and reviewing the presentation?

Were the team members and team leader satisfied with the final presentation?

Did the provisional coach prepare a coaching plan and review it with the team?

Was the coach effective in guiding the team to a successful meeting outcome?

Comments:

\section{Meeting 9}

Evaluation Topics

Did senior management attend meeting 9?

Did at least some of the team members participate in presenting the plan?

Did management ask probing questions about the team?

Did some team members participate in answering management's questions?

Where the team's plan did not meet management's goals, did the team prepare

alternative plans?

Where management asked for other alternatives, did the team take an action to develop alternatives rather than guess?

Did the provisional coach present and discuss the coaching plan?

Were management and the team satisfied with the meeting outcome?

Was the coach effective in guiding the team to a successful meeting outcome?

Comments:

\section{(Re)Launch PM}

\begin{tabular}{|c|c|c|}
\hline Evaluation Topics & Yes & No \\
\hline Did the planning manager review plan status and identify and assign open items? & $\square$ & L \\
\hline $\begin{array}{l}\text { Did the team discuss the (re)launch process and participate in considering possible } \\
\text { PIPs? }\end{array}$ & $\square$ & $\square$ \\
\hline Did the coach address any open issues? & $\square$ & $\square$ \\
\hline Was the coach effective in guiding the team to a successful meeting & $\square$ & $\square$ \\
\hline
\end{tabular}




\section{Submission Instructions}

Please email this form along with any supporting artifacts to the provisional coach in order to provide immediate feedback. Depending on the nature of the feedback the mentor coach may also need to followup with a phone call or meeting to discuss the observation results and needed steps to correct any identified issues.

Please email a copy of all completed $(\mathrm{Re})$ Launch Observation Evaluation forms along with the Final Assessment Report as supporting evidence, to certification-info@sei.cmu.edu.

Or mail your Final Assessment Report along with these completed forms to:

Software Engineering Institute

Carnegie Mellon University

Attn: Certifications

4500 Fifth Avenue

Pittsburgh, PA 15213-2612

Direct any questions to the SEI Certification Manager:

Phone: 412-268-5800 or email: certification-info@sei.cmu.edu 


\section{(Re)Launch Observation Summary - Form LOS}

\section{SEI-Certified TSP Coach Mentoring Program}

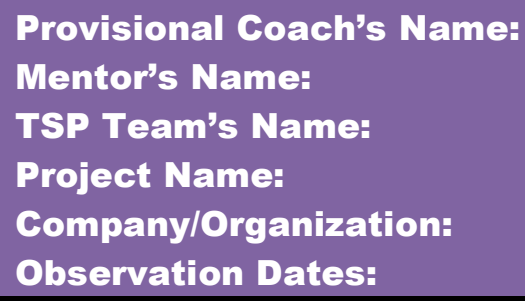

(Re)Launch Preparation Evaluation

Evaluation Topics

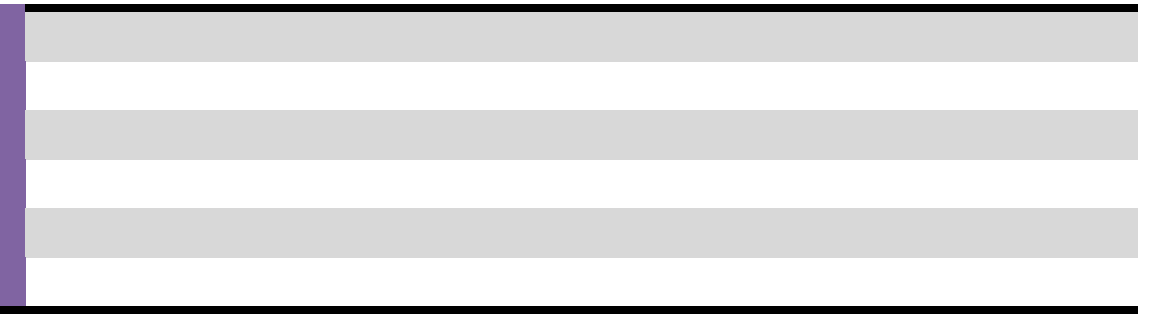

Had all development team members completed PSP training?

Had all other team members completed team member training?

Had the team leader and other involved managers attended the Leading a

Development Team course?

Was senior management properly briefed on their role in the launch?

Did the provisional coach adequately prepare the team and team leader for the

(re)launch?

Did the provisional coach arrange for adequate (re)launch meeting facilities?

Did the provisional coach review (re)launch preparation progress with mentor before

the (re)launch?

Comments:

(Re)Launch Evaluation (attach (Re)Launch Observation Evaluation form)

\begin{tabular}{l|l|}
\hline Evaluation Topics & Yes \\
\hline Did management attend meetings 1 and 9, and were they prepared? \\
\hline Did management communicate their goals and the project's importance to the team? \\
\hline Did the team make a competent plan and alternative plans if needed? \\
\hline Were management and the team satisfied with the (re)launch outcome? \\
\hline Did the provisional coach produce a coaching plan and review it with the team? \\
\hline Was the provisional coach effective in handling meeting dynamics? \\
\hline Was the provisional coach effective in guiding the (re)launch to a reasonable \\
outcome?
\end{tabular}




\section{Submission Instructions}

Please email this form along with any supporting artifacts to the provisional coach in order to provide immediate feedback. Depending on the nature of the feedback, the mentor coach may also need to follow up with a phone call or meeting to discuss the observation results and needed steps to correct any identified issues.

Please email a copy of all completed $(\mathrm{Re})$ Launch Observation Summary forms, along with the Final Assessment Report as supporting evidence, to certification-info@sei.cmu.edu.

Or mail your Final Assessment Report, along with these completed forms, to:

Software Engineering Institute

Carnegie Mellon University

Attn: Certifications

4500 Fifth Avenue

Pittsburgh, PA 15213-2612

Direct any questions to the SEI Certification Manager:

Phone: 412-268-5800 or email: certification-info@sei.cmu.edu 


\section{TSP Data Submission Form - Form DSF}

\section{SEI-Certified TSP Coach and TSP Mentor Coach Programs}
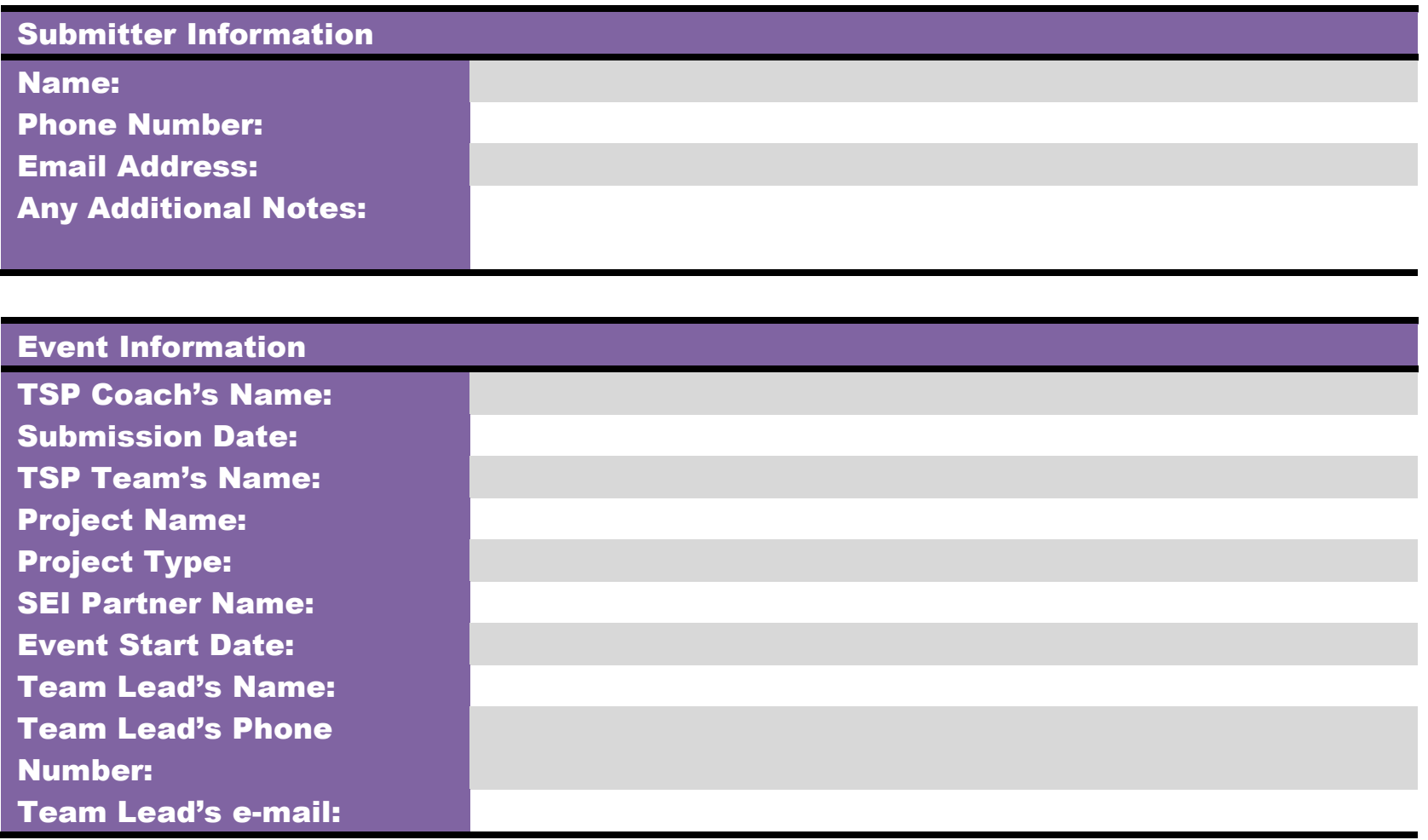

Select event and associated artifacts (Please use one form for each TSP cycle event.)

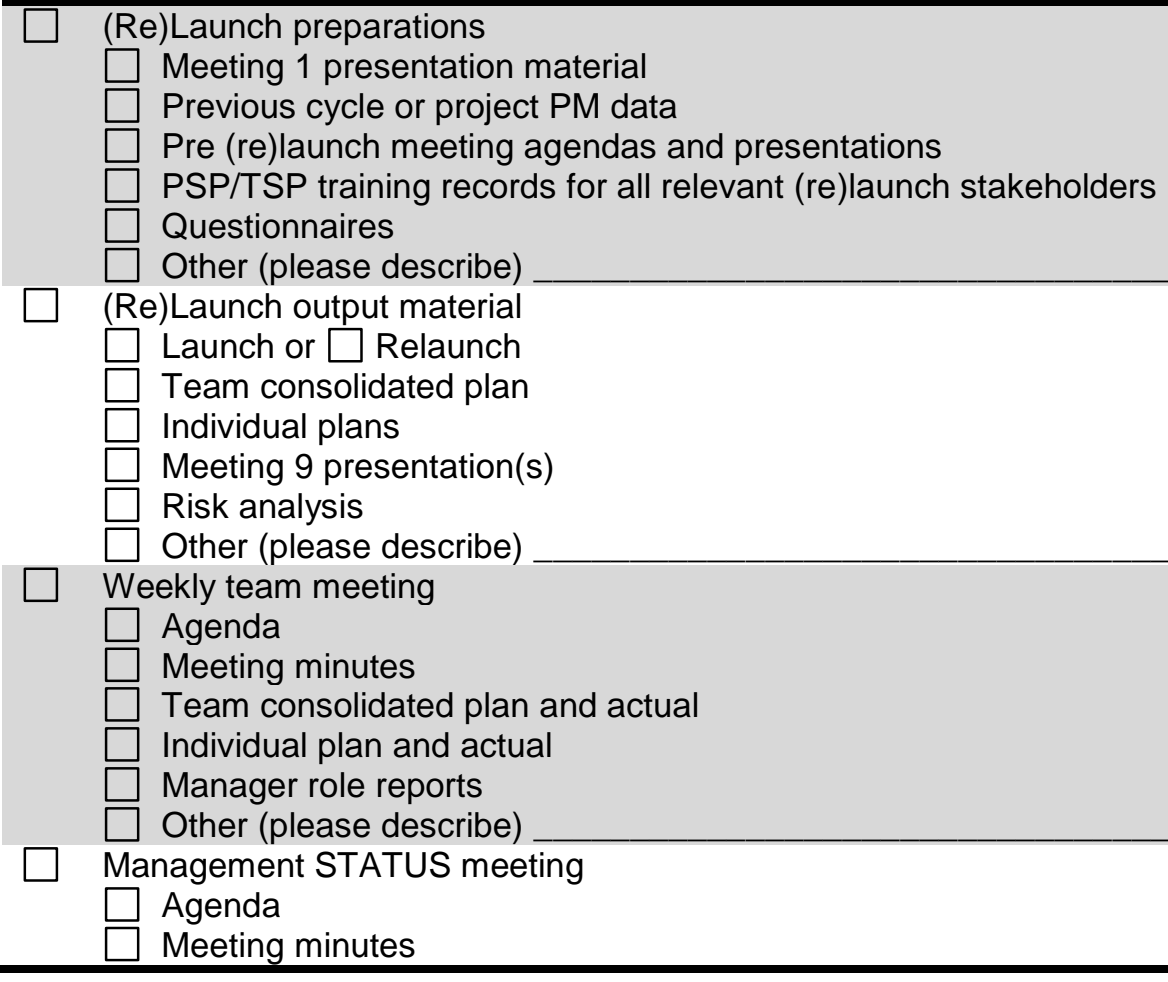




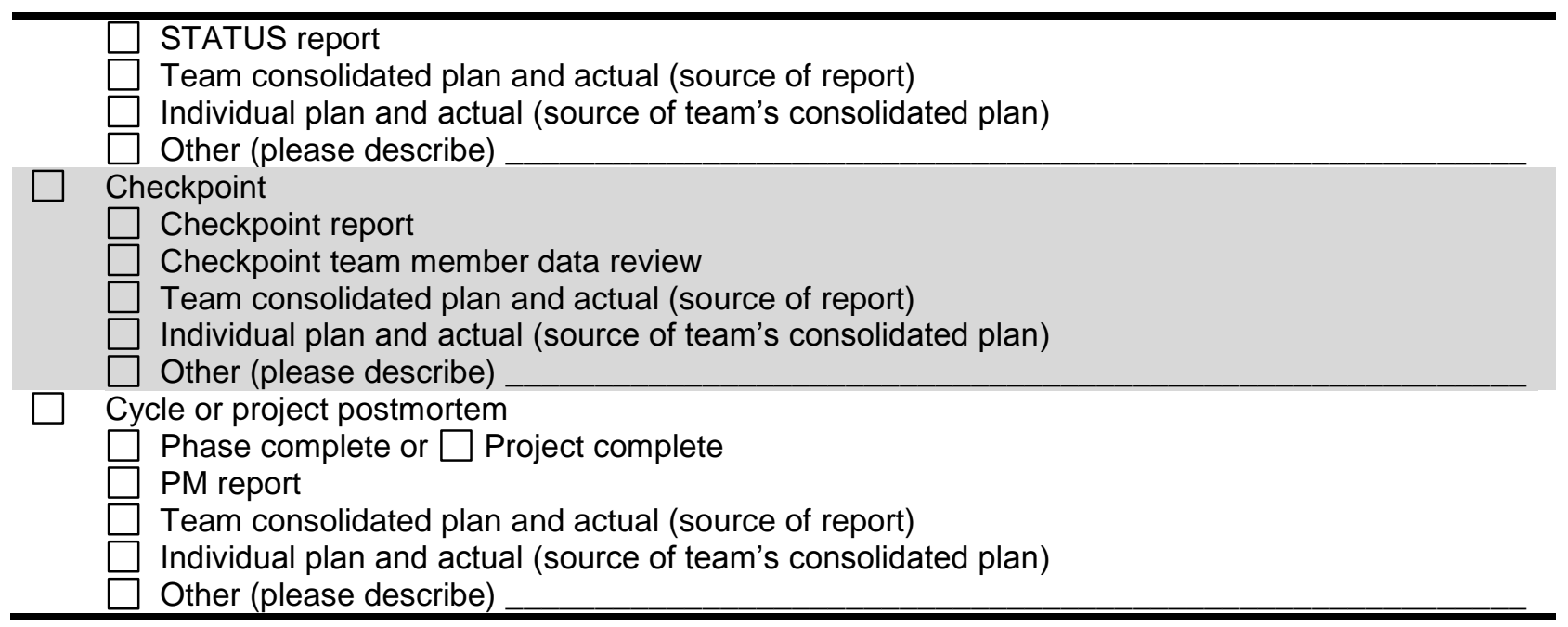

\section{File names associated with this data submission:}

\section{Additional information needed to correctly interpret data submitted:}

\section{Submission Instructions}

Please submit your zipped data files through the SEI Partner Resource Center website (https://partnerresources.sei.cmu.edu/). Once you log in, click on the TSP Data Submission button and follow the directions to submit your data. If you have any issues submitting data, please email tsp-

data@sei.cmu.edu.

Or mail this form and CD with data to:

Software Engineering Institute

Carnegie Mellon University

Attn: TSP Team

4500 Fifth Avenue

Pittsburgh, PA 15213-2612 


\section{Final Assessment Report - Form FAR}

\section{SEI-Certified TSP Coach Mentoring Program}

Provisional Coach Information (Please use the exact name that appears on your identification documents.)

\begin{tabular}{lll}
\hline Last Name (Family Name) & First Name (Given Name) & Middle Name(s)
\end{tabular}

\section{Mentor Coach Information}

\begin{tabular}{lll}
\hline Last Name (Family Name) & First Name (Given Name) Middle Name(s)
\end{tabular}

\section{Supporting Data}

Did the provisional coach successfully demonstrate the responsibilities of a TSP coach, as outlined in Sections C through G of Appendix B, TSP Coach Job Analysis Report?

If no, please explain:

At least one of each TSP event below is required during the mentoring process. If you supported more than one of any of the given events, please list both the first and last in which you provided mentoring. Also enclose a copy of all mentoring evaluation forms associated with the events listed below.

Please provide the following information regarding the launches in which you provided mentoring support to the provisional coach.

\begin{tabular}{|l|l|l|l|}
\hline TSP Team's Name & Team Lead's Name & $\begin{array}{l}\text { Date of Data } \\
\text { Submission to the } \\
\text { SEl }\end{array}$ & $\begin{array}{l}\text { Mentoring Artifact } \\
\text { Evaluation Date }\end{array}$ \\
\hline & &
\end{tabular}

Please provide the following information regarding the Provisional Coach's relaunches in which you provided mentoring support. *

\begin{tabular}{|l|l|l|l|}
\hline TSP Team's Name & Team Lead's Name & $\begin{array}{l}\text { Date of Data } \\
\text { Submission to the } \\
\text { SEl }\end{array}$ & $\begin{array}{l}\text { Mentoring Artifact } \\
\text { Evaluation Date }\end{array}$ \\
\hline & & & \\
\hline
\end{tabular}

*All data must be submitted to the SEI using the TSP Data Submission Form 
Please provide the following information regarding the checkpoints in which you provided mentoring support to the provisional coach.

\begin{tabular}{|l|l|l|l|}
\hline TSP Team's Name & Team Lead's Name & $\begin{array}{l}\text { Date of Data } \\
\text { Submission to the } \\
\text { SEl }\end{array}$ & $\begin{array}{l}\text { Mentoring Artifact } \\
\text { Evaluation Date }\end{array}$ \\
\hline & & & \\
\hline
\end{tabular}

Please provide the following information regarding the project or cycle postmortems in which you provided mentoring support to the provisional coach. ${ }^{*}$

\begin{tabular}{|l|l|l|l|}
\hline TSP Team's Name & Team Lead's Name & $\begin{array}{l}\text { Date of Data } \\
\text { Submission to the } \\
\text { SEl }\end{array}$ & $\begin{array}{l}\text { Mentoring Artifact } \\
\text { Evaluation Date }\end{array}$ \\
\hline & & & \\
\hline
\end{tabular}

\section{Recommendation}

Please indicate your opinion about the provisional coach becoming an SEI-Certified TSP Coach.

$\square \quad$ I enthusiastically recommend this applicant.
$\square \quad$ I recommend this applicant.
$\square \quad$ I recommend this applicant with some reservations.
$\square \quad$ I do not recommend this applicant.

Reservations about this provisional coach:

\section{Mentoring Metrics (Time Spent with this Provisional Coach)}

How many total task hours did you spend working with this provisional coach? How many launch preparations did you evaluate? How many relaunch preparations did you evaluate? How many launch output materials did you evaluate? How many relaunch output materials did you evaluate? How many weekly team meetings did you evaluate? How many management STATUS meetings did you evaluate? How many checkpoints did you evaluate? How many cycle or project postmortems did you evaluate?

*All data must be submitted to the SEI using the TSP Data Submission Form 


\section{Statement of Accuracy}

I certify that all of the information included in this report packet is true, complete, and accurate. I understand that submitting false data or making inaccurate claims will result in the termination of my SEICertified TSP Mentor Coach certification, without refund. I also understand that all components of this report are subject to verification, and I give my permission for any person or entity to provide the Software Engineering Institute, Carnegie Mellon University, with information relevant to such verification. I understand that all components of this report become the property of the Software Engineering Institute and that they will not be returned to me or duplicated for me.

\section{Submission Instructions}

Please email this form as an attachment to certification-info@sei.cmu.edu, along with any supplementary pages. Note: This submission must come from the Mentor's SEI Partner Resource Center email account.

Or place the final assessment report, any supplementary pages, and your business card in a sealed envelope and place your signature across the seal. Mail the envelope directly to:

Software Engineering Institute

Carnegie Mellon University

Attn: Certifications

4500 Fifth Avenue

Pittsburgh, PA 15213-2612

Direct any questions to the SEI Certification Manager:

Phone: 412-268-5800 or email: certification-info@sei.cmu.edu 


\section{Mentor Coach Application - Form MCA}

SEI-Certified TSP Coach Mentoring Program

Personal Information (Please use the exact name that appears on your identification documents.)

\begin{tabular}{lll}
\hline Last Name (Family Name) & First Name (Given Name) & Middle Name(s)
\end{tabular}

Primary Language

Secondary Language

Job/Position

SEI Partner Sponsor

Business Point of Contact (POC)

POC Phone Number

\section{Contact Information}

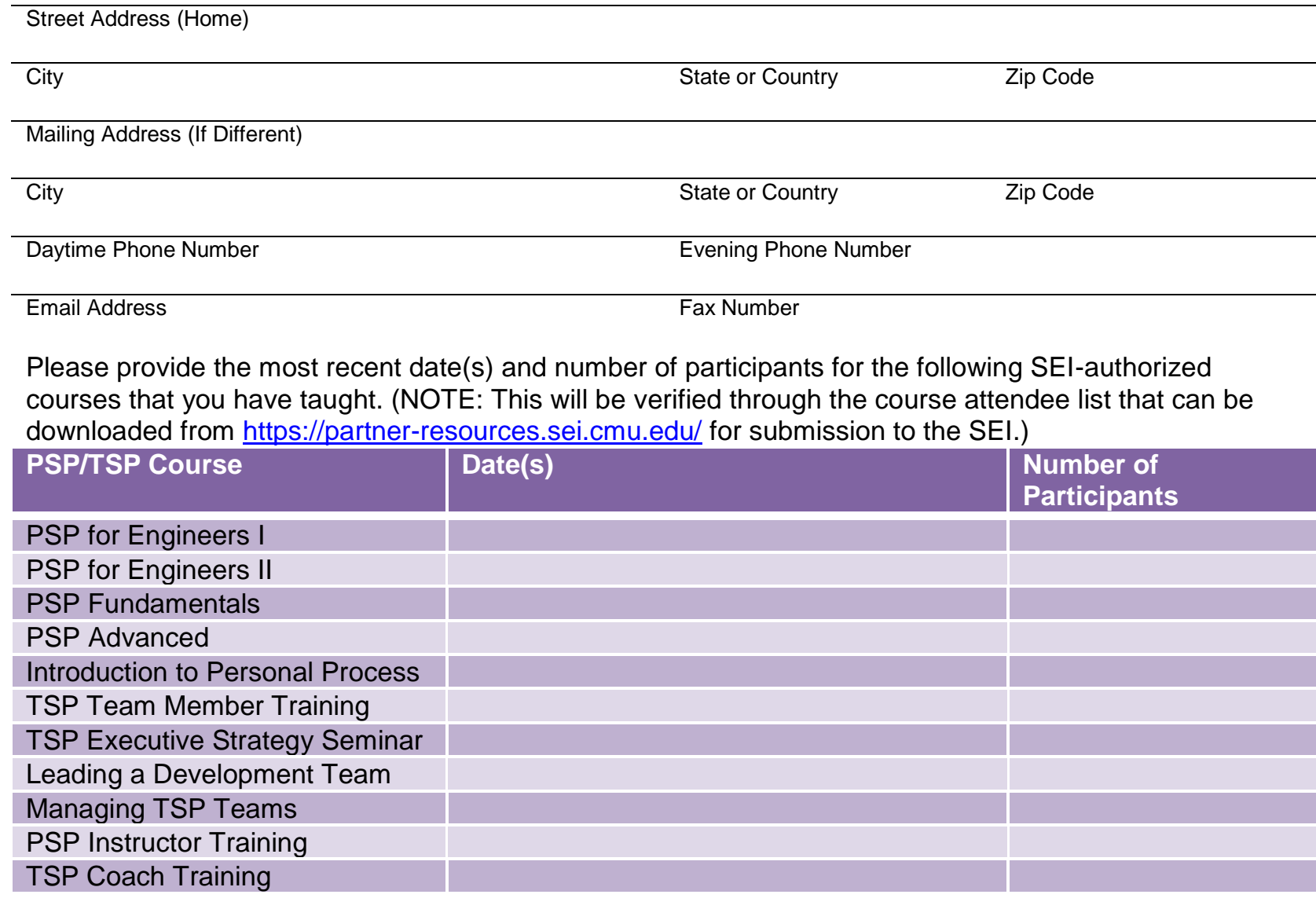


Are you currently an SEI-Authorized PSP Instructor? $\square$ Yes $\square$ No If your authorization has lapsed, please contact the SEI to make arrangement to renew your authorization, as this is a prerequisite to becoming an SEI-Certified TSP Mentor Coach.

Please provide the following information regarding the last time you launched or relaunched a team, for the last three TSP teams you coached.

\begin{tabular}{|l|l|l|}
\hline TSP Team's Name & Team Lead's Name & $\begin{array}{l}\text { Date of Data Submission to } \\
\text { the SEI }\end{array}$ \\
\hline & & \\
\hline & & \\
\hline
\end{tabular}

Please provide the following information regarding the last four TSP teams in which you conducted a (re)launch, checkpoint, and PM. (Note: The launch or relaunch to postmortem cycles must total at least 52 team-weeks of coaching experience.)

TSP Team's Name Team Lead's Name

\begin{tabular}{|l|l|l|}
\hline & & \\
\hline & & \\
\hline & & \\
\hline & & \\
\hline & & \\
\hline
\end{tabular}

Please provide one or both of the following sets of recommendations.

- Letters of recommendation to be a mentor coach from all team leaders of the aforementioned (re)launched teams, and a few of the associated team members. (NOTE: Submitters must use the approved Mentor Recommendation form (MR) and follow its submission instructions.)

- Launch Participant Feedback Forms and a Launch Coach Feedback form for the aforementioned (re)launched teams.

\section{Statement of Accuracy}

I certify that all of the information included in my application packet is true, complete, and accurate. I understand that all components of my application are subject to verification, and I give my permission for any person or entity to provide the Software Engineering Institute, Carnegie Mellon University, with information relevant to such verification. I understand that all components of my application packet become the property of the Software Engineering Institute and that they will not be returned to me or duplicated for me. I understand that the application fee is not refundable.

\footnotetext{
*All data must be submitted to the SEI using the TSP Data Submission Form.
} 


\section{Submission Instructions}

Please email this form, along with any supplementary pages, as an attachment to certificationinfo@sei.cmu.edu.

Or mail your application to:

Software Engineering Institute

Carnegie Mellon University

Attn: Certifications

4500 Fifth Avenue

Pittsburgh, PA 15213-2612

Direct any questions to the SEI Certification Manager:

Phone: 412-268-5800 or email: certification-info@sei.cmu.edu 


\section{Mentor Recommendation - Form MR}

\section{SEI-Certified TSP Coach Mentoring Program}

\section{Applicant's Section}

\section{Recommender's Section}

\begin{tabular}{|c|c|}
\hline Name of Recommender & Title \\
\hline Company Name & Phone Number (Include Country Code) \\
\hline \multicolumn{2}{|l|}{ Street Address } \\
\hline City & State or Country \\
\hline
\end{tabular}

Email Address

How long have you known the applicant, and in what capacity?

Are you a certified PSP Developer?

Are you recommending this coach in the role of a team lead or a team member?

As a team lead:

How many TSP checkpoints has the applicant performed for you?

How many TSP cycle or project postmortems has the applicant facilitated for you?

How many TSP (re)launches has the applicant facilitated for you?

\section{Evaluation of Applicant}

Please rate the applicant according to the following scale. Choose "No Basis for Evaluation" if you cannot make a judgment. Use the spaces below or attach a separate sheet for additional comments.

The applicant ensures that ...

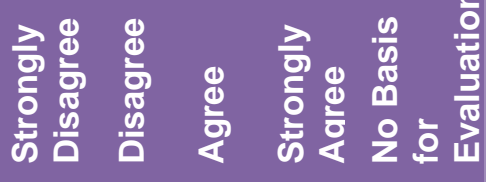

The process is followed

Everyone is involved

Everyone contributes to every part of the process

There is complete communication among team members, team

leader, management, and other relevant stakeholders 


\begin{tabular}{ll|l|l|l|} 
The applicant ... & \\
\hline Is available for consultation as needed & & \\
\hline Respects others and supports their individual development & & \\
\hline Works effectively with teams & & \\
\hline Effectively provides the required skills, discipline, insight, and \\
outside perspective that teams and individuals need to be \\
successful, using tailored approaches to meet the needs of the \\
team and its members
\end{tabular}

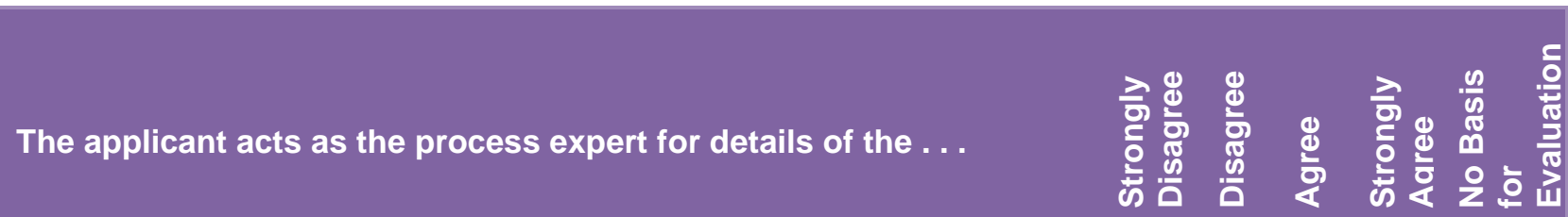

(Re)Launch process

Day-to-day work processes

Role manager processes

Weekly reporting processes

Project /phase postmortem process

Checkpoint process

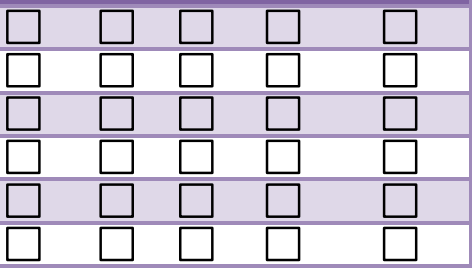




$\begin{array}{lll}\text { As a facilitator, the applicant understands the ... } & \\ \text { Team life cycle } & & \end{array}$

\section{Recommendation}

Please indicate your opinion about the applicant becoming an SEI-Certified TSP Mentor Coach.

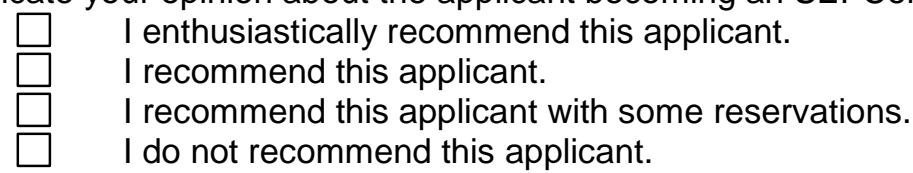

Reservations about this applicant:

\section{Signature}

\begin{tabular}{ll}
\hline Recommender's Signature & Date
\end{tabular}

\section{Submission Instructions}

Please email this form as an attachment to certification-info@sei.cmu.edu, along with any supplementary pages.

Or place your recommendation form, any supplementary pages, and your business card in a sealed envelope and place your signature across the seal. Either return the envelope to the applicant or mail it directly to:

Software Engineering Institute

Carnegie Mellon University

Attn: Certifications

4500 Fifth Avenue

Pittsburgh, PA 15213-2612

Direct any questions to the SEI Certification Manager:

Phone: 412-268-5800 or email: certification-info@sei.cmu.edu

Thank you for taking the time to respond. The SEI-Certified TSP Coach Mentoring Program believes that recommendations are among the most valuable data in the application review phase. We sincerely appreciate your help. 


\section{Provisional Coach Mentoring Evaluation - Form PCME}

\section{SEI-Certified TSP Coach Mentoring Program}

\section{Your name: \\ Mentor's name: \\ Date mentoring started: \\ Date mentoring ended: \\ Today's date: \\ Phone: \\ Email:}

\section{Mentor Program}

Please rank your experience with the SEI-Certified TSP Coach Mentoring Program according to the following scale. Use the spaces or attach a separate sheet for additional comments.

\section{Applicant}

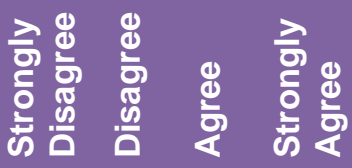

This program helped me to be a more successful TSP coach.

The required activities were appropriate.

Overall, I believe that participating in this program was a good use of my time.

What additional support would you suggest be provided to future provisional coaches? 
Please list any mentor - provisional coach activities you recommend adding or deleting, and why.

\section{Mentor}

Please rate your mentor according to the following scale. Use the spaces below or attach a separate sheet for additional comments.

\begin{tabular}{|l|l|l|}
\hline & \\
\hline My mentor was available for consultation as needed. & & \\
\hline My mentor was willing to share best practices. & & \\
\hline My mentor assisted me in successfully working through a TSP cycle as a & $\square$ & $\square$ \\
\hline TSP coach. & $\square$ & $\square$ \\
\hline I believe that consulting my mentor was a good use of my time. & $\square$ \\
\hline My mentor regularly contacts me. & $\square$ & $\square$ \\
\hline I felt comfortable talking to my mentor about concerns or problems. & $\square$ \\
\hline My mentor treated me in a courteous and professional manner. & $\square$ \\
\hline My mentor was supportive of my individual needs. & $\square$ \\
\hline My mentor used active listening skills. & $\square$ \\
\hline My mentor appeared knowledgeable. & $\square$ \\
\hline My mentor knew where to find information when necessary. & $\square$ \\
\hline
\end{tabular}


My Mentor ...

Comes prepared for mentoring meetings

Is prompt for mentoring meetings

Is courteous and professional

Promptly responds to messages

Communicates effectively

Fully utilizes time with me

Suggests ideas for discussion and individual growth

Actively participates in mentoring meetings

\section{The positive attributes of my mentor are:}

Areas in which my mentor could improve are:

\section{Submission Instructions}

Please email completed evaluation forms to:

tsp-eval@sei.cmu.edu

Or send completed form to:

Software Engineering Institute

Carnegie Mellon University

Attn: TSP Administrator

4500 Fifth Avenue

Pittsburgh, PA 15213-2612

Direct any questions to the SEI Certification Manager:

Phone: 412-268-5800 or email: certification-info@lists.sei.cmu.edu 


\section{Mentor Coach's Mentoring Program Evaluation - Form MPE}

\section{SEI-Certified TSP Coach Mentoring Program}

\section{Your Name:}

Today's Date:

Phone Number:

Email Address:

\section{Mentor Program Evaluation}

What is your general assessment of the mentoring program?
Very Successful
Successful
Moderately Successful
Unsuccessful

Did you receive adequate assistance from the SEI? $\square$ Yes $\square$ No If no, please explain:

How satisfied were you with your experience as a mentor?

$\square$ Very Satisfied $\square$ Satisfied $\square$ Slightly Satisfied $\square$ Dissatisfied

What is your general assessment of the mentoring program?

$\square$ Very Effective $\square$ Effective $\square$ Not Very Effective $\square$ Not at All Effective

Please indicate the reasons for your assessment:

Please rate each of the following program components:

\section{Mentor training}

Provisional training

Mentor support

Interaction with the SEI Certification Coordinator

How did you approach the mentoring relationship? What mentoring or communication skills and strategies did you use? 
As you went through the mentoring process, did you see growth and development in your provisional coach? If so, would you share an example?

Was the mentoring relationship meaningful to your own growth and development? If so, in what ways?

Do you have any ideas for improving the mentoring program? If so, please note these below.

\section{Submission Instructions}

Please email completed evaluation forms to:

tsp-eval@sei.cmu.edu

Or send completed form to:

Software Engineering Institute

Carnegie Mellon University

Attn: TSP Administrator

4500 Fifth Avenue

Pittsburgh, PA 15213-2612

Direct any questions to the SEI Certification Manager:

Phone: 412-268-5800 or email: certification-info@sei.cmu.edu

Email: certification-info@lists.sei.cmu.edu 


\section{REPORT DOCUMENTATION PAGE}

Form Approved

Public reporting burden for this collection of information is estimated to average 1 hour per response, including the time for reviewing instructions, searching existing data sources, gathering and maintaining the data needed, and completing and reviewing the collection of information. Send comments regarding this burden estimate or any other aspect of this collection of information, including suggestions for reducing this burden, to Washington Headquarters Services, Directorate for information Operations and Reports, 1215 Jefferson Davis Highway, Suite 1204, Arlington, VA 22202-4302, and to the Office of Management and Budget, Paperwork Reduction Project (0704-0188), Washington, DC 20503.

\begin{tabular}{ll|l|l}
\hline $\begin{array}{l}\text { AGENCY USE ONLY } \\
\text { (Leave Blank) }\end{array}$ & $\begin{array}{l}\text { REPORT DATE } \\
\text { June } 2010\end{array}$ & $\begin{array}{l}\text { REPORT TYPE AND DATES } \\
\text { COVERED } \\
\text { Final }\end{array}$ \\
\hline $\begin{array}{l}\text { TITLE AND SUBTITLE } \\
\text { Team Software Process (TSP) Coach Mentoring Program Guidebook Version 1.1 }\end{array}$ & $5 . \quad$ FUNDING NUMBERS \\
\end{tabular}

6. $\operatorname{AUTHOR}(\mathbf{S})$

Timothy A. Chick, Robert Cannon, James McHale, William Nichols, Marsha Pomeroy-Huff, Jefferson Welch, Alan Willett

\begin{tabular}{|c|c|c|}
\hline 7. & $\begin{array}{l}\text { PERFORMING ORGANIZATION NAME(S) AND ADDRESS(ES) } \\
\text { Software Engineering Institute } \\
\text { Carnegie Mellon University } \\
\text { Pittsburgh, PA } 15213\end{array}$ & $\begin{array}{l}\text { 8. PERFORMING ORGANIZATION } \\
\text { REPORT NUMBER } \\
\text { CMU/SEI-2010-SR-016 }\end{array}$ \\
\hline 9. & $\begin{array}{l}\text { SPONSORING/MONITORING AGENCY NAME(S) AND ADDRESS(ES) } \\
\text { HQ ESC/XPK } \\
5 \text { Eglin Street } \\
\text { Hanscom AFB, MA 01731-2116 }\end{array}$ & $\begin{array}{l}\text { 10. SPONSORING/MONITORING } \\
\text { AGENCY REPORT NUMBER }\end{array}$ \\
\hline
\end{tabular}

11. SUPPLEMENTARY NOTES

\begin{tabular}{l|l}
\hline 12A DISTRIBUTION/AVAILABILITY STATEMENT & 12B DISTRIBUTION CODE \\
Unclassified/Unlimited, DTIC, NTIS & \\
\hline 13. ABSTRACT (MAXIMUM 200 WORDS) & This guidebook is designed to explain the steps for becoming an SEI-Certified Team Software Process (TSP) Coach or SEI-Certified \\
TSP Mentor Coach, with emphasis on guiding individuals through the mentoring process. This guidebook defines the structure and for- \\
mat of the mentor and provisional coach relationship, and explains the process steps and evaluation criteria for becoming an SEl- \\
Certified TSP Coach or Mentor Coach.
\end{tabular}

\begin{tabular}{|l|l} 
14. SUBJECT TERMS & 15. NUMBER OF PAGES
\end{tabular}

TSP, team software process, TSP mentor coach

94

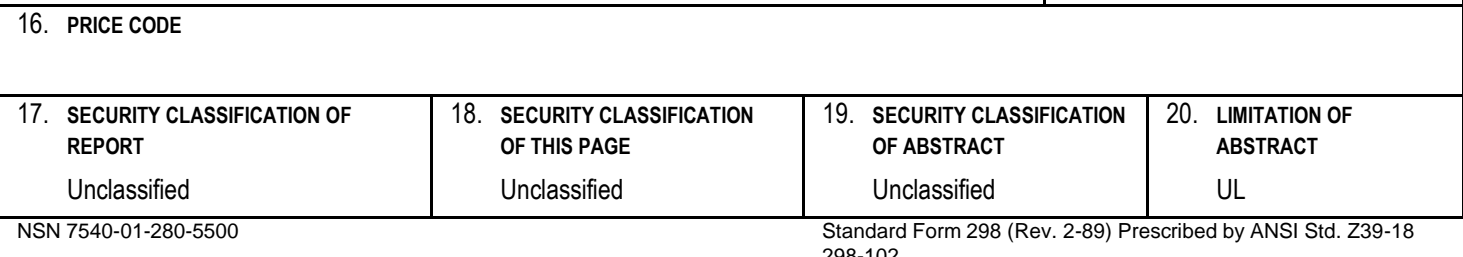

